NBER WORKING PAPER SERIES

\title{
LANGUAGE TRAINING AND REFUGEES' INTEGRATION
}

\author{
Jacob Nielsen Arendt \\ Iben Bolvig \\ Mette Foged \\ Linea Hasager \\ Giovanni Peri \\ Working Paper 26834 \\ http://www.nber.org/papers/w26834 \\ NATIONAL BUREAU OF ECONOMIC RESEARCH \\ 1050 Massachusetts Avenue \\ Cambridge, MA 02138 \\ March 2020, Revised February 2021
}

The paper is a substantially revised version of NBER WP 26834. This project is conducted as part of the Economic Assimilation Research Network (EARN), generously financed by the Innovation Fund Denmark (grant no. 6149-00024B). Mette Foged also acknowledges funding from EPRN (grant no. 107757). We thank the Ministry of Immigration and Integration for assistance with data and reports on early language training in Denmark and Janis Kreuder for excellent research assistance. The project benefited from feedback and discussions with Oddbjorn Raaum, Tommaso Frattini, Jakob Roland Munch, Torben Tranaes, Matti Sarvimaki and participants at the following seminars and workshops: "Forced Displacement, Asylum Seekers and Refugees", Queen Mary University London; the first "EARN Workshop on Integration", University of Copenhagen; Uppsala; Global Migration Research Center, UC Davis; Danish Center for Social Science Research (VIVE); CReAM, UCL; University of Bristol; Senior Migration Seminar; FAIR, NHH; Monash University; ZEW, Mannheim; and UCLA. The views expressed herein are those of the authors and do not necessarily reflect the views of the National Bureau of Economic Research.

NBER working papers are circulated for discussion and comment purposes. They have not been peer-reviewed or been subject to the review by the NBER Board of Directors that accompanies official NBER publications.

(C) 2020 by Jacob Nielsen Arendt, Iben Bolvig, Mette Foged, Linea Hasager, and Giovanni Peri. All rights reserved. Short sections of text, not to exceed two paragraphs, may be quoted without explicit permission provided that full credit, including $\odot$ notice, is given to the source. 
Language Training and Refugees' Integration

Jacob Nielsen Arendt, Iben Bolvig, Mette Foged, Linea Hasager, and Giovanni Peri

NBER Working Paper No. 26834

March 2020, Revised February 2021

JEL No. E64,I30,J18,J24,J60

\begin{abstract}
$\underline{\text { ABSTRACT }}$
We evaluate a Danish reform focused on improving Danish language training for those granted refugee status on or after January 1, 1999. Using a Regression Discontinuity Design we find a significant, permanent, positive effect on earnings. This effect emerged after completion of language classes and was accompanied by additional schooling and higher probability of working in communication-intensive jobs, suggesting that language training, rather than other minor aspects of the reform, produced it. We also find evidence of higher completion rates of lower secondary school and lower probability of crime for male children with both parents exposed to the reform.

Jacob Nielsen Arendt

The Rockwool Foundation's Research Unit

Ny Kongensgade 6, DK 1472

Copenhagen $\mathrm{K}$

Denmark

jar@rff.dk

Iben Bolvig

The Danish Center for

Social Science Research (VIVE)

Olof Palmes Alle 22, DK 8200

Aarhus N

Denmark

IbBo@vive.dk

Mette Foged

Department of Economics

Univertsity of Copenhagen

Øster Farigmagsgade 5, building 26

1353 Copenhagen $\mathrm{K}$

Denmark

Mette.Foged@econ.ku.dk

Linea Hasager

University of Copenhagen

Øster Farimagsgade 5

Building 26,

DK 1353 Copenhagen

tlh@econ.ku.dk

Giovanni Peri

Department of Economics

University of California, Davis

One Shields Avenue

Davis, CA 95616

and NBER

gperi@ucdavis.edu
\end{abstract}




\section{Introduction}

International refugees, who usually escape from extreme conditions of persecution or war, begin their lives in the host country with significant disadvantages. Research shows that even in the medium and long run, the employment and wage gap between them and natives or other immigrants is significant (Fasani, Frattini, and Minale, 2018; Brell, Dustmann, and Preston, 2020).

Policies that are effective in improving the labor market integration of refugees, therefore, could bring large economic returns to the refugees and to their host economy. Additionally, these economic benefits could make other forms of social integration more likely, possibly reducing social marginalization and crime.

While enhancing the labor market outcomes of refugees is a high priority of many countries, the way to effectively achieve such outcomes is less clear. Integration efforts have taken many forms. Several countries, such as the US, mostly leave this task to local interventions (Bloemraad and De Graauw, 2012; Williamson, 2018), often enacted by private charities and churches. Most European governments, instead, consistent with their tendency to take a more active role in the economy and society, have supported early integration interventions for refugees since the 1990s or longer (Arendt, 2018). Such integration programs are usually a combination of several measures, including active labor market support, provision of incentives, and teaching of relevant skills. How effective each of these interventions is in improving labor market and social outcomes for refugees has been the subject of lively debate but very limited rigorous analysis has been performed. Limited longitudinal data following refugees over time and lack of policies with a clean experimental design have prevented a causal assessment of those interventions.

Lacking a consensus on how effective each policy intervention is, different countries have moved in different directions. Germany and France have increased their focus on immigrants' language training over time ${ }^{1}$ The Netherlands, Denmark and other North European countries have instead moved in the opposite direction in recent years, reducing the focus on language skills while encouraging job search and labor market participation early on ${ }^{2}$ In Denmark early language training was a focus in the 1990s and early 2000s, and early labor market entry has been emphasized to an increasing extent in the recent decade, resulting in a policy in 2016 that required the refugees to actively search for jobs and participate

\footnotetext{
${ }^{1}$ In 2005 Germany mandated language (and German history, law and culture) classes for newly arrived refugees (Hübschmann 2015, Martin et al. 2016). France introduced the Contract d'accueil et d'intgration in 2007, requiring immigrants to participate in language training and civic training (Lochmann, Rapoport, and Speciale 2019).

${ }^{2}$ The Dutch government mandated a 12-month language, social orientation and labor market orientation program in 1998. In 2007 participation in this program was made optional (Joppke, 2007) and more costly (De Vries 2013).
} 
in job-training immediately upon arrival $\mathrm{S}^{3}$

While countries have moved towards or away from policies focused on teaching language skills, there is little solid evidence on the impact of language training on refugees' integration. In this paper we focus on a major reform that was implemented in Denmark for all immigrants granted refugee status on or after January 1, 1999. The reform significantly increased resources, duration and incentives for refugees to attend language training. The sudden and discontinuous implementation of the reform, which applied to refugees admitted on or after a specific date, and the very detailed administrative data following those individuals for many years allows us to establish short and long run causal effects of this reform on refugees' economic and social outcomes. The reform also had other, relatively minor, aspects (affecting the process of geographic relocation and imposing a one-year welfare cut on a subgroup) which were also discontinuously applied and we will carefully describe and consider them in our analysis.

Specifically, the Danish 1999 reform involved four components. The first, and most significant, change was a substantial increased in duration (the reform entitled the treated to 430 additional hours that could be taken over an extended period of time, three years compared to 1.5 years before the reform), the funding and the quality (better instructors) of the language training provided to refugees in Denmark. The new program was mandatory for refugees and reunified family members (for brevity we refer to both as refugees). Individuals who obtained refugee status in Denmark on or after January 1, 1999 were entitled to (mandated to) attend the expanded language program. Those who obtained refugee status before that date did not qualify and only had access to more limited language training. This feature allows us to use a Regression Discontinuity (RD) design based on the date when refugee status was granted relative to January 1, 1999, which is the threshold date. Additionally, there were three smaller changes introduced on the same date.

The second change was a reduction in welfare benefits for refugees, limited to those over age 25 or with children. This change was temporary and rolled back after 13 months (February 1, 2000). As only a sub-group of refugees was subject to it, and as the policy was in place for only a year, we evaluate its potential additional effects by analyzing the subject group and the non-subject group and the time-profile of the estimated effects. The third change was the introduction of a more mechanical way of distributing refugees across municipalities, by allocating them in proportion to the local population, with the longterm goal of distributing them more widely than had been accomplished with the past dispersal policy.

\footnotetext{
3 Arendt (2020) finds large positive employment effects of this new policy one year after settlement in Denmark. However he also finds that the effect is temporary and crowds out language course participation.
} 
Fourth, the municipality of resettlement was responsible for providing the integration program and this seems to have postponed some post-resettlement mobility. As we will show, there is no evidence that the reform generated a sudden change for people admitted after January 1, 1999 in the type of municipalities where they were settled. A more gradual and long-term change occurring over years may have taken place, but our treatment and control groups do not seem to be affected by the refinement of the dispersal policy. We consider as treatment the whole package of changes introduced by the reform and mandated for post-January 1 admissions. Hence, our design corresponds to a sharp RD for such a treatment.

Several features make this reform interesting and the content of this paper novel. First, the RD design and random assignment around the threshold date (which we check for all observable characteristics of refugees) allows a credible causal estimation of the impact of a reform focused on language training, which is new in the literature. One limitation is that the reform did not only implement language training changes but other small changes as well. We analyze those and conclude that it is unlikely that they contributed to any long-run effects. Second, as we can observe a rich set of variables for the refugees over an extended period of time, we can look at the effects on education, labor market, social and criminal outcomes occurring both in the short and in the long run. Importantly, we can analyze the channels and the dynamics through which the economic effects took place and lend more support to the idea that improved language skills are likely the main factor at work. Third, as we can link the refugees to their spouses and children, we can analyze effects on family structure, fertility and on the second generation's outcomes. The long time horizon and the rich set of outcomes are unique to our paper in this literature.

Several important findings emerge from the analysis. First, refugees "treated" by the reform experienced greater employment probabilities and higher earnings in the long-run. The positive effects emerged four to five years after the reform was implemented and were statistically significant, especially on earnings, starting six years after the reform. These dynamics are consistent with the fact that the language classes were attended in the first three to four years after settlement ${ }_{4}^{4}$ Second, we find evidence of formal skill upgrading for the treated group, in the form of more years of schooling, and occupational upgrading to jobs with a stronger communication requirement. This is also consistent with the idea that better language skills facilitated access to education and communication-intensive jobs in Denmark. We also find that refugees speaking languages very different from Danish experienced stronger employment and earnings benefits from the reform. Third, we do not find evidence of an additional short-run impact

\footnotetext{
${ }^{4}$ The point estimates are extremely robust to alternative bandwidths and functional forms. The statistical significance of the earnings effects is also insensitive to most of the robustness checks we perform while the employment effects are on the margin of significance in some specifications.
} 
on employment or earnings for the group subject to the one-year welfare cut (age 25 and older or with children). Instead, we find a one year decrease in disposable income and a one year increase in the probability of committing property crime (mainly shoplifting) for this group. Fourth, while we do not find effects on fertility and family formation, we find that male children of refugees with both parents "treated" by the reform were more likely to complete lower secondary school and less likely to commit a crime when 15 years or older.

This paper contributes to two related strands of research. First, we contribute to the literature on the role of language in the economic assimilation of immigrants. Early studies established a strong and positive association between language proficiency and the earnings of immigrants 5 Part of this correlation certainly arises from omitted variable bias, as more able and more motivated immigrants acquire better language skills and earn more, and part of the correlation likely reflects a causal link between language proficiency and earnings in the host country (Borjas, 1994). Hence, a second and more recent strand of the literature tries to estimate the causal effect of language training on immigrants and is focused on identifying the effect of language classes offered to refugees or other immigrants on their labor market outcomes. Three recent papers stand out in this literature. Closest to our study in its identification strategy is Sarvimäki and Hämäläinen (2016), who use a reform in Finland that affects the integration services provided to immigrants who arrived after May 1, 1997, generating a discontinuity and random assignment to treatment around this date. The authors show that the reform changed the composition of services provided during the first five years in Finland towards more language training and away from traditional active labor market policies (such as policies encouraging job search). The treated group had a very significant 47 percent increase in earnings and 13 percent decrease in cumulative social benefits over a ten year period but no change in employment. Contrary to the reform in Finland, the Danish reform explicitly expanded and improved language training, and we analyze several other outcomes besides labor market outcomes, such as schooling and crime, which are quite relevant in designing policies for refugees' integration. Finally, we analyze effects for a much longer time horizon, including the effects on the second generation and focus on refugees, a particularly disadvantaged group with significant issues in economic integration, rather than all immigrants.

The second relevant paper focused on the impact of language training on economic outcomes of refugees is Lochmann, Rapoport, and Speciale (2019). They analyze the introduction of a program in France that assigns non-EU immigrants to language training based on a threshold in their score in an initial test ${ }^{6}$ Such a discontinuity in the score produces random assignment to the language treatment

\footnotetext{
${ }^{5}$ See for instance Chiswick (1991); Chiswick and Miller (1995) and Dustmann (1994).

${ }^{6}$ In France, unlike Denmark and Finland, many immigrants come from French-speaking countries due to colonial ties.
} 
around the threshold. The authors find that 100 hours of language training increased labor force participation by 15 to 27 percentage points two years after completion of classes. This is a very large effect equal to a quarter of the sample mean (labor force participation is 81 percent). However, the authors also show some puzzling findings, such as no effect on employment (in spite of much larger participation), and no effect on the ability to speak the French language. The small number of observations that can be used in their RD design is a limitation of their power to identify effects and limits the robustness of their results.

A very recent paper, Heller and Mumma (2020), evaluates a language training program for immigrants in the US. The study evaluates the ESOL (English for Speakers of Other Languages) program using data for Massachusetts. As it exploits lotteries for places in the ESOL program that were conducted for first time applicants between 2008 and 2016, its identification is credible. The study looks at earnings and voting effects only within 2 years of the program. It finds significant average treatment effects on earnings, comparable to what we find and those found in Sarvimäki and Hämäläinen (2016).

A few additional studies analyze how reforms that change welfare assistance or enhance active labor market policies affected immigrants' labor market outcomes. LoPalo (2019) finds that the generosity of welfare benefits (Temporary Assistance for Needy Families) across US states had no significant effect on refugees' employment, while it produced an increase in their wages in the long run. Identification is based on cross-state variation of benefit generosity and hence is potentially subject to significant omitted variable bias. A few studies in Denmark look at the effects of a reduction in the welfare benefits for refugees that was introduced by a reform in 2002. They show that this reform produced large positive short-term employment effects 7 However, Andersen, Dustmann, and Landers $\varnothing$ (2019) show that the effect disappeared after 7-8 years and that the same reform produced adverse effects on crime rates and educational achievement among teenagers in treated households 8 Joona and Nekby (2012) evaluate a program in Sweden where new immigrants were randomly selected to receive more intensive counselling. They find significant employment effects one year after assignment but no evidence of longer-run effects. Taking the previous studies as a whole, the impact of active labor market policies and economic incentives on refugees labor market outcomes seems short-lived 9

The rest of the paper is structured as follows. Section [I] discusses the recent history of refugees and

Furthermore, the reform was not restricted to the newly arrived and the language training provided was much less ambitious than programs in the Northern European countries.

${ }^{7}$ See Huynh, Schultz-Nielsen, and Tranæs (2007); Rosholm and Vejlin (2010); Andersen, Dustmann, and Landers $\emptyset$ (2019).

8 Agersnap, Jensen, and Kleven (2020) use three reforms of the welfare benefit generosity to investigate the effect of welfare generosity on immigration rates, i.e., to test the "welfare magnet" hypothesis.

${ }^{9}$ In a more general context, Card, Kluve, and Weber 2010 2018) argue that returns to job search assistance are small or zero, whereas returns to programs with a skill-training component are significant after a couple of years. 
the 1999 reform in Denmark. Section [III describes the samples, the key variables and their summary statistics. Section IV.C discusses the empirical strategy and identification. Section V presents the longrun impact of the reform on the labor market outcomes of adult refugees (Section V.A) and on schooling and juvenile crime outcomes for their children (Section V.B. Section VI disentangles the potential mechanisms behind the main effects of language training and extends the results to inquire whether other aspects of the reform may have had effects. Finally, we perform a simple cost-benefit analysis in Section VII and we conclude the paper in Section VIII.

\section{Refugees History in Denmark and the 1999 Reform}

\section{II.A Recent History}

Following decades of relatively small immigration flows, refugees started resettling in Denmark in significant numbers in the mid 1980s and the 1990s. Refugee admissions to Denmark averaged 2,500 per year in the following decades with some significant spikes due to international crises ${ }^{10}$ The process of resettlement of refugees had constant aspects since the 1980s, while some other aspects have changed as a consequence of policy reforms. Throughout these years, displaced individuals who applied for asylum in Denmark were registered and placed in accommodation centers until their cases were adjudicated. These centers were (and are) usually in sparsely populated areas. Until 2013 the asylum seekers were not allowed to work while residing in these centers. Most asylum seekers, therefore, had very little contact with the Danish population prior to obtaining refugee status. In the late 1990s, the time of the considered reform, refugees waited, on average, more than one year before a decision on asylum was made (Table 3). When the asylum status was granted, the refugee was resettled in a municipality chosen by placement officers in the Danish Refugee Council with the aim of distributing them across municipalities and encouraging assimilation 11 The municipality administration was responsible for finding housing for the refugees and providing social support and employment services. Up to 1999 language training was offered for a maximum of 1.5 years after resettlement by the Danish Refugee Council. Within this general background, significant changes were brought about by the 1999 reform described in the next section.

A motivation for the reform was the significant initial disadvantage and slow earnings convergence of refugees relative to natives. Refugees arrived without a job and were initially dependent on welfare.

\footnotetext{
${ }^{10}$ Large and sudden waves were represented by the Bosnians in the early 1990s and the Syrians in the post-2015 period. In both cases more than 30,000 people were resettled in Denmark within a short period of time.

${ }^{11}$ UNHCR Quota refugees are resettled directly from refugee camps abroad. They constitute 10 percent of our sample.
} 
Their employment rate and their earnings grew during the first five to ten years after settlement. However, after that, they seemed to stabilize at a considerable gap, not only relative to natives, but also to other immigrants ${ }^{12}$

The employment gap between refugee men and low skilled native-born men was still 15-16 percentage points ten years after immigration (Schultz-Nielsen, 2017, Table 2). While the countries of origin of refugees have changed over time, the initial conditions and the difficulty in integrating them economically and socially have been persistent features of the Danish experience as well as of the experience of other European countries (Schultz-Nielsen, 2017, Bratsberg, Raaum, and Røed, 2017, Brell, Dustmann, and Preston, 2020). Evaluating the causal impact of the 1999 reform on the employment and earnings gap of refugees and on other social outcomes of their families and children will be an important step in understanding policy effectiveness in refugee integration.

\section{II.B The 1999 Reform}

The Danish 1999 reform affected more than one aspect of the integration policy for refugees. It was based on legislative changes described in the first Act on Integration of Immigrant ${ }^{13}$ and the new Act on Language Education for Adult Immigrants $\$$, which went into effect on January 1, 1999. Individuals granted refugee status before this date were subject to the old rules, whereas individuals granted status on or after this date were subject to the new rules. This sharp change in the application of the new policies is what offers a unique opportunity to causally identify its effects using a regression discontinuity approach, on the premise that refugees admitted on either side of the cutoff date are similar.

The reform consisted of one primary change, accompanied by smaller additional changes. While our strategy can only identify causally the joint effect of the whole reform on "treated" refugees, we will carefully describe each change, its magnitude, the group targeted and the change of measurable outcomes of the refugees associated with that change. This will give us a good idea of which changes were more significant and more likely to be the drivers of the long-run effects that we will measure.

\footnotetext{
${ }^{12}$ Appendix Figure 1.1 in Schultz-Nielsen (2017) shows the employment rate, the earnings and the welfare dependency of the refugees who arrived between 1997 and 2001.

${ }^{13}$ Act 474. In Danish: Lov nr. 474 af 01/07/1998. Lov om integration af udlændinge i Danmark, https://www. retsinformation.dk/eli/lta/1998/474.

${ }^{i 4}$ Act 487. In Danish: Lov nr. 487 af 01/07/1998: Lov om undervisning i dansk som andetsprog for voksne udlændinge m.fl. og sprogcentre, https://www.retsinformation.dk/Forms/R0710.aspx?id=87625.
} 


\section{II.B.1 The Language Training Component: Quality, Quantity and Funding}

The primary change introduced by the 1999 reform was more extensive language training and the fact that participation in the enhanced language training program became mandatory. Non-participants could be financially sanctioned by losing part of their benefits. Even more importantly, acquiring permanent residence status required proof of completion of the program 15

The new language training policy increased the potential instruction time from 1,370 to 1,800 hours and allowed such training to occur over an extended period of 36 months, doubling the 18-month limit existing before ${ }^{16}$ The structure and quality of language training was also changed; centralized goals and national tests were introduced and resources to increase the qualifications of the teachers were provided. The Act on Integration also introduced a course in civic education. While important, this was more limited in scope when compared to the great boost of language education. Only 20 hours were dedicated to civic education, compared to 430 hours of additional language training.

The mandated increase in hours of language training were accompanied by an administrative restructuring that guaranteed their implementation and funding. After January 1, 1999, the municipalities (rather than the Danish Refugee Council) became responsible for managing language training. Moreover they were provided with reimbursement in the form of a fixed monthly payment per refugee and activity-based payments for the months of language services. Both the fixed and the activity-based payments were higher for refugees arriving after the reform and they lasted twice as long (36 compared to 18 months) ${ }^{17}$ Hence, the financial incentives of the municipalities were also aligned to provide the expanded services only to "treated" refugees, (i.e., those arrived on or after January 1, 1999) because they would only be reimbursed for those 18

In short, the main component of the reform was an increase in quantity and quality of language

\footnotetext{
${ }^{15}$ Refugees only hold a temporary residence permit, and therefore, if they do not qualify for permanent residency, they risk being returned to their home country. At the time of the reform, refugees could apply for permanent residency after three years if they had completed the integration program, had no major public debt and had not been sentenced to a jail term. The relevant legislation on temporary and permanent residency can be found in the amendment to the act on Foreigners, Act 473. In Danish: Lov nr. 473 af 01/07/1998: Lov om ændring af udlændingeloven og straffeloven, https://www.retsinformation. $\mathrm{dk} / \mathrm{eli} / \mathrm{lta} / 1998 / 473$

${ }^{\text {io }}$ This reform made language training even more extensive in Denmark than in most other countries (e.g., the German introductory language course is 600-900 hours, and Sweden offers on average 525 hours of language training).

${ }^{17}$ The fixed payments to assist refugees were increased to USD 515 per refugee per month (from USD 340 before the reform) and the activity-based payments were raised to USD 288 per month (from USD 212). Moreover, USD 500 per month was introduced expressly for language services to refugees arriving after January 1, 1999, whereas no earmarked payment was made for language services to refugees arriving before the reform. These provisions are summarized in the Act on Integration (Act 474), section 45(5-7) and section 59(3-4). All dollar amounts in the paper are given in USD converted from DKK using 6.6 DKK/USD.

${ }^{18}$ Municipalities also became responsible for managing the active labor market programs for refugees during the integration program. This was previously handled by the Danish Refugee Council. However, refugees on the margin of treatment all receive active labor market programs from 1999 in the municipalities, and hence, this component does not differ around the arrival cutoff.
} 
training, that was better funded than before and administered at the municipality level. We will refer to this whole package of augmented language instruction and civic orientation as "language training". Let us emphasize that the reform did not affect other forms of training, such as on-the-job training, professional training or other forms of "employment support" training.

\section{II.B.2 Additional Policy Changes}

Besides language training, the first additional, but smaller and temporary, change introduced by the reform, was a cut in the welfare benefits. While the enhanced language training was mandatory for all refugees 18 years or older, the welfare cut was only for those older than 25 or with children. Welfare benefits to this group were reduced by 29 percent ( 25 percent if children were present) for 13 months only, as on February 1, 2000 their welfare benefits were reinstated to the original level. While the goal of this change was to increase the work-incentives of adult breadwinners in the household, there are doubts about whether the welfare benefits reduction was fully enforced. A report released in December 1999 showed that affected individuals had been compensated by increases in supplementary transfers (Ministry of Interior Affairs, 1999), 19 Overall it is reasonable to think of the "welfare cut" part of the policy as relatively small, short lived and not very aggressively enforced 20

A third change introduced by the reform acted to reinforce the incentives to stay in the municipality of resettlement for the duration of the language classes (about three years). Specifically, welfare benefits became conditional on participation in the program and the municipality of resettlement had the responsibility for managing the program and handling the benefits. Hence, refugees subject to the new Integration Act could only move municipality of residence and keep their benefits if the new municipality agreed to take over the responsibility for the continued integration process. This was a rare occurrence. We will analyze explicitly the effect of the reform on initial mobility of refugees in Section VI.A. A recent study by Azlor, Damm, and Schultz-Nielsen (2020) and an older report by Nielsen and Jensen (2006) following post-reform refugees for seven years have already noted that the mobility

\footnotetext{
${ }^{19}$ The welfare portion of the reform was heavily debated even before it came into effect. In the summer of 1998, the UNHCR stated that the welfare benefit reduction "violates Article 23 of the UN Refugee Convention" (equal public relief and assistance for refugees and nationals). The UNHCR, however, agreed to the Danish Ministry of Interior Affairs' request to await an evaluation. In November 1999, the Danish Prime Minister announced that the reduced benefits did not work as intended, based on results from an evaluation published in December 1999 (Ministry of Interior Affairs [1999). The evaluation showed that very few immigrants could supplement the welfare benefits with income from work, which was part of the motivation for the reduced welfare benefits.

${ }^{20}$ Earlier studies, e.g., Andersen, Dustmann, and Landers $\varnothing$ (2019) and Rosholm and Vejlin (2010), have analyzed the effects of a different cut to welfare, implemented in 2002, on employment and income of refugees. That cut was larger (around 50 percent of the benefits) and lasted for longer (at least seven years for newly arrived immigrants). Those studies find significant positive employment effects of that cut but also negative effects on disposable income and Andersen, Dustmann, and Landers $\varnothing$ (2019) show an increase in crime rates as a consequence of the cut.
} 
of the post-reform cohorts was low in the first years but increased upon completion of the three-year program 21

The fourth change brought by the reform was that, starting on January 1, 1999, the geographic dispersion of refugees was determined in a more mechanical way according to a formula, rather than bilaterally negotiated with each municipality as was done before the reform. ${ }^{22}$ After the reform refugees were distributed according to county quotas determined by the Danish Immigration Service ("Udlændingestyrelsen") with the goal of achieving greater dispersion (Azlor, Damm, and Schultz-Nielsen, 2020). The municipalities within a county were then to agree upon the within-county settlement, but if they failed to agree, the central government would determine the municipal quotas. This change could have consequences in the initial distribution of refugees, as the goal was to increase the presence of refugees in smaller cities and in the long run it may have generated a more "dispersed" distribution of refugees with fewer of them in larger cities (as argued by Azlor, Damm, and Schultz-Nielsen (2020), who analyze the dispersal of refugees between 1999 and 2010). However, due to inertia and capacity constraints in finding suitable housing, this change does not appear to have affected allocation of refugees across municipalities within the first year after the reform, which is the period we use for our discontinuity analysis (typical bandwidth is seven months). We will show in Section VI.A. Table 6 that all the geographic, economic and demographic characteristics of the municipalities of settlement are extremely balanced for refugees resettled around the cutoff date. Hence this change in policy, while it might have generated changes over the following years, did not change the settlement decisions discontinuously and, hence, is unlikely to have contributed to the estimated effects in our RD design.

Given the described features of the reform, which provide us with the ability to make a clean identification of its aggregate effects due to the discontinuous implementation on January 1, 1999, but which also introduced more than one change, we proceed in two steps. We first present the estimates of the aggregate reform effects (our treatment) on hours of language training and then on the long-run outcomes of refugees and their children, exploiting the discontinuity in treatment based on the date they were granted asylum (Section $\mathrm{V}$ ). In a second step we analyse the dynamics, the channels and the heterogeneity of the effects which, in connection with the discontinuity of some indicators and not of others around the reform threshold, help us gain insight into which component of the reform affected the outcomes of refugees and how (Section $\mathrm{VI}$ ).

\footnotetext{
${ }^{21}$ Consistent with this, we also find an initial mobility gap between post-reform and pre-reform refugees and a period of catch-up mobility between four and six years after the reform (section VI.A Figure 5 .

${ }^{22}$ The new act on the dispersal of refugees. In Danish: Bekendtgørelse nr. 630 af 25/08/1998; Bekendtgørelse om boligplacering af flygtninge, https://www.retsinformation.dk/eli/lta/1998/630
} 


\section{Data}

\section{III.A Variable Definition, Samples and Sources}

Our full sample includes all refugees and reunified family members admitted in a four year window around January 1, $1999 \sqrt{23}$ We restrict the analysis to individuals who were between 18 and 49 years old at the time they were granted asylum and we follow them until 2016, covering 18 years after the reform. The age range is chosen to include individuals who were old enough to qualify for the program at the time of arrival (18 or older), and still young enough to be of working age ( 65 or younger) by $2016{ }^{24} \mathrm{We}$ include as family-reunified individuals, the members of the immediate family (spouse and children) of a refugee in Denmark. These steps leave us with a sample of 8,558 individuals.

These 8,558 refugees can be linked to 16,598 children, 45 percent of whom $(7,436)$ were born before arrival in Denmark and 14 percent $(2,294)$ who were born after arrival but before 2003. In order to observe schooling and social outcomes for these children, we restrict the "children sample" to those 9,730 born between 1986 and 2002. This allows us to observe schooling and other outcomes into their teenage years for most of these children. In particular, we observe graduation from lower secondary school for everyone who is in the correct grade for age, and we obtain measures of crime at age 15 or older.

To construct the outcome and control variables we use administrative data from multiple sources. The Integrated Database for Labor Market Research ("IDA"), the Income Register, databases on enrollment in and completion of schooling, and a database on charges and convictions for criminal activities are merged to construct the main outcomes of employment, occupation, earnings, education and crime 25 We link these longitudinal data to the Population Register ("BEF"), the Admission Register ("OPHG"), the Migration Register ("VNDS"), and the register on internal mobility ("FLYT"). The combined data provide key individual variables, including identification of refugee status, date of grant of refugee status, the country of origin and the date of settlement in a Danish municipality, that allows us to implement our identification strategy ${ }^{26}$ They also allow for merging the refugees with their spouses and children. Finally, we link each individual to the Register for Labor Market Policy Measures ("AMFORA"),

\footnotetext{
${ }^{23}$ Specifically, from January 1, 1997 to December 31, 2000.

${ }^{24}$ We exclude a few individuals for whom no address could be found within the first two years of arrival, and we also exclude Somali refugees due to irregularities in the processing of asylum applications for this particular group in the last months of 1998.

${ }^{25}$ The Integrated Database for Labor Market Research (IDA) that we rely on to construct labor market outcomes, such as employment and occupation, is available from Statistics Denmark with a few years' lag. This is the reason why we only follow the refugees until 2016 while we can follow the educational and crime outcomes of their children until 2018.

${ }^{26}$ They also include age, gender and post-settlement geographic mobility, which we use as controls and additional outcomes.
} 
which includes the services received in the municipality of settlement, and to additional information on the refugees from the language training facilities ("Danskuddannelsesdatabasen"), such as their mother tongue and their initial assignment to language training track 1,2 or 3 , which is a proxy for their education and skills on arrival. Individuals with no or only basic schooling and individuals who need a thorough introduction to the Latin alphabet are usually assigned to Danish 1. Danish 3 is a fast learner track, and individuals with a long education from abroad or individuals who are likely to pursue further education in Denmark are usually assigned to this track, while Danish 2 is an intermediate track.

\section{III.B Summary Statistics}

The summary statistics of the main outcome variables are shown in Table 1 . Our measure of labor income is the annual gross earnings of an individual measured in US dollars and deflated to year 2000 prices as the base year. A considerable share of refugees had no earned income and so the average annual income (across individuals and over years) was a very modest USD 8,600. The second important outcome we analyze is employment measured as the fraction of a full-time working year. This measure takes the value one if the worker was a full time-employee during the whole year while it is less than one if the individual was either a part-time employee or not employed at some point throughout the year. The average employment in the sample of refugees was 20 percent of a full-time working year. This implies substantial non-employment or under-employment for this group throughout the sample period. The third variable is an index of task complexity of the occupation performed by the refugee. It is constructed as the difference between the natural logarithm of the communication task intensity of the occupation and the natural logarithm of the manual task intensity of the occupation. Those measures of intensity are obtained by linking the occupations to $\mathrm{O} * \mathrm{NET}$ data. ${ }^{27}$

We analyze a number of additional outcomes to shed light on the mechanisms behind the labor market effects as well as to go beyond them and produce a more complete picture of the intended and unintended consequences of the policy change. These outcomes include the specific occupation held, additional education obtained in Denmark, changes in municipality of residence and indicators of criminal activities. In terms of occupations performed by the refugees, Table 1 shows that a large share of refugees were employed in Personal and Protective Services $(I S C O=51)$, Sales and Services $(I S C O=91)$, and as Machine Operators and Assemblers $(I S C O=82)$. These three occupations represent 83 percent of employment in the refugee sample and they are the top three occupations, not

\footnotetext{
${ }^{27}$ The task intensities from the O*NET database (US Bureau of Labor Statistics) are merged to Danish register data via the International Standard Classification of Occupation.
} 
only overall, but also if we split by gender, age or language training track. Personal care $(I S C O=513)$ is the most frequent occupation for women and for young individuals. Moreover, the typical additional education pursued by refugees is as personal care assistants ("SOSU medhjælper" in Danish). Many refugees assist health care professionals and provide personal care for the elderly or persons with a disability or poor health.

Education is measured by enrollment in and completion of an educational program in Denmark. 13 percent of the analyzed refugees had completed additional education in the 18 years after settlement (the language course does not count as additional education). In terms of internal mobility, Table 1 shows that 57 percent of refugees were not living in the municipality where they first settled by 2016, denoting a high rate of relocation.

The last category of outcomes we analyze for first generation refugee is crime. We use data on the number and type of criminal charges and convictions. Property crime was the most common criminal activity in our sample, and the effects we find are driven almost exclusively by shoplifting crimes. Table 1 shows that the annual average crime rate was three percent in our sample with one percent committing a shoplifting crime. The probability of ever being convicted of a crime for individuals in our sample was 24 percent (not reported in the table). Among those, property crimes were the more common category, with 17 percent of the sample convicted at some point of such a crime, and with shoplifting as the most common single crime (eight percent of refugees convicted at some point), as also pointed out in Andersen, Dustmann, and Landers $\varnothing$ (2019) ${ }^{28}$ As a comparison, 13.7 percent of natives aged 18-49 in 1999 were ever convicted of a crime.

We analyze two types of outcomes for the children of refugees born before 2003 (second generation). The first is a set of schooling outcomes; specifically, sitting the exams at the end of lower secondary school, graduating from lower secondary school, and enrolling in upper secondary education 29 The second is a set of criminal outcomes, namely being charged with a crime and being convicted of it as a juvenile or young adult.

If no information on earnings, employment, education, crime (or other outcomes) was provided in the registers, we assigned no earnings, no employment, no education and no crime to the observation. Most of these will be true zeros as the register covers the universe of individuals. Attrition due to emigration is around 14 percent by year 18 after the reform but the emigration rate is similar for treated

\footnotetext{
${ }^{28}$ The conviction rates of the refugees decreased steadily over time, so that the early years were those with highest conviction rates (around 5 percent), while after 10 years in the country, the yearly conviction rate was less than two percent.

${ }^{29}$ The slightly higher percentage of individuals enrolling in upper secondary school relative to those graduating from lower secondary school is due to some people enrolling after having taken enrolment tests, without having graduated from a regular Danish lower secondary education.
} 
and untreated refugees; hence, this does not affect our results. The RD estimate for a difference in long-run emigration rates across the cutoff is 0.04 and not statistically significant (the standard error is 0.04). In the analysis we define the long-run impact as the average cumulative value of a variable. That is, we sum the outcome over all post-1999 periods and divide by the number of periods. This provides a measure of the long-run average performance of the refugees, and this value will become more stable as more years elapse from the reform. In the empirical analysis we first report the impact of the reform on outcomes in levels and we then translate them into percentage effects relative to the pre-reform mean at the cutoff point (see Section IV.A).

\section{Empirical Design and Identification}

\section{IV.A Empirical Specification}

Our empirical approach compares refugees granted refugee status right before and right after January 1, 1999 in a regression discontinuity design. We consider the post-January 1, 1999 refugees as the treated group, where the treatment is the full "package" of policy reforms passed in the First Act on Integration and the new Act on Language Education (see section II.B. In formal notation, the treatment variable for individual $i, D_{i}$, is a deterministic function of the date that refugee status was granted $x_{i}$ :

$$
D_{i}=1\left\{x_{i} \geq c\right\}
$$

where $c$ is the cutoff date of January 1,1999 . Hence, $x_{i}-c$ is the time in days between the cutoff date and the date individual $i$ was granted refugee status and it is the so called "running variable". In our baseline specification we assume locally linear trends on either side of the threshold date, so that the estimated equation is as follows:

$$
Y_{i t}=\alpha+\tau D_{i}+\beta_{1}\left(x_{i}-c\right)+\beta_{2} D_{i}\left(x_{i}-c\right)+\varepsilon_{i t} .
$$

The coefficient $\tau$ is the regression discontinuity (RD) estimate and captures the causal average treatment effect of the reform on outcome $Y_{i t}$. The two linear terms $\beta_{1}\left(x_{i}-c\right)$ and $\beta_{2} D_{i}\left(x_{i}-c\right)$ capture the linear dependence of outcomes on admission dates measured relative to the cutoff date ${ }^{30}$ Therefore, in this specification, the intercept $\alpha$ captures the pre-reform mean at the boundary point which we use when

\footnotetext{
${ }^{30}$ The recent consensus, exemplified in Gelman and Imbens (2019), is in favor of the local linear specification. We analyze alternative specifications estimating second and third order local polynomials $\left(\left(x_{i}-c\right)^{2}\right.$ and $\left(x_{i}-c\right)^{3}$ as the running variable) on either side of the discontinuity in the robustness checks.
} 
re-scaling the estimated coefficients into percentage effects.

The variable $Y_{i t}$ in equation (1) represents the outcome of interest. We estimate a separate regression for outcomes in each year after the reform and cumulative measures of long-run outcomes at the end of our panel (year 18 for adults and year 20 for children) using Weighted Least Squares with a triangular kernel to give more weight to the observations closer to the cutoff. We usually restrict the observations used in the estimations to a relatively narrow window around the cutoff, determined by the optimal bandwidth selection algorithm from Calonico et al. (2019). This mean squared error (MSE) optimal bandwidth varies across outcomes and years. It ranges between four and nine months around the cutoff for the main outcomes analyzed and is never beyond one year. Such bandwidth intervals are enough to include several thousand observations on either side of the cutoff providing significant power to our method ${ }^{31}$ We also show that our key estimates are insensitive to the exact choice of bandwidth within a reasonable range around the MSE-optimal bandwidth. We use heteroskedasticity-robust standard errors (as suggested, e.g., in Lee and Lemieux, 2010).

Notice that to correctly interpret the estimated $\hat{\tau}$ we should consider this parameter as the intent to treat (ITT) estimate for the reform as a whole. While everyone who was granted asylum after January 1 , 1999 was subject to the new rules and, hence, mandated to attend the additional language training hours, subject to the temporary welfare reduction (if aged above 25 or with children) and to the new resettlement process and penalties, there may have been some individuals (especially the ill or incapacitated) who did not fully comply with the whole treatment, especially the extra hours of language training. If compliance was 100 percent then the estimate $\hat{\tau}$ would also correspond to the average treatment effect of the whole "package" on the treated (ATE). We have tried to exclude non-compliance using information on child birth, illness diagnosis and hospitalizations. The estimated effects got somewhat stronger and more significant (as expected if the percentage complying increases) but the sample definition becomes somewhat arbitrary. Therefore, we decided to retain the more conservative estimates using all refugees and interpreting the estimates as an ITT.

\section{IV.B Language Training Discontinuity}

Given the centrality of the language component of the reform, we first analyze whether we observe an abrupt change in the observed intensity of language training for refugees admitted around the threshold date. We also analyze whether any form of employment training or support, for which we have data, changed discontinuously at the date of the reform. This was not supposed to be the case as the reform

\footnotetext{
${ }^{31}$ In some sub-samples the power may be lower due to there only being hundreds of observations on each side.
} 
only affected language training and can be used as a falsification check. Table 2 shows such estimates of the discontinuity at the reform cutoff date. Panel a shows the regression discontinuity (RD) estimate of the share that ever participated in the language program ${ }^{32}$ Below the estimates, we also show the mean of the participation share for the control group at the cutoff ( $\alpha$ in equation 11). The columns show the effects from one to three years after the reform.

None of the estimates in Panel a are significant at the five percent level, implying that participation in the language program did not change discontinuously with the reform. The greater incentives to attend classes and the higher penalties for not obtaining a certificate did not operate on the pure "enrollment" margin. After all, the course was considered mandatory even before the reform. However, as shown in Panel c, what substantially changed for the treated group was the number of hours of assignment to language training. Qualifying refugees accumulated between 200 and 250 extra hours of language training in three years, on average, relative to non-qualifying ones. This is about one fifth to one fourth more language training than the control group (980 hours at the boundary point). While large, the additional training hours logged by the treated group, on average, was less than the total potential extra hours (total of 430) for which they would be eligible. Additional data from the training facilities reveals that treated and control refugees were rarely in the same classes, which suggests that language support was possibly of a different quality.

Panels $b$ and d show instead the probability of enrolling in employment support programs (b) and the cumulative extra hours (d) of active labor market support for the treated group of refugees relative to the untreated. In this case both estimates are small and not significant, confirming that the reform, which did not encourage nor fund additional employment support (which was offered to refugees throughout), did not alter this aspect of the integration package for refugees who arrived after the cutoff date.

\section{IV.C Balancing Tests around the Threshold}

One important concern regarding our identification strategy is that asylum seekers or Danish authorities could manipulate the exact date of granting of refugee status around the cutoff by strategically setting the application date or the length of the review process. The first argument against the validity of such hypotheses is that, at the time of applying, most refugees had no knowledge of the reform. The Act on Integration was proposed on April 16, 1998, and approved on June 26, 1998. The average waiting

\footnotetext{
${ }^{32}$ The data refers to participation in January 1999 or later as 1999 is the first year that we observe the intermediate outcomes shown in Table 2 We use the specification in equation (1) for all RD estimates, allowing for different slopes on either side of the cutoff. The fact that the program participation data is only available post 1999 mechanically generates, in this case, a declining probability of being in training for people arriving earlier, hence there is a positive gradient in the pre-1999 months. This does not affect the identification of discontinuities at the cutoff.
} 
time for decisions on applications for asylum was 13 months at the time (Table 3), and the median was slightly more than ten months. Hence, a large share of the refugees who were granted asylum near January 1, 1999 had applied before the law was proposed or approved 33 A second argument against the possible manipulation of total numbers or individual applications is that the authority in charge of granting residence permits and setting the admission dates, the Danish Immigration Service, was separate and totally independent of the municipalities, which were in charge of implementing the reform and providing the respective services. Analyzing reports about implementation of the reform and talking to local authorities, we were not made aware of any change in processing times or selectivity in the processing of asylum applications around January 1999. To formally test that no change in processing times and selectivity of processing took place around the cutoff date, we perform two types of checks.

First, we test that the number of approved applications did not show any unusual bunching (increase or decrease) on either side of the cutoff. Panel a of Figure 1 shows the raw distribution of admissions, as a share of total admissions over the the four-year period considered, by month (from January 1, 1997 to February 28,2001$)$. Then, to account for seasonality and cyclical behavior in refugee admissions, we show, for each month, the share of annual admissions as the deviation from the mean share for that month over the four years in Panel b ${ }^{34}$ A value of zero in the observations of Panel b implies that the admissions in the month equal the average for that month over the four years shown. Very little variation, both in the raw count (Panel a) and in the "de-seasonalized count" (Panel b), is observed from December 1998 to January 1999 (Panel a), and we conclude that the density was smooth around the cutoff date. January is right at the mean for this month and December is slightly below (-0.03 percentage points). The most unusual months (out of the 50 months we show) are April 2000 (-0.05), April 1997 (0.04) and May 1998 (0.04). Additionally, the estimated discontinuity test of waiting times (in days) to granting of asylum status reveals no evidence of "time manipulation" around the cutoff. This estimate is reported in Table 3 and it is equal to 17 days (with a standard error of 348 days), hence not significant and very small relative to the average wait which was 404 days.

A second possibility that could threaten identification, even without time manipulation, is that caseworkers continued to process a uniform number of cases around the cutoff but they were selective about the characteristics of refugees allowed into the new policy regime. If at work, this change would result in a discontinuous change in the average characteristics of refugees after the cutoff date and produce a bias in the estimated effect of the reform. We test such a threat to identification in Table 3, which

\footnotetext{
${ }^{33}$ See Hvidtfeldt et al. (2018) for more information on the process and waiting times in the Danish asylum system.

${ }^{34}$ Our full sample includes a four year window around the reform, as explained in Section III Figure 1 includes two additional months to better illustrate the seasonality around the new year.
} 
shows that individual refugee characteristics did not differ across the cutoff date 35 The table shows the predetermined individual characteristics in our refugee sample (Panel a) and for the children of the refugees (Panel b). Columns 1 and 2 show the sample mean and standard deviation of these variables. Column 3 shows the difference around the RD threshold in each of the variables and column 4 shows the 95 percent confidence interval for testing the hypothesis that the difference is equal to 0 , based on equation (1). These are checks that the individual characteristics are balanced around (on either side of) the discontinuity 36

The average statistics provide a picture of the main characteristics of the considered refugee group. Their average age at admission in the sample was 31.5 years (after excluding individuals older than 49 as we follow individuals for 18 years). The typical refugee was married (67 percent), male (58 percent) and the average number of children was slightly above one at the time of admission. We also report the percentage of refugees admitted under different channels, such as the Geneva convention, UNHCR quota refugees and family-reunification with existing refugees. The majority, 53 percent, were granted refugee status under supplementary Danish laws. The single most important country of origin around the reform was Iraq, representing 44 percent of our sample ${ }^{37} 16$ percent of refugees were from Afghanistan, and the rest came from a range of smaller origin countries (see Section [II] for a thorough description of our sample and data).

Columns 3 and 4 of Table 3 show no evidence of differences in composition and characteristics of refugees on the two sides of January 1, 1999. They are of similar age, equally likely to be married and have the same number of children. The refugees could not be employed upon arrival and we do not have information on education received in their country of origin. Instead, assignment to language training can be considered as a rough indicator of academic skills. The language training facilities placed refugees into Danish 1, 2 or 3 based on their skills at arrival. Those with primary schooling or less were typically assigned to the lowest level, Danish 1 . Tertiary educated refugees were most often assigned to Danish 3, and Danish 2 was an intermediate group. Using this as a proxy for educational attainment, the tests in Table 3 show no differences in skills around the cutoff. Finally, we see from the summary statistics that 35 percent of the admitted refugees spoke Arabic as their mother tongue, while 9 percent reported Dari as their first language. These are the most common languages in Iraq and Afghanistan.

The children of refugees, selected to be born in the period 1986 to 2002 such that we can observe

\footnotetext{
${ }^{35}$ We will evaluate whether the procedural change making the geographic resettlement process more mechanical affected the refugee-municipality matching systematically at the time of discontinuity when analyzing the channels and mechanisms of the working of the reform in Table 6

${ }^{36}$ Appendix Figure A.1 illustrates the balancing tests for each of the variables in Table 3

${ }^{37}$ Iraqi refugees in our sample fled Saddam Hussain's regime well before the Iraq War which started in 2003.
} 
school and crime outcomes up until they are at least 16 years old, are, on average, 4 years old around the time the first parent was granted asylum. 57 percent of them are boys. The age difference is significant while the other characteristics are not. The share of children from Iraq is similar to the parent's share and smooth around the threshold date. A larger share of children are from Afghanistan and, hence, fewer from the various smaller origin countries contained in the category "other country", implying higher fertility of this group relative to others. Overall, columns 3 and 4 imply that the characteristics are balanced between the two sides of the date cutoff, suggesting that our strategy is valid to assess the impact of the reform on refugees and their children.

\section{The Long-Run Impact of the Reform}

The first goal of our analysis, described in Section V.A below, is to estimate, using the regression discontinuity approach, the average causal impact of the 1999 reform on four important long-run socioeconomic outcomes of the first generation refugees. Then, in Section V.B we analyze the causal impact on two important outcomes for the second generation refugees (children of refugees).

\section{V.A The Impact on Adult Refugees}

\section{V.A.1 Main Estimates}

The first three outcomes we analyze are related to the labor market integration of the refugees. They are their earnings, their employment, and the task complexity of their occupation. The earnings are measured as the annual gross earnings in US dollars and deflated to year 2000 prices. The measure of annual employment takes a value of one if the worker was a full time employee during the whole year, while it is less than one if the individual was either a part-time employee or not employed at some point throughout the year. It represents the fraction of a full-time year worked. Finally the indicator of task complexity is constructed as described in Section III above, and it is increasing in the use of communication/complex tasks and decreasing in the use of manual/physical tasks on the job.

Improving the economic success of refugees would certainly be strongly correlated with their material (and possibly psychological) well-being. It would also improve natives' sentiment towards this group (Bansak, Hainmueller, and Hangartner, 2016). An equally important dimension of integration, even more relevant to natives' sentiments towards refugees, is the propensity of refugees to commit crime. Partly as a consequence of their marginalization, trauma and disenfranchisement, there is a diffused perception that refugees are more likely to commit crimes. Unlike economic immigrants who are 
usually associated with low crime rates (e.g. Butcher and Piehl, 1998), evidence from several European countries show higher crime rates for refugees than for natives, especially when refugees are marginalized in their economic opportunities (see Bell, Fasani, and Machin, 2013). For Denmark, Andersen, Dustmann, and Landersø (2019) report that the refugee crime rate was about double that of similar natives, and most of this difference was due to property crime, mainly shoplifting. Our summary statistics broadly confirm these averages for the group of refugees analyzed in this paper. The last outcome we analyze for the first generation is the probability that refugees are charged with and convicted of a crime.

To capture the long-run effects we calculate the average cumulative value of each of the outcomes in year 18 after the reform. Hence, for each outcome we sum the the variable over the post-reform period and divide by the number of years elapsed since the reform 38

Figure 2 shows the mean of each of the long-run outcomes by one-month bins of admission together with the linearly fitted regression lines on either side of the threshold date. The RD design allows for changes in subsequent arrival cohorts, their characteristics and the economic conditions at admission to be captured by the linear trends. The discontinuity at the boundary point, however, separates the effect of the reform from any such secular slower changes in the long-run performance across admission cohorts. In Panels a, b and c, we observe a clear jump in long-run labor market performance, especially if we zoom in on individuals who obtained asylum around January 1, 1999 (time 0 in the graphs). Refugees who were subject to the new policy earned more, worked more, and were employed in more complex occupations over the 18 year following the reform. On the other hand, crime rates do not show any discontinuity around the cutoff date. This suggests that the reform improved the long-run labor market integration, but it did not affect crime rates in the long run. These results, captured visually by Figure 2. are quantified in the RD estimates of the long-run impact of the reform reported in Table 4, where outcomes are the average cumulative value of each outcome in year 18 .

Our main specification, in Panel a, is a local estimation of equation (1) with a triangular kernel and the MSE-optimal bandwidth selector from Calonico et al.(2019). The estimates of the coefficients imply significant discontinuities in all three measures of labor market outcomes. The long-run earnings level of refugees increased by USD 2,500 as a result of the reform. The impact is significant at the 5 percent level and corresponds to a remarkable 34 percent increase in yearly earnings relative to the baseline. Annual employment increased by 4.2 percentage points. The employment effect corresponds to a 23 percent increase relative to the untreated group's employment of 18.3 percent of a full-time year at the

\footnotetext{
${ }^{38}$ The average cumulative job complexity is conditional on employment; the remaining outcomes are cumulative over all 18 years.
} 
cutoff. This estimate is only significant at the 10 percent level. Lastly, we observe a strong and highly significant increase in occupational task complexity. Unlike the labor market outcomes, the estimated impact on average cumulative crime rates, reported in column 4 , is small and insignificant. While significant, the impact on earnings may not be large enough to affect the "marginal" person committing a crime, or people fully complying with the language requirements of the reform were not those more likely to commit a crime ${ }^{39}$

\section{V.A.2 Robustness Checks and Falsification}

The Panels $\mathrm{b}$ to $\mathrm{f}$ of Table 4 show the sensitivity of our main results to different estimation methods and functional form assumptions. First, we include control variables in the regression, specifically gender, age, family size and country of origin controls. The results are rather insensitive to the inclusion of controls, which is consistent with the previous results (Table 3) that shows that these variables are balanced across the cutoff. Second, we investigate the sensitivity of our RD estimate to the use of polynomial functions of the running variable, instead of the linear functions, on either side of the cutoff in equation (1). The estimated RD coefficients are reasonably robust to the use of quadratic or cubic trends, and, if anything, their point estimates increase for earnings and employment. We notice, however, that standard errors increase when fitting higher order polynomials, and, as a consequence, neither of the estimates of earnings nor employment effects are statistically significant if we go beyond second order polynomials ${ }^{40}$ In Panel e we perform a "donut" specification where we exclude refugees admitted in the two weeks immediately before and after the cutoff to test whether the RD estimate is driven by only a few observations (with some potential outliers) close to the boundary point. This does not seem to be the case as these estimates are remarkably close to the main specification. Finally, we show the estimates from a simple OLS regression where all observations are weighted equally and the time to the cutoff is a linear variable on the two sides of the threshold date. We obtain similar and somewhat larger and more significant estimates of the discontinuity effect on earnings and employment and an almost identical estimate on the task complexity. In all the specifications, the discontinuity in crime rates is not statistically significant. Overall, the estimates from different specifications tell a robust story of the reform producing higher earnings, higher employment (marginally significant) and higher occupational

\footnotetext{
${ }^{39}$ Later, we will show that the temporary benefit reduction lead to higher crime rates in year 1 only (Table 7); hence, while not significant the treated group would tend to be less criminal in the subsequent years to produce a cumulative effect close to zero in year 18 .

${ }^{40}$ It is well known and eloquently expressed in Gelman and Imbens (2019) that higher order polynomials tend to over-fit the data close to the cutoff. Recent consensus is moving to favor the linear specification in RD estimation as chosen in our main specification.
} 
task complexity for refugees in the long-run, while not significantly affecting their crime rates.

Figure 3 shows that the magnitude and (up to a point) the statistical significance of the RD estimates are robust to the choice of bandwidth. The figure shows that the discontinuity estimates for earnings and employment are very stable and, in most cases, statistically significant when choosing alternative bandwidths ranging from 120 to 360 days, including the optimal bandwidth, which is 256 for earnings and 217 for employment. For bandwidths between 60 and 120 days around the discontinuity, the point estimate of the earnings and employment effect are also quite stable, but their statistical significance is reduced below the 5 percent level. The size of the task complexity effect is a little more volatile, possibly reflecting that this outcome is estimated on fewer observations because we observe task complexity conditional on employment. But the effect is positive and significant for all bandwidths between 120 and 360, including the optimal bandwidth of 181, and it is also positive for all bandwidths between 60 and 120. For bandwidths of 30 days or less (which would include only a few dozens observations), the standard error is too large and one has no power to identify any reasonably sized effect. While we think that the size of our bandwidth is very reasonable, we need to keep in mind that the density of our data does not allow us to just consider observations with admission dates within a few days of the threshold date to identify the reform effect. Finally, let us emphasize that we never observe any significant discontinuities in crime rates, but the point estimates are larger and noisier at small bandwidths. In the case of crime, the sparsity of observations is combined with the relatively rare occurrence of these outcomes and this generates very low power in our identification strategy when we select small bandwidths. In summary, all our main findings are robust to a reasonable range of bandwidths around the MSE-optimal one.

As an additional check on our empirical strategy we perform a falsification exercise. In Figure 4 we show the estimates of the discontinuity in long-run outcomes, that are obtained at arbitrary cutoff dates up to six months before and six months after the actual cutoff date. The red line shows the estimate of the impact at the actual cutoff date and, for the earnings, employment and task complexity, this line is among the top one to five estimates in the placebo distribution. In most cases we estimate smaller effects at arbitrary cutoff points which are statistically insignificant. However, some placebo effects are noisy and occasionally some larger significant effects are estimated. It is reassuring that there is no effect of January 1998 (-365) or January 2000 (+365), ruling out that some reoccurring seasonal events related to the new year are driving our results. For the crime convictions, the red line is very close to many of the placebo estimates, revealing lack of a significant difference and confirming no evidence of a discontinuity in crime. 


\section{V.B Effects on Families and Second Generation Refugees}

The statistically significant and economically important effects on earnings, employment and occupational task complexity of treated refugees may generate consequences that propagate to important aspects of their family life and, possibly, to their children's outcomes.

\section{V.B.1 Marriage and Fertility}

Greater assimilation into the Danish labor market may encourage assimilation to social and cultural norms of the host society. This could modify preferences towards marrying outside of the ethnic group or having fewer children, as average fertility of native Danish women was significantly lower than that in the countries of origin of refugees. Therefore, we investigate whether marriage outcomes, namely the probability of marrying outside ones' ethnic group and total fertility were different for "treated" refugees. We found no effects of the reform on the probability of inter-ethnic marriage and on total completed fertility. Similarly other related family outcomes such as the number of children born in Denmark and the timing of the first and subsequent children do not show a significant difference between treatment and control groups ${ }^{41}$ The insignificant effects on inter-ethnic marriage probability and on the fertility rates suggest that the reform did not change the structure, size and composition of the families of the refugees in a significant way. This implies that effects on their children (second generation), if present, are more likely arising through the economic channels identified for their parents, than from modification in size, structure and composition of the family.

\section{V.B.2 Schooling and Crime of Children}

In order to study the effect on children's outcomes, we need to choose whether we consider as treated those children with one parent (or specifically the father or the mother) or both, subject to the new policies introduced by the 1999 reform. This choice will also determine who constitutes the control group. As the father was usually admitted earlier than (57.3 percent of the cases in the children sample) or together with (19 percent of the cases) the mother, choosing the father's status as determining the treatment implies, in two thirds of the cases, that both parents were treated. We use treatment of the earliest arrived parent (which was usually the father and implies that both parents were treated) as our main specification, reported in columns 1 and 5 of Table 5. In this case the control group includes children with zero or one treated parent. We also consider, as an alternative, having the father treated

\footnotetext{
${ }^{41}$ See Appendix Table A.1 for the estimated impact on important marriage and fertility outcomes.
} 
and we show the results in columns 2 and 6. Alternatively, we consider admission of the last parent as the assignment to treatment (columns 3 and 7) or the treatment of the mother (columns 4 and 8 ). Both of these cases imply that it is more likely that only the mother is treated, while the father, who typically arrived earlier, is not. In measuring children's outcomes in Table 5, we distinguish between boys (columns 1 to 4 ) and girls (columns 5 to 8 ).

We select all children born between 1986 and 2002, and we analyze two types of outcomes, following them up to 2018. First we consider three variables measuring their schooling achievements, namely whether they "took any exam at the end of lower secondary school", whether they completed lower secondary education, and whether they enrolled in upper secondary education. Then we consider two variables capturing their criminal activity, namely whether they had a criminal charge and whether they had a conviction. The youngest of the children considered in this sample turned 16 in 2018, while the oldest were thirty-two years old in 2018.

Children born after admission and before 2003 were typically born while their parents were attending the three-year language program and they would be of school age after their parents completed the program. Children born before admission, on the other hand, were on average 6 to 7 years old (based on the admission date of the first parent) when their parents were attending the three-year integration program. The estimates in columns 1 and 2 of Table 5, which consider as treated the earliest arrived parent or the father (which often coincide), are rather similar. They show that boys of treated parents were 15 to 17 percentage points more likely to take the final exams in lower secondary education (the 9th grade graduation exams) and 9 to 11.5 percentage points more likely to graduate. These effects are statistically significant. No significant effects on enrolling in upper secondary education are found.

We find quite large but rather imprecisely estimated effects for crime. Male children of refugees subject to the 1999 reform were 15 to 22 percentage points less likely to be charged with a crime by 2018, relative to similar children of non-treated refugees and 10 to 16 percentage points less likely to be convicted. The next two specifications, which consider as treated children with only the second parent (column 3) or the mother (column 4) arriving after the 1999 cutoff date, find a similar or stronger effect on education outcomes for boys but no significant effect on crime outcomes. Columns 5 to 8 in the table show the coefficient on girls' outcomes for the corresponding specification that we ran for the boys. In this case we find very small point estimates and no significant coefficient on any of the variables. A large body of literature emphasizes how boys' basic school outcomes may be more sensitive to the family conditions as they are more subject at an early age to lose focus and motivation in school (see for instance DiPrete and Buchmann, 2013). The stronger effect on crime prevention from having a father 
more integrated in the Danish labor market and possibly society (because of the reform), as shown in the larger estimates of columns 1 and 2, is also in line with the importance of a male role model for these type of extreme outcomes for boys.

Appendix Figures A.2 and A.3 show a series of robustness checks for the main outcomes of the second generation refugees, separately for boys and girls. We focus on "taking the exit exam in lower secondary school" and "being charged with a crime". For both we found significant effects for boys and no effect for girls in our main analysis ${ }^{42}$ Appendix Figure A.3 shows that the RD estimates for girls are close to zero and never significant for any alternative specification of equation (1) (Panels a and b) or any bandwidth (Panels $\mathrm{c}$ and d). The effect on crime is zero, and we often see larger values at alternative cutoffs (Panel f), and it is also very small for exam taking when compared with placebo cutoffs. Appendix Figure A.2 displaying boys' outcomes, on the contrary, generally shows large and significant RD estimates. A few outliers at the cutoff receive too much weight with a narrow bandwidth while all estimates that use a wider range of the data produce stable and more credible results (Panels $\mathrm{c}$ and d). Similarly, we see in Panels a and b that higher order polynomials, allowing a closer fit at the cutoff, produce rather extreme estimates, while OLS and a "donut" approach to the RD design that rely on data further away from the cutoff, produce smaller estimates. In general, we see a consistent and strong effect on boys' schooling as captured by lower secondary exit exam taking but a less clear pattern for the crime effect, which, as noted above, is also sensitive to the definition of the running variable.

Overall, we we do not find evidence that the reform had an effect on family structure nor on education outcomes and crime propensity of second generation women. On the contrary, we find a clear positive effect on completing lower secondary education (corresponding to compulsory schooling) for second generation males. We also find some evidence that these second generation males were less likely to commit crime when their father was (and hence likely both parents were) treated by the reform.

\section{Channels and Mechanisms}

The changes to the refugee integration policy, enacted with a sharp discontinuity in admission dates, enabled us to identify its causal effects on treated refugees in Section $\mathrm{V}$. The multiple changes introduced by the reform, however, make it hard to assess which of them was responsible for each finding. While it is impossible to fully and definitely separate the impact of each component of the reform independently, as we do not have random assignment of each of them, we can gain useful insight into the channels and

\footnotetext{
${ }^{42}$ Using being convicted or being charged with a crime as the outcome variable in the analysis shows similar patterns.
} 
the relative importance of each component by analyzing the timing of the effects, by differentiating the impact among groups and by characterizing the early and subsequent changes.

We start by considering the aspect of the reform that may have affected the spatial distribution of refugees and the characteristics of the initially assigned municipality. In Section VI.A we analyze whether the initial municipality assignment discontinuously changed in some significant way post 1999 relative to pre-1999. Then, as the reform implied stronger incentives to stay in the initial municipality until the end of the language program (both due to larger risks of penalties and the requirement of language certificate completion for permanent residence), in Section VI.B we analyze whether refugees were more likely to stay in the initial location after the reform and for how long. Since a third change brought by the reform was lower welfare benefits for one year only for the refugees over 25 and those with children, in SectionVI.C we analyze more outcomes and dynamics of the effects to see whether this group shows different outcomes relative to the rest in the first year after the reform or in any subsequent period. Finally, as the main change was quality, quantity and funding of language training, in Section VI.D, we analyze whether the impacts on labor market outcomes and the subsequent educational choices of treated refugees and some specific subgroups seem consistent with acquisition of better language skills in the first 3 years of the reform.

\section{VI.A Geographical Distribution}

As described in Section III.B, the reform introduced a more "mechanical" formula to distribute refugees across municipalities, with the goal of spreading them more evenly across Denmark. If such new mechanism altered the sorting of refugees and assigned larger numbers in more (or less) economically successful, dense or diverse locations, it may have affected their future success through local labor market or local network effects ${ }^{43}$ Such a mechanism would be able to generate the long-run effects identified in the RD if at the time of the discontinuity there was a significant change in the characteristics of the municipalities where the refugees were relocated. A slow enactment of the new mechanisms, producing a more diffused distribution of refugees over the years would not be able to generate the discontinuous employment, earnings and occupation effects found in Section $\mathrm{V}$. Hence, in Table 6 we show the regression discontinuity estimates of the predetermined characteristics of the municipality assigned to refugees before and after the cutoff estimated using equation (17). Table 6 also shows the sample mean and standard deviation for those characteristics. The first row shows that 33 percent of refugees were

\footnotetext{
${ }^{43}$ See Edin, Fredriksson, and Åslund (2004); Damm (2009); Battisti, Peri, and Romiti (2018) and Aksoy, Poutvaara, and Schikora (2020) for analyses of the impact of initial network and initial economic conditions on refugees' performance.
} 
placed in urban municipalities and the RD estimate for this characteristic is 0.11 . Although not significant, this is a relatively large difference. However, it turns out that it is driven by municipalities on the margin between urban and non-urban. In fact, when looking at the 17 percent of our sample placed in one of the five largest cities (likely to provide an economic advantage), we observe no difference across January 1, 1999 in this variable (RD estimate 0.01 and standard error 0.05 in the second row of the table) ${ }^{44}$ Additionally, the treated and the control groups are distributed in municipalities with no significant differences in employment and unemployment rates (as measured in 1996), and in average labor income (see the third to fifth rows of Table 6). Essentially, the new reform did not produce any stronger tendency to relocate refugees in economically more (or less) successful municipalities around the threshold date. In the last two rows of Table 6 we look at a discontinuity in the number and share of co-nationals already residing in the municipalities of first assignment. Even this variable is very stable across the cutoff. Overall, the balancing test shows a remarkable similarity of observable characteristics of the locations where they were settled before and after the cutoff date.

Let us emphasize that the change in the redistribution formula did produce, in the long run, the effect of reducing the number of refugees in large cities and in making their population more proportional to the distribution of the Danish population, rather than concentrated in larger cities. Table A.2 in the Appendix shows that, when we drop the two year window used in the main specifications of this paper and we compare municipality characteristics of refugees resettled in 1997 with those of 2000, we observe a decrease in urban location and an even stronger and very significant decrease in resettlement to the five largest urban areas with large pre-existing immigrant populations. It looks like the change in dispersion policy did alter the distribution of refugees over time, but the change, likely because of inertia and constraints as well as local adjustments, was more gradual than the documented change in language training. Its impact, which may depend on time since the reform and is therefore controlled for by linear or polynomial terms in that variable, does not affect the RD identification we use in this analysis. The lack of any measurable discontinuous change in the allocation of refugees to municipalities around January 1, 1999 suggests that this mechanism did not produce the observed results in our main analysis.

\section{VI.B Mobility}

The reform increased the incentives for refugees to complete the language course and stay in the initial municipality where those courses were offered. This may have affected mobility temporarily by delaying moving out of the initial municipality (which eventually about 57 percent of refugees do, see Table 1 ) or

\footnotetext{
${ }^{44}$ The five largest cities are Copenhagen (including Frederiksberg), Aarhus, Aalborg, Odense and Esbjerg.
} 
permanently by increasing the probability of staying in the municipality in the long run.

To show the impact of the reform on geographic mobility and on the timing of this outcome, we show graphs in Panels a and b of Figure 5 that capture the dynamics of the outcome from one to eighteen years after resettlement. Panel a shows the discontinuity, estimated using a local linear regression with the MSE-optimal bandwidth, in the probability of having moved from the initial municipality separately estimated in each year after resettlement and the 95-percent confidence interval. The chart, therefore, shows the estimated difference between treated (post-reform admission) and control (pre-reform admission) refugees in the probability of being in the initial municipality for each year after resettlement. Panel a shows the effects for all refugees, while Panel $b$ splits the impact by initial placement in rural versus urban municipalities. The pattern is interesting and quite clear. Treated refugees were much less likely to have moved from their first municipality during the first three to four years. This corresponds closely to the duration of the language classes. After year 5 they seem to mostly catch up in mobility with the control group. Smaller and mostly insignificant differences in the probability of having moved are found in the long-run.

The time profile of the estimates implies a delay in the propensity to move. This is consistent with the idea that refugees qualifying for and given incentives to attend the additional language training in their municipality of resettlement were more likely to stay during the first three to four years after 1999 to take advantage of this service. This result is consistent with attending the language class being an important channel of the subsequent effects. Panel b of Figure 5 separates the refugees initially assigned to urban and rural municipalities. We see that the initial mobility gap between treated and control refugees is larger for those assigned to rural municipalities. This is consistent with the idea that a larger share of those initially settled in rural areas were kept in place by the language class, while they would have relocated early on to seek economic opportunities if language courses were not mandatory. The treated refugees resettled in urban areas only had a smaller initial mobility gap and quickly appear to catch up to mobility of the control group. Those in rural areas, instead, where more likely to stay after the reform for several years, and even in the long run their mobility never fully catches up with the control group. A possibility is that the language training and longer residence may have integrated this group better in rural communities where they would otherwise not have resided and made them a bit more likely to stay in the long run 45

Therefore, the distribution of refugees into municipalities did not change much with the reform, and the post-reform refugees were almost as likely to leave the initial municipality as the pre-reform one, in

\footnotetext{
${ }^{45}$ We investigate whether the reform was more beneficial for rural or urban initial residence in section VI.E
} 
the long run. The main difference between the treated and the control seems to be a delay in mobility corresponding to the duration of language training (consistent with Azlor, Damm, and Schultz-Nielsen, 2020). This suggests that moving to job opportunities may have been as prevalent a mechanism of success in the long run after as before the reform, and the delayed mobility is more likely driven by attending the language class than by better or different labor market opportunities in the initial municipality of settlement.

\section{VI.C One-Year Welfare Cut}

In most cases the treated refugees attended the language courses during the first three to four years after January 1, 1999. Moreover in the first year after January 1, 1999, the group of 25 and older (or those with children) was subject to the welfare cut. Therefore, it is useful to show the dynamics of the employment and earnings effects, how they accumulated over time, and separate between those exposed and those not exposed to the one-year welfare cut, especially in the early years. Figures 6 and 7 show exactly this information. Panel a shows the RD estimates and the 95 percent confidence intervals (using linear regressions at the MSE-optimal bandwidth) of the reform on the average cumulative gross earnings (Figure 6) and employment (Figure 7) for each year from 1999 (year 1) to 2016 (year 18), for the average refugee ${ }^{46}$ Panel $b$, instead, shows separately the effects every fourth year for refugees aged 18-24 with no dependents (children), who were unaffected by the one-year welfare cut, (indicating this group with a full square) and for those above 25 and/or with children, who experienced a reduction in benefits in year one (indicating them with a hollow triangle).

Looking first at the average earnings and employment effects over time in Panel a of Figures 6 and 7. two features emerge. First, while we see small to no labor market effects on the treated in years 1 to 4 , the period corresponding to language class attendance, a gradual but significant improvement in employment and earnings occurred from year 5 to years 9-10. This timing is consistent with the effects being the consequences of better language skills accumulated thanks to the improved language classes. The second fact emerging from the graphs is that the earnings and employment effects stabilize after year 10 and are permanent (at least up to year 18). The treated group reached a permanently higher income level than the control group. The treated group accumulated an average of USD 2,504 higher earnings per year, as reported in Table 4. They also accumulated 0.76 years ( 9 months) of extra employment over the 18 years, corresponding to a 4 percentage point higher employment rate in each year for the treated (as reported in Table 4 , 47

\footnotetext{
${ }^{46}$ The RD estimate in year 18 is identical to the one reported in Table 4

${ }^{47}$ Employment is measured as a fraction of a full working year. Hence, the long-run average cumulative employment effect
} 
The zero difference in employment and earnings between the treated and the untreated in the first year (and in the years up to the fourth year) and the gradual improvement starting in year 5 are consistent with a labor market effect of language skill acquisition. The first-year estimates, instead, are not consistent with a work-incentive effect in year 1 generated by the lower welfare benefits. Panel $b$ of Figures 6 and 7 separates individuals who were aged 18-24 and without children in 1999 and everyone else: The first group had no change in welfare in the first year while the others experienced a drop in welfare from January 1, 1999 to February 1, 2000. While the effect on the first subgroup is estimated with substantial noise due to its small size in our sample, there are no significant differences in the effects between the two groups either in the early or in the later years. This is further evidence against the idea that the one-year reduction of benefits generated a work-incentive effect on the group subject to the temporary welfare cut.

The findings shown in Figure 6 imply that affected refugees did not replace the lost welfare benefits with higher employment or earnings ${ }^{48}$ This must imply that disposable income of the affected group fell in the first year after the reform.

To focus our attention on the effects of the welfare cut in 1999 (year 1 of the reform) and to understand other possible consequences, in Table 7 column 1 we show the impact on disposable income, overall (Panel a) and on the exposed (Panel b) and non-exposed (Panel c) groups in year 1 (when the cut was in place) and in year 2 after the reform (when it was rescinded), based on equation (1). Column 1 of Table 7 shows that disposable income dropped by 22 percent for the treated compared to the untreated in the exposed group (an estimated decrease of USD 2,723 relative to the mean of the untreated at the boundary point equal to USD 12,507 in Panel c). The effect is strongly significant overall (Panel a) and it is driven by the group who experienced the cut in welfare benefits (Panel c). The disposable income decline was similar to the size of the welfare cut, which was 25 to 29 percent depending on the family structure 49 On the contrary, the refugees who did not experience a welfare cut had the same level of disposable income, as shown in Panel b of Table 7, in the treatment and control groups. Notice also that, consistent with the temporary nature of the cut, disposable income is equalized between treatment and control groups in year 2 after the reform. All the estimates of column 1 of Table 7 are, therefore, consistent with a one-year welfare cut for the group under 25 with no dependents, which did not produce

\footnotetext{
may be interpreted as a 4 percentage point increase in the fraction of a year worked.

${ }^{48}$ This was also noted in a report published by the Ministry of Interior Affairs in 1999 showing that very few immigrants could supplement the welfare benefits with income from work. This contributed to the perception that this reduction did not create employment and learning opportunities as intended, and it was then abandoned shortly after.

${ }^{49}$ The actual welfare cut is well within the bandwidth of the estimated reduction in disposable income. The reduction in disposable income may be smaller due to supplementary transfers (Ministry of Interior Affairs. 1999).
} 
any impact on employment and earnings and hence was reflected in lower disposable income that year. The following year the cut was rescinded and the disposable income of the group went back to normal. The group treated by the reform but not subject to the one year welfare cut did not have any significant fluctuation in earnings and disposable income in year 1 or year 2 of the reform.

Focusing on the first two years of the reform, we can also analyze whether the welfare cut may have produced any other unintended effects on the group subject to it. Recalling that, on average, the reform did not produce any significant long-run effect on the crime propensity of the refugees (see Table 4), we show in columns 2 to 5 of Table 7 the RD estimate of the average annual probability of being charged with or convicted of a crime (columns 2 and 3), and similar estimates specifically for shoplifting in supermarkets in columns 4 and 5 (the most common crime committed by refugees) in years 1 and 2 after the reform. Interestingly, we find a positive and significant discontinuity in crime and shoplifting exactly in year 1 and only for the group subject to the welfare cut (Panel c). The impact disappeared in year 2 for all outcomes (except a small persistence in convictions) and is small and never significant for the group not subject to the welfare cuts (Panel b).

Columns 4 and 5 show that most of the effects were driven by shoplifting in supermarkets. The probabilities of being charged and convicted with a shoplifting crime are nine and eight percentage points higher for the treated group in the one year when welfare cuts were applied. In year two and in all subsequent years, as well as in the long run (as shown above), the difference in crime rates between the treated and untreated group was close to zero and insignificant. These findings, especially the timing, the group affected, the type of crime and the coincidence with lower disposable income, suggest that welfare cuts may have produced the spike in property crime by pushing people into poorer material conditions. One has to acknowledge that the two groups may differ in other dimensions and the period in which this policy was in place was short. Still, our findings are consistent with the impact on crime found in response to a cut in welfare benefits for immigrants in the later reform of 2002 (Andersen, Dustmann, and Landers $\varnothing, 2019$ ).

\section{VI.D Occupational Skills and Additional Education}

To understand whether better language skills were likely to drive the employment and earnings gains of treated refugees it is important to look at what type of jobs they took. Figure 8 looks at the estimates of occupational differences conditional on being employed (in November) between treated and control groups. Panels a, b and c show the differences in communication, manual and complex task intensity, and Panel d shows differences in the occupational category that employs the most refugees, namely per- 
sonal and protective services. Post-reform refugees tended to upgrade their occupations towards jobs with higher communication and less manual content. As a result task complexity, defined as communication relative to manual tasks, increases. The transition towards more communication-intensive jobs becomes significant 4 to 5 years after 1999, when refugees likely completed their language training and obtained their certification, and it remained significant after that. The average cumulative effect on task complexity is significant from year 6 on, revealing a statistically strong and persistent occupational change towards jobs that are more intense in language skills and less intense in manual skills. Panel $\mathrm{d}$ shows that after completion of language training, we see a clear transition into personal and protective services, which represent a well paid job, requiring some level of Danish proficiency. The effect is significant from around year 6 and implies about 10 percentage points higher share of employment in personal and protective services for the treated refugees. Nurses, health care assistants and personal assistants for elderly citizens are sub-categories of this occupation 50 These findings are consistent with improved language skills as a consequence of enhanced language training giving refugee access to better paid and more communication-intensive jobs.

Improved language skills could also be a catalyst for educational upgrading. The panels of Figure 9 show the differences in the probability of enrolling in and obtaining more education for treated refugees in the years after the reform. Panel a shows enrollment rates by four year intervals since the reform, Panel $\mathrm{b}$ shows completion rates of an education program. Panels $\mathrm{c}$ and $\mathrm{d}$ do the same by age, separating those between 18 and 24 (solid square) and those above 25 (hollow triangle). A positive average effect on treated refugees appears in Panels a and b beginning 8 years after resettlement, i.e., 4 to 5 years after the end of the language training. This leads to a six percentage point higher share of treated refugees with an education in Denmark relative to the untreated (on the margin of significance). When separating the young (under 25) from the older refugees in Panels $\mathrm{c}$ and $\mathrm{d}$, we see that the effect is driven exclusively by the young while older refugees are unlikely to study in Denmark. Appendix Figure A.4. shows that the young group is more likely to obtain lower secondary education (significant coefficient) and a subgroup of them may also obtain tertiary education (Panel f) in Denmark as a consequence of the reform. The largest effect is observed on attending vocational education programs that can be attended while working (Appendix Figure A.4, Panel d). In summary, treated refugees were more likely to be hired in communication-intensive jobs and many young refugees increased their schooling, starting from the time language classes were completed. Both channels can contribute to explaining the better

\footnotetext{
1 .

${ }^{50}$ We do not see a clear pattern in the two other top-three occupations among the refugees discussed in Section III (Table
} 
employment/earnings opportunities and are consistent with language training being the underlying cause of such effects.

\section{VI.E Heterogeneity Analysis: Who Benefited the Most?}

An important question is whether some sub-groups of refugees particularly benefited from the reform. We performed heterogeneity analyses on several dimensions without finding very significant differences. In Table 8 we focus on the long-run labor market integration splitting by alphabet of mother tongue of the refugee and by initial resettlement placement. The three outcomes are described by the column headers.

Panel a of Table 8 shows the reform impact on refugees who use the Latin alphabet and are at least initially able to read in Danish and refugees using other alphabets and are, hence, farther away from reading and understanding the language. For this second group learning Danish is particularly difficult and particularly important as it gives access to basic understanding. For the second group, who may already have a very basic understanding of the alphabet and language, the returns to language education may be smaller ${ }^{51}$ Table 8 shows some evidence that labor market effects on earnings and employment effects are larger and much more significant for those who spoke languages farther from Danish, i.e., not using the Latin alphabet 52 The larger earnings and employment effects do not correspond, however, to a significantly higher transition to complex occupations, which is similar for the two groups (column 3) ${ }^{53}$ The occupational change is somewhat noisily estimated within groups, possibly suggesting a larger dispersion of outcomes.

In section VI.B we show that refugees resettled in rural municipalities were somewhat more likely to stay put and not re-migrate after the reform. This raises the question about whether improved rural location quality for refugees, after the reform, produced the incentives to stay as well as higher earnings and employment. Panel $\mathrm{b}$ of Table 8 shows the estimated impact on labor market outcomes split by initial location. The reform generally increased occupational task complexity (conditional on employment) consistent with improved language skills, but it did not increase job finding and earnings of those in rural areas. Rather, Panel b of Table 8 shows that employment and earnings improved most in urban

\footnotetext{
${ }^{51}$ Specifically, we create two broad categories based on the mother tongue of the refugee: languages written using the Latin alphabet and others. The Latin alphabet group includes Kurdish (8 pct.), Albanian (6 pct.), Serbian (5 pct.), Bosnian (3 pct.) as well as Turkish (1 pct.). The largest group of non-Latin languages is made of those speaking Arabic (35 pct.), Dari (9 pct.), Farsi (4 pct.), Pashto (3 pct.), Assyrian (1 pct.) and a number of smaller groups of which many are categorized as Arabic alphabet.

${ }^{52}$ Consistent with this we also find larger effects on individuals assigned to Danish 1 (not shown here) which is designed for those with little schooling from their origin country and those who cannot read or write in the Latin alphabet at arrival.

${ }^{53}$ Appendix Table A.3 presents tests of differences between the two groups.
} 
municipalities, which is consistent with a story that better language skill allowed the refugee access to more communication-intensive jobs that are more prevalent and better paid in urban municipalities. It is not consistent with a story of better "economic" quality of rural locations after the reform.

In summary, the findings of this section are consistent with the hypothesis that the largest part of the effect of the reform on employment and earnings was due to the better language training. First, such effects arose after the language training was completed. Second, they were associated with a transition towards communication-intensive occupations and with an increase in formal schooling. Third, they benefited more significantly refugees speaking languages very different from Danish. Additionally, we find an increased propensity of refugees to stay in the initial (rural) municipality where the courses were offered and move only after the courses were completed ${ }^{54}$ This is consistent with the effects of increased economic incentives to attend the course and larger sanctions for not doing it. However, we do not find any evidence that the allocation of refugees across municipalities changed with the reform, nor any evidence of employment or earnings effects of the one-year welfare cut on the group affected by it, while we find evidence of a one-year drop in disposable income and a one year increase in crime rates for this group and no remaining effects after one year. We therefore conclude that better language training generated better long-run labor market integration of the refugees subject to the 1999 reform.

\section{Cost-Benefit Analysis}

We have shown that the 1999 policy reform improved the labor market integration of refugees in Denmark. To evaluate whether it produced benefits for the Danish economy, we conduct a simple costbenefit analysis. Hence, we calculate the discounted stream of economic benefits produced by the policy, according to our causal estimates, and we subtract the costs.

The main economic benefit we consider is the increase in annual earnings for treated refugees as estimated above. The main cost is represented by the operating expenses of the additional language courses as measured by the monthly activity-based payment for language services paid by the municipality 55 The language course lasted for about 18 months prior to the reform, and the reform increased the time by 6 months and the resources for the language course by 30 percent. An additional component in the cost-benefit analysis is also added to evaluate the program using an unchanged public budget. This implies adding the change in the deadweight loss of taxation equal to the change in fiscal budget

\footnotetext{
${ }^{54}$ Notice, that most post-resettlement mobility is from rural to urban, explaining why we find a small long-run mobility gap only in rural municipalities.

${ }^{55}$ The activity-based payment for language training is found in Act on Integration No 474 of 1998, section 45(6).
} 
(a positive change) multiplied by a tax distortion rate of 50 percent in the base scenario. The impact on the fiscal budget is the sum of the negative of the operating costs of the extended program, plus the increased tax revenue plus the savings on welfare benefits ${ }^{56}$ We use a societal discount rate of 3 percent (see, e.g., Heckman et al., 2010, for a similar approach). The time horizon analyzed is the 18 years over which outcomes are measured.

The results of this cost-benefit analysis are shown in Table 9 . In the baseline scenario of the first row, the extended language course has a net present value of USD 40,100 per participant and the benefit-cost ratio is equal to 15.4. We see that the cost of providing the additional language training per refugee (around USD 2,800) is only a fraction of the present value of earnings benefits generated by the reform which amounts to USD 35,200. The simple comparison of these two numbers already suggests that the language training is a very effective policy investment. This investment breaks even after 5 years. The next four rows of Table 9 show the results when we modify some of the assumptions in the analysis. First, "Alternative price" is based on data from 2008 on prices per language course module instead of prices stated in the law we analyze ${ }^{57}$ Then in the third row, we use a discount rate of 7 percent instead of 3 percent in the baseline and in the fourth row we set the tax distortion rate to 0 instead of 50 percent. Finally, in the last row we include among the the costs, the funding of additional education obtained by refugees ${ }^{58}$ In this case the net present value is above USD 22,000. The benefit-cost ratio in these exercises ranges from 10 to 15 without the cost of formal education and it drops to 2 if we include the cost of the additional formal education obtained among the treated. The time to break-even never exceeds 6 years.

The reform also generates large gains for the government due to income tax savings on social welfare payments and added tax payments from the increase in earnings. This also holds when we include the added costs of further education (Appendix Table B.1).

In this exercise we have only considered the earnings gains as benefits. We omitted the one-year reduction in welfare payments to refugees older than 25 or with children. The welfare cut did not increase their propensity to work nor their labor earnings, but instead increased their propensity to commit crimes, especially shoplifting. Hence, while there were some savings from welfare, those should, in principle, be compared with the costs of increased crime. Since the major part of the increase in crime derives from increases in shoplifting and lasts only one year, the costs could be small and are hard to

\footnotetext{
${ }^{56}$ Tax revenues are estimated by an average tax rate times the effect on earnings, while savings on welfare payments are estimated using individual data on welfare payments. The results available upon request.

${ }^{57}$ Prices were found here on the website of the Danish Ministry of Immigration and Integration: https://integrationsbarometer.dk/danskuddannelserne/takster, checked on June 112020.

${ }^{58}$ Section VII in the Appendix describes and discusses the assumptions in more detail.
} 
quantify 59 We also ignore the positive spillovers to children in our cost-benefit analysis.

Overall, the cost-benefit analysis suggests that investing in the language skills of newly arrived refugees is an economically sound policy. The investment in adult refugees pays for itself within a few years from program completion and exhibits substantial long-run returns even before considering the impacts on the second generation 60

\section{Conclusion}

In this paper we analyze the impact of the new policies applied to refugees who were granted refugee status on or after January 1, 1999. The sharp temporal discontinuity in qualifying for the reform allows a causal estimation of the effect of the reform, as refugees are randomly distributed in terms of characteristics, around the cutoff date. The reform had a main component that increased the time spent in and the resources devoted to language training of refugees. It also increased the incentives to attend/complete such training. Three other changes were introduced by the reform. First, welfare benefits were lowered for one year for the group older than 25 . Second, the dispersal policy was modified to be become "mechanical" and gradually to increase the spread of refugees across regions. Third, mobility during the three-year language program was restricted.

When estimating the consequences of the reform, we find a significant and persistently positive effect on employment rates and earnings that accrued gradually starting in years 3 or 4 after the reform, i.e., around the time the refugees completed their language training. After eighteen years, the treated refugees were four percentage points more likely to be employed (a 23 percent rise relative to the baseline) and earned USD 2,500 per year more (a 34 percent rise relative to the baseline). As their income and employment rate gradually rose, those refugees also transitioned to more communication-intensive occupations and obtained additional formal education. These effects are consistent with labor market consequences of the improved language skills. Additionally, we find a larger propensity to stay in the initial municipality in the first 3 to 4 years, when language classes were mandatory. This might have reduced slightly the mobility out of rural municipalities without generating any economic effects.

We found effects on the children of refugees that imply a very long-lasting impact of the reform. These effects, however, are less significant and more circumscribed. First, it appears to matter whether one or both parents were treated and, in particular, whether the father was treated. Second, the effects

\footnotetext{
${ }^{59}$ Further details on the cost of crime are found in Section VII in the Appendix.

${ }^{60}$ Hendren and Sprung-Keyser (2020) evaluate 130 historical policy changes in the United States and find that programs/interventions that produce spillovers on the children generally have high returns.
} 
appear to vary by the gender of the child. The more significant effects we found are a positive impact from having both parents subject to the reform (treated) on male children's probability of completing upper secondary school and a negative impact on the probability of committing crime as juveniles or young adults, for the same group. We do not find any effect on female children. These effects are partly consistent with previous findings that unfavorable family backgrounds are especially harmful for boys (Bertrand and Pan, 2013; Chetty et al., 2016; Autor et al., 2019; Andersen, Dustmann, and Landersø, 2019). They are also consistent with an interpretation that the main changes brought about by the reform were improvements in parental language proficiency and subsequent education and labor market attachment. The estimates on the effects on children, however, are noisy and somewhat sensitive to outliers close to the cutoff. Hence, we should be cautious when interpreting the magnitude of the impact on the second generation.

We do not observe any discontinuous change (between treatment and control groups) in the distribution of refugees across municipalities, by economic, geographic and demographic characteristics. These findings suggest that the change in allocation across municipalities did not occur right away; hence, it is not the source of the estimated impacts. Other studies have found a long-run effect of this reform on the geographic distribution of refugees. However, we do not see such a change in the treated group, represented by refugees who were admitted in the first 6 to 8 months of 1999 relative to the control group who were admitted in the last 6 to 8 months of 1998. Similarly we do not see any employment or earnings effects in the first year after the reform for the group subject to the one-year welfare reduction. We find, however, higher property crime in the group experiencing lower disposable income due to the welfare cut, which may suggest negative unintended consequences of this minor measure.

Our results suggest that investment in language training of refugees after settlement lead to higher earnings, more education, more communication-intensive jobs, and better schooling and crime outcomes for their male children. The effects are significant and economically advantageous, in the sense that the economic gains are several times larger than the costs (up to USD 15 in returns for USD 1 invested) and are permanent. It is the first time, to our knowledge, that such a significant and long lasting effect for a reform focused on language training of immigrants has been established in the literature. 


\section{References}

Agersnap, Ole, Amalie Sofie Jensen, and Henrik Kleven. 2020. "The Welfare Magnet Hypothesis: Evidence From an Immigrant Welfare Scheme in Denmark." American Economic Review: Insights $2(4): 527-42$.

Aksoy, Cevat Giray, Panu Poutvaara, and Felicitas Schikora. 2020. "First Time Around: Local Conditions and Multi-Dimensional Integration of Refugees." CESifo Working Paper Series 8747.

Andersen, Lars Højsgaard, Christian Dustmann, and Rasmus Landersø. 2019. "Lowering Welfare Benefits: Intended and Unintended Consequences for Migrants and their Families." CReAM Discussion Paper 05/19.

Arendt, Jacob Nielsen. 2018. "Integration and Permanent Residence Policies - A Comparative Pilot Study.” The Rockwool Foundation's Research Unit Study Paper No. 130, The Rockwool Foundation's Research Unit.

2020. "Labor Market Effects of a Work-First Policy for Refugees." The Journal of Population Economics URL https://doi.org/10.1007/s00148-020-00808-z.

Autor, David, David Figlio, Krzysztof Karbownik, Jeffrey Roth, and Melanie Wasserman. 2019. "Family Disadvantage and the Gender Gap in Behavioral and Educational Outcomes." American Economic Journal: Applied Economics 11 (3):338-381.

Azlor, Luz, Anna Piil Damm, and Marie Louise Schultz-Nielsen. 2020. "Local Labor Demand and Immigrant Employment.” Labour Economics 63 (101808).

Bansak, Kirk, Jens Hainmueller, and Dominik Hangartner. 2016. "How Economic, Humanitarian, and Religious Concerns Shape European Attitudes Toward Asylum Seekers.” Science 354 (6309):217222.

Battisti, Michele, Giovanni Peri, and Agnese Romiti. 2018. "Dynamic Effects of Co-Ethnic Networks on Immigrants' Economic Success." CESifo Working Paper Series 7084.

Bell, Brian, Francesco Fasani, and Stephen Machin. 2013. "Crime and Immigration: Evidence from Large Immigrant Waves." Review of Economics and Statistics 95 (4):1278-1290.

Bertrand, Marianne and Jessica Pan. 2013. "The Trouble with Boys: Social Influences and the Gender Gap in Disruptive Behavior." American Economic Journal: Applied Economics 5 (1):32-64.

Bloemraad, Irene and Els De Graauw. 2012. "Immigrant Integration and Policy in the United States: A Loosely Stitched Patchwork.” International Perspectives: Integration and Inclusion :205-232.

Borjas, George J. 1994. "The Economics of Immigration." Journal of Economic Literature, XXXII:1667-1717.

Bratsberg, Bernt, Oddbjørn Raaum, and Knut Røed. 2017. "Immigrant Labor Market Integration Across Admission Classes.” Nordic Economic Policy Review :17-54.

Brell, Courtney, Christian Dustmann, and Ian Preston. 2020. "The Labor Market Integration of Refugee Migrants in High-Income Countries.” Journal of Economic Perspectives 34 (1):94-121.

Butcher, Kristin F and Anne Morrison Piehl. 1998. "Cross-City Evidence on the Relationship Between Immigration and Crime." Journal of Policy Analysis and Management 17 (3):457-493.

Calonico, Sebastian, Matias D. Cattaneo, Max H. Farrell, and Roco Titiunik. 2019. "Regression Discontinuity Designs Using Covariates." The Review of Economics and Statistics 101 (3):442-451. 
Card, David, Jochen Kluve, and Andrea Weber. 2010. "What Works? A Meta Analysis of Recent Active Labor Market Program Evaluations." Journal of the European Economic Association 16 (3):452-477.

. 2018. "Active Labor Market Program Evaluations: A Meta-Analysis." The Economic Journal 120 (November):894-931.

Chetty, Raj, Nathaniel Hendren, Frina Lin, Jeremy Maherovitz, and Benjamin Scuderi. 2016. "Childhood Environment and Gender Gaps in Adulthood." American Economic Review: Papers \& Proceedings 106 (5):282-288.

Chiswick, Barry R. 1991. "Speaking, Reading, and Earnings Among Low-Skilled Immigrants.” Journal of Labor Economics 9:149-170.

Chiswick, Barry R. and P. W. Miller. 1995. "The Endogeneity between Language and Earnings: International Analyses." Journal of Labor Economics 13 (3):246-288.

Damm, Anna Piil. 2009. "Ethnic Enclaves and Immigrant Labor Market Outcomes: Quasi-Experimental Evidence.” Journal of Labor Economics 27 (2):281-314.

De Vries, Karin. 2013. Integration at the Border: The Dutch Act on Integration Abroad and International Immigration Law. Bloomsbury Publishing.

DiPrete, Thomas A and Claudia Buchmann. 2013. The Rise of Women: The Growing Gender Gap in Education and What It Means for American Schools. Russell Sage Foundation.

Dustmann, Christian. 1994. "Speaking Fluency, Writing Fluency and Earnings of Migrants." Journal of Population Economics 7 (2):133-156.

Edin, Per-Anders, Peter Fredriksson, and Olof Åslund. 2004. "Settlement Policies and the Economic Success of Immigrants." Journal of Population Economics 17 (1):133-155.

Fasani, Francesco, Tommaso Frattini, and Luigi Minale. 2018. "(The Struggle for) Refugee Integration into the Labour Market: Evidence from Europe.” IZA Discussion Paper 11333.

Gelman, Andrew and Guido Imbens. 2019. "Why High-Order Polynomials Should Not Be Used in Regression Discontinuity Designs." Journal of Business \& Economic Statistics 37 (3):447-456.

Heckman, James J., Seong Hyeok Moon, Rodrigo Pinto, Peter A. Savelyev, and Adam Yavitz. 2010. "The Rate of Return to the HighScope Perry Preschool Program." Journal of Public Economics 94 (1-2):114-128.

Heller, Blake and Kirsten Slungaard Mumma. 2020. "Immigrant Integration in the United States: The Role of Adult English Language Training." Job Market Paper .

Hendren, Nathaniel and Benjamin Sprung-Keyser. 2020. "A Unified Welfare Analysis of Government Policies." Quarterly Journal of Economics 135 (3):1209-1318.

Hübschmann, Zuzanna. 2015. "Migrant Integration Programs: The Case of Germany." The Graduate Institute of International and Development Studies, Global Migration Centre .

Huynh, Duy T., Marie Louise Schultz-Nielsen, and Torben Tranæs. 2007. "The Employment Effects upon Arrival of Reducing Welfare to Refugees." The Rockwool Foundation's Research Unit Study Paper No. 15, The Rockwool Foundation's Research Unit.

Hvidtfeldt, Camilla, Marie Louise Schultz-Nielsen, Erdal Tekin, and Mogens Fosgerau. 2018. "An Estimate of the Effect of Waiting Time in the Danish Asylum System on Post-Resettlement Employment Among Refugees: Separating the Pure Delay Effect from the Effects of the Conditions Under which Refugees are Waiting." PLOS ONE 11 (13):1-14. 
Joona, Pernilla Andersson and Lena Nekby. 2012. "Intensive Coaching of New Immigrants: An Evaluation Based on Random Program Assignment." The Scandinavian Journal of Economics 114 (2):575600.

Joppke, Christian. 2007. "Beyond National Models: Civic Integration Policies for Immigrants in Western Europe.” West European Politics 30 (1):1-22.

Lee, David S. and Thomas Lemieux. 2010. "Regression Discontinuity Designs in Economics." Journal of Economic Literature 48 (2):281-355.

Lochmann, Alexia, Hillel Rapoport, and Biagio Speciale. 2019. "The Effect of Language Training on Immigrants' Economic Integration: Empirical Evidence from France.” European Economic Review 113:265-296.

LoPalo, Melissa. 2019. "The Effects of Cash Assistance on Refugee Outcomes." Journal of Public Economics $170(\mathrm{C}): 27-52$.

Martin, Iván, Albert Arcarons, Jutta Aumüller, Pieter Bevelander, Henrik Emilsson, Sona Kalantaryan, Alastair MacIver, Isilda Mara, Giulia Scalettaris, Alessandra Venturini, H Vidovic, I Welle, M Windish, R Wolffberg, and A Zorlu. 2016. "From Refugees to Workers: Mapping Labour Market Integration Support Measures for Asylum-seekers and Refugees in EU Member States." Volume II: Literature review and country case studies .

Ministry of Interior Affairs. 1999. "Rapport om resultaterne af Indenrigsministeriets sagsbaserede evaluering af integrationsloven." Ministry of Interior Affairs .

Nielsen, Chantal Pohl and Kræn Blume Jensen. 2006. "Integrationslovens betydning for flygtninges bosætning." AKF report .

Rambøll and the Danish Center for Social Science Research. 2013. "Samfundsøkonomisk analyse af metoder. Hjemløsestrategien." Report for the Danish Ministry of Social Affairs and the Interior Appendix 3. URL https://socialstyrelsen.dk/filer/voksne/hjemloshed/ samfundsoekonomisk_analyse.pdf.

Rosholm, Michael and Rune Vejlin. 2010. "Reducing Income Transfers to Refugee Immigrants: Does Start-Help Help you Start?” Labour Economics 17 (1):258-275.

Sarvimäki, Matti and Kari Hämäläinen. 2016. "Integrating Immigrants: The Impact of Restructuring Active Labor Market Programs.” Journal of Labor Economics 34 (2):479-508.

Schultz-Nielsen, Marie Louise. 2017. "Labor Market Integration of Refugees in Denmark." Nordic Economic Policy Review :55 - 90.

Williamson, Abigail Fisher. 2018. Welcoming New Americans? Local Governments and Immigrant Incorporation. University of Chicago Press. 


\section{Tables and Figures}

Table 1: Summary Statistics of Main Outcomes

\begin{tabular}{lrr}
\hline & $\begin{array}{r}\text { Mean } \\
(1)\end{array}$ & $\begin{array}{r}\text { S.D. } \\
(2)\end{array}$ \\
\hline \multicolumn{1}{c}{ Panel a. The Adult Refugees } & & \\
& 8.60 & 12.41 \\
Earnings & 0.20 & 0.26 \\
Employment & -1.07 & 0.90 \\
Task Complexity & & \\
Top-Three Occupations: & 0.31 & 0.46 \\
$\quad$ Personal and Protective Services & 0.31 & 0.46 \\
$\quad$ Sales and Services & 0.21 & 0.40 \\
$\quad$ Machine Operating and Assembling & 0.13 & 0.33 \\
Obtained Education in Denmark, Year 18 & 0.57 & 0.49 \\
Left Initial Municipality, Year 18 & 0.03 & 0.07 \\
Criminal Convictions & 0.01 & 0.03 \\
Convictions for Shoplifting (Supermarket) & & \\
$\quad$ Panel b. The Children of the Refugees \\
Took Any Exam in Lower Secondary School & 0.78 & 0.42 \\
Graduated Lower Secondary School & 0.77 & 0.42 \\
Enrolled in Upper Secondary Education & 0.80 & 0.40 \\
Charged with a Crime & 0.33 & 0.47 \\
Convicted of a Crime & 0.29 & 0.45 \\
\hline
\end{tabular}

Notes: Earnings are expressed in thousands of US Dollars (at year 2000 prices). Employment is measured as a fraction of a full-time working year. The ratio of task intensities is calculated as $\log$ (communicative tasks)- $\log ($ manual tasks). The variables relative to "obtained education" and location of living are measured in year 2016, 18 years after the reform. The remaining variables are sample means for the 18 year period from January 1999 to December 2016. Our sample is constituted by 8,558 adult refugees. Task intensity and occupations are conditional on being employed with a valid ISCO code $(\mathrm{N}=5,195$ and $\mathrm{N}=5,122$ can be linked to task data). The sample of children of the refugees consists of 9,730 children. 
Table 2: Language Training and Employment Support the First Three Years After Arrival

\begin{tabular}{|c|c|c|c|c|c|}
\hline & $\begin{array}{c}1 \text { Year } \\
\text { (1) }\end{array}$ & $\begin{array}{l}1.5 \text { Years } \\
\text { (2) }\end{array}$ & $\begin{array}{l}2 \text { Years } \\
\text { (3) }\end{array}$ & $\begin{array}{l}2.5 \text { Years } \\
\text { (4) }\end{array}$ & $\begin{array}{l}3 \text { Years } \\
(5)\end{array}$ \\
\hline & \multicolumn{5}{|c|}{ Panel a. Share Ever Participating in Language Training } \\
\hline \multirow[t]{2}{*}{ RD Estimate } & 0.053 & 0.041 & -0.025 & 0.001 & 0.011 \\
\hline & $(0.064)$ & $(0.048)$ & $(0.037)$ & $(0.032)$ & $(0.030)$ \\
\hline \multirow[t]{2}{*}{ Mean of Untreated at Cutoff } & 0.806 & 0.854 & 0.915 & 0.906 & 0.919 \\
\hline & \multicolumn{5}{|c|}{ Panel b. Share Ever Participating in Employment Support } \\
\hline \multirow[t]{2}{*}{ RD Estimate } & $0.160^{*}$ & 0.030 & -0.038 & -0.066 & -0.081 \\
\hline & $(0.085)$ & $(0.069)$ & $(0.065)$ & $(0.063)$ & $(0.064)$ \\
\hline Mean of Untreated at Cutoff & 0.280 & 0.423 & 0.529 & 0.596 & 0.654 \\
\hline \multirow[t]{2}{*}{$\mathrm{N}$} & 6,868 & 7,631 & 8,558 & 8,558 & 8,558 \\
\hline & \multicolumn{5}{|c|}{ Panel c. Cumulative Hours of Language Training } \\
\hline \multirow[t]{2}{*}{ RD Estimate } & $104.987^{* *}$ & $147.946^{* *}$ & $228.432^{* * *}$ & $253.201^{* * *}$ & $186.853^{*}$ \\
\hline & $(50.846)$ & $(60.937)$ & $(75.357)$ & $(94.297)$ & $(97.930)$ \\
\hline \multirow[t]{2}{*}{ Mean of Untreated at Cutoff } & 355.575 & 517.920 & 662.987 & 789.475 & 981.739 \\
\hline & \multicolumn{5}{|c|}{ Panel d. Cumulative Hours of Employment Support } \\
\hline \multirow[t]{2}{*}{ RD Estimate } & 73.475 & -129.844 & -61.183 & -39.840 & -36.505 \\
\hline & $(159.041)$ & $(98.478)$ & $(101.132)$ & $(136.952)$ & $(148.881)$ \\
\hline Mean of Untreated at Cutoff & 512.459 & 811.708 & 948.167 & 1156.387 & 1347.726 \\
\hline $\mathrm{N}$ & 4,446 & 5,028 & 5,576 & 5,996 & 6,324 \\
\hline
\end{tabular}

Notes: $* \mathrm{p}<0.10, * * \mathrm{p}<0.05, * * * \mathrm{p}<0.01$. Robust standard errors in parenthesis. Each panel reports the RD estimate and the mean of the variable for the untreated group measured at the cutoff, corresponding to $\alpha$ from equation (1). Estimates are obtained from local linear regressions using the triangular kernel and the optimal bandwidth selector from Calonico et al. (2019). 
(a) Distribution of Admissions

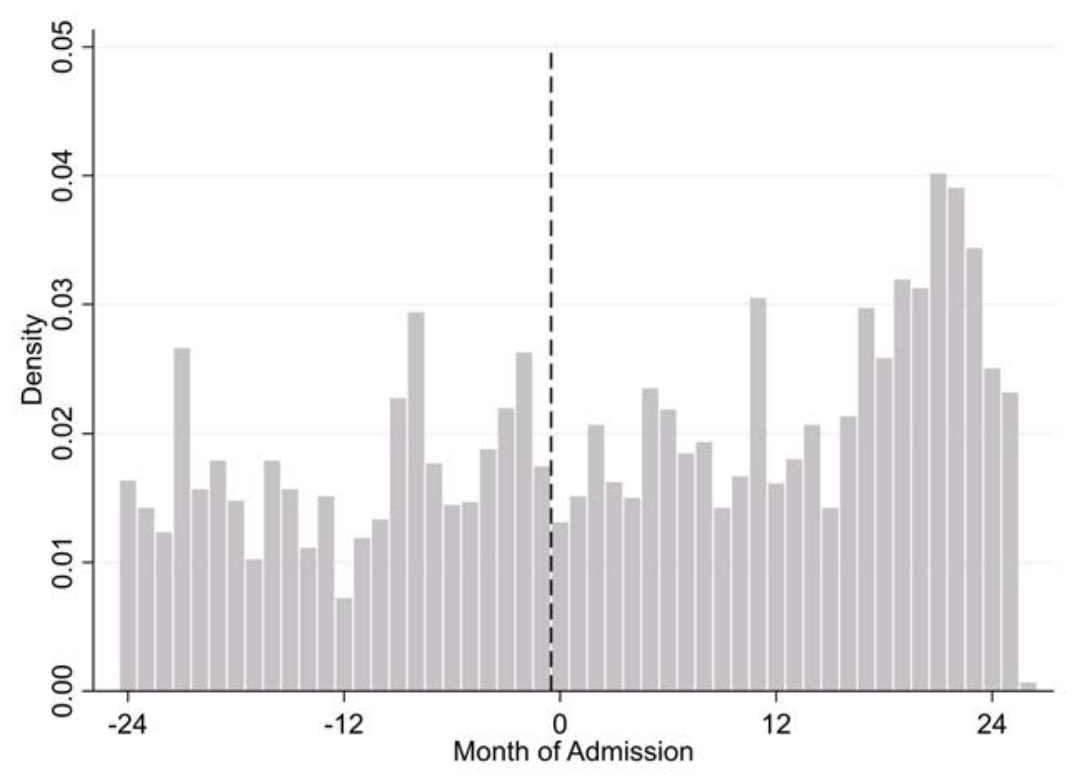

(b) Demeaned Monthly Share of Annual Admissions

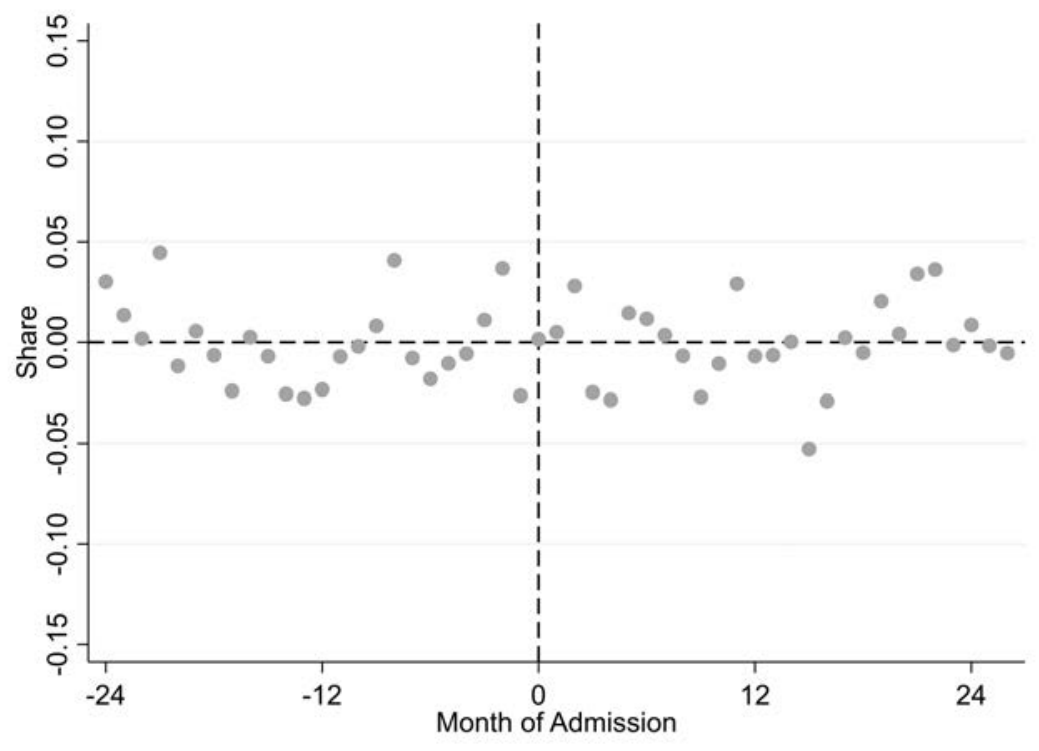

Figure 1: Refugees by Month of Admission

Notes: Admissions from January 1997 to February 2001. Panel a shows the density and Panel b shows the share of refugees in each month demeaned by the average monthly share of annual admissions, excluding from the mean the 6 months before and after the reform. 
Table 3: Summary Statistics and Balancing Tests

\begin{tabular}{lrrrr}
\hline & Mean & S.D. & RD Estimate & Confidence Interval \\
& $(1)$ & $(2)$ & $(3)$ & $(4)$ \\
\hline \multicolumn{4}{c}{ Panel a. The Adult Refugees } \\
Age & 31.50 & 7.68 & -0.39 & {$[-1.71 ; 0.92]$} \\
Married & 0.67 & 0.47 & 0.05 & {$[-0.04 ; 0.13]$} \\
Female & 0.42 & 0.49 & 0.04 & {$[-0.04 ; 0.13]$} \\
No. Children $<3 y$ & 0.19 & 0.43 & 0.03 & {$[-0.05 ; 0.10]$} \\
No. Children 3-17y & 1.00 & 1.51 & -0.04 & {$[-0.42 ; 0.34]$} \\
Iraq & 0.44 & 0.50 & -0.03 & {$[-0.14 ; 0.08]$} \\
Afghanistan & 0.16 & 0.36 & -0.02 & {$[-0.11 ; 0.07]$} \\
Other Country & 0.40 & 0.49 & 0.03 & {$[-0.10 ; 0.15]$} \\
Speaks Arabic & 0.35 & 0.48 & -0.04 & {$[-0.13 ; 0.05]$} \\
Speaks Dari & 0.09 & 0.29 & -0.01 & {$[-0.05 ; 0.03]$} \\
Danish 1 & 0.22 & 0.42 & -0.07 & {$[-0.19 ; 0.05]$} \\
Danish 2 & 0.35 & 0.48 & -0.00 & {$[-0.09 ; 0.08]$} \\
Danish 3 & 0.32 & 0.46 & 0.05 & {$[-0.04 ; 0.15]$} \\
Quota Refugee & 0.10 & 0.30 & -0.03 & {$[-0.08 ; 0.02]$} \\
Convention Refugee & 0.18 & 0.38 & -0.08 & {$[-0.19 ; 0.02]$} \\
Family-Reunified & 0.19 & 0.40 & 0.03 & {$[-0.07 ; 0.13]$} \\
Other Refugee & 0.53 & 0.50 & 0.01 & {$[-0.13 ; 0.14]$} \\
Wait Time Asylum (Days) & 404.33 & 348.11 & 16.58 & {$[-72.41 ; 105.56]$}
\end{tabular}

Panel $b$. The Children of the Refugees

\begin{tabular}{lrrrr} 
Girl & 0.43 & 0.50 & -0.02 & {$[-0.12 ; 0.07]$} \\
Age & 4.37 & 4.87 & 0.97 & {$[0.09 ; 1.85]$} \\
Iraq & 0.44 & 0.50 & 0.04 & {$[-0.07 ; 0.15]$} \\
Afghanistan & 0.23 & 0.42 & -0.04 & {$[-0.10 ; 0.03]$} \\
Other Country & 0.33 & 0.47 & -0.06 & {$[-0.17 ; 0.05]$} \\
\hline
\end{tabular}

Notes: Summary statistics (columns 1-2) and balancing tests (columns 3-4) of the impact of the reform on predetermined variables for refugees obtaining refugee status in Denmark between January 1997 and December 2000. The RD estimates are from local linear regressions using the triangular kernel and the optimal bandwidth selector from Calonico et al. (2019). The 95-pct. confidence intervals are constructed based on robust standard errors. Age, marital status and the number of children are measured at date of immigration. Danish 1 to 3 refer to the language track the individual was initially placed in. Wait time for asylum is the number of days between application and admission, and it is calculated for refugees (excluding quota refugees). The RD estimate in Panel $b$ is based on admission of the first parent, our main specification in Section V.B. Age of the child is measured on January 1, 1999. Quota refugee refers to those granted refugee status under the UNCHR quota, and Convention refugee refers to the Geneva Convention. 
(a) Earnings

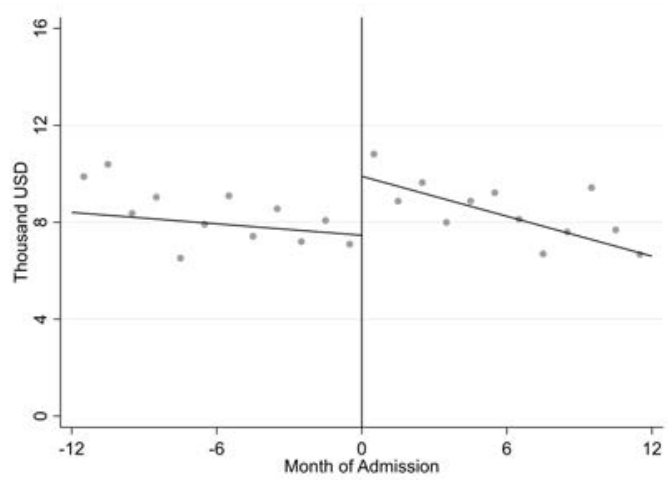

(c) Task Complexity

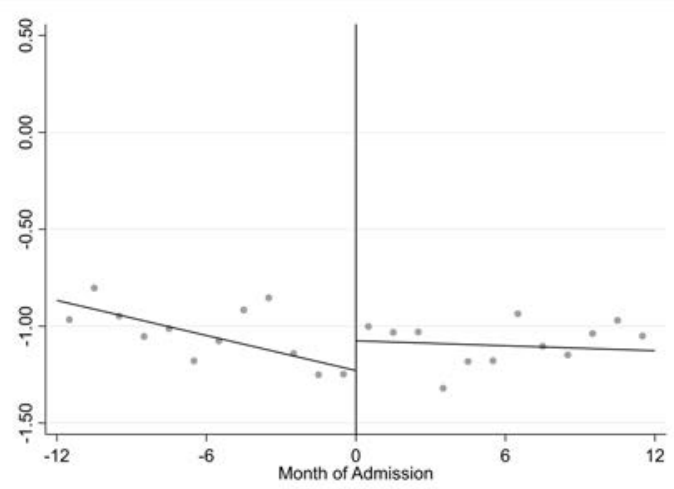

(b) Employment

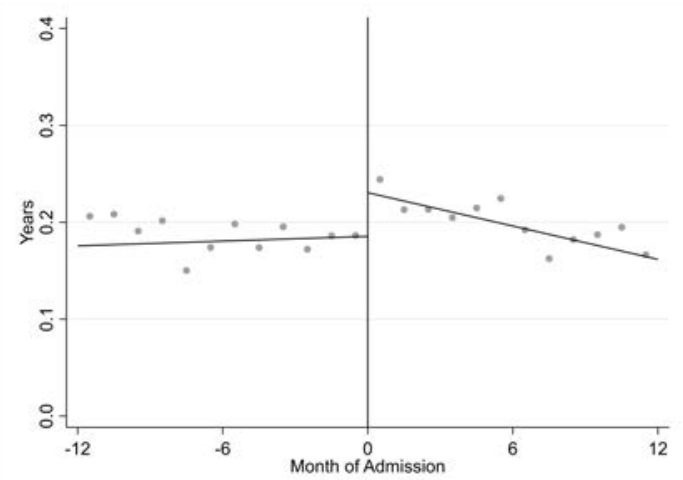

(d) Criminal Convictions

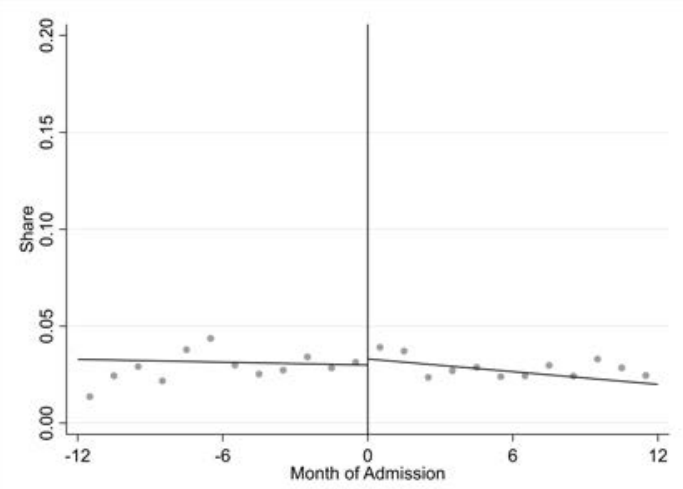

Figure 2: Long-Run Integration by Month of Admission

Notes: The graphs show sample means of average cumulative earnings, employment, task complexity conditional on employment, and criminal charges in year 18 after the reform by one-month bins of admission dates. 
Table 4: The Impact of the Reform on Long-Run Integration

\begin{tabular}{|c|c|c|c|c|}
\hline & $\begin{array}{l}\text { Earnings } \\
\text { (1) }\end{array}$ & $\begin{array}{l}\text { Employment } \\
\text { (2) }\end{array}$ & $\begin{array}{l}\text { Task Complexity } \\
\text { (3) }\end{array}$ & $\begin{array}{c}\text { Criminal Convictions } \\
\text { (4) }\end{array}$ \\
\hline & & & Panel a. Main & \\
\hline \multirow[t]{2}{*}{ RD Estimate } & $2.504^{* *}$ & $0.042^{*}$ & $0.386^{* * *}$ & 0.012 \\
\hline & $(1.087)$ & $(0.025)$ & $(0.128)$ & $(0.010)$ \\
\hline \multirow[t]{2}{*}{ Mean of Untreated at Cutoff } & 7.457 & 0.183 & -1.351 & 0.030 \\
\hline & & & Panel b. Controls & \\
\hline \multirow{2}{*}{ RD Estimate } & $2.216^{* *}$ & 0.032 & $0.269^{* *}$ & 0.015 \\
\hline & (1.039) & $(0.022)$ & $(0.124)$ & $(0.010)$ \\
\hline \multirow[t]{2}{*}{ Mean of Untreated at Cutoff } & 7.449 & 0.186 & -1.367 & 0.030 \\
\hline & & & anel c. 2nd Order & \\
\hline \multirow[t]{2}{*}{ RD Estimate } & $3.220^{*}$ & 0.050 & $0.519^{* * *}$ & 0.018 \\
\hline & $(1.883)$ & $(0.039)$ & $(0.184)$ & $(0.013)$ \\
\hline \multirow[t]{2}{*}{ Mean of Untreated at Cutoff } & 7.185 & 0.187 & -1.436 & 0.030 \\
\hline & & & anel d. 3rd Order & \\
\hline \multirow[t]{2}{*}{ RD Estimate } & 3.195 & 0.052 & $0.543^{* *}$ & 0.020 \\
\hline & $(2.235)$ & $(0.051)$ & $(0.226)$ & $(0.014)$ \\
\hline \multirow[t]{2}{*}{ Mean of Untreated at Cutoff } & 7.251 & 0.198 & -1.470 & 0.030 \\
\hline & & & Panel e. Donut & \\
\hline \multirow[t]{2}{*}{ RD Estimate } & $2.688^{*}$ & 0.041 & $0.486^{* * *}$ & 0.004 \\
\hline & $(1.381)$ & $(0.027)$ & $(0.148)$ & $(0.007)$ \\
\hline \multirow[t]{2}{*}{ Mean of Untreated at Cutoff } & 7.664 & 0.191 & -1.413 & 0.028 \\
\hline & & & Panelf. OLS & \\
\hline \multirow[t]{2}{*}{ RD Estimate } & $3.525^{* *}$ & $0.056^{*}$ & $0.353^{* * *}$ & 0.005 \\
\hline & (1.476) & $(0.030)$ & $(0.122)$ & $(0.010)$ \\
\hline \multirow{2}{*}{$\begin{array}{l}\text { Mean of Untreated at Cutoff } \\
\mathrm{N}\end{array}$} & 7.217 & 0.183 & -1.329 & 0.033 \\
\hline & 8,558 & 8,558 & 5,122 & 8,558 \\
\hline
\end{tabular}

Notes: $* p=0.10, * * p=0.05, * * * p=0.01$. Table entries are the RD estimates $(\widehat{\tau})$, robust standard errors in parentheses, and the mean of the outcome for the untreated group measured at the cutoff ( $\widehat{\alpha})$ from a local linear estimation of model (1) using the triangular kernel and the optimal bandwidth selector from Calonico et al. (2019). Panel a shows the estimates from the main specification. Panel $b$ includes control variables. Control variables are age, age squared, unmarried, female, number of children between 0-2 years old and 3-17 years old, Iraq, Afghanistan, speaks Arabic, speaks Dari, Danish 1,2 or 3 (unknown level is the reference), quota refugee, family-reunified or other refugee (convention refugee is the reference). Panels $\mathrm{c}$ and d compare the main specification to estimates using 2 nd or $3 \mathrm{rd}$ order polynomials. In Panel e refugees admitted in the four weeks immediately around the cutoff are admitted ("donut"). In Panel f OLS estimates are presented. 
(a) Earnings

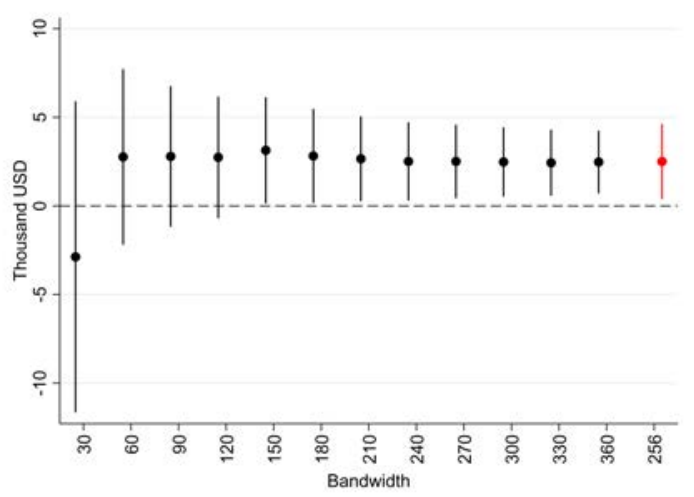

(c) Task Complexity

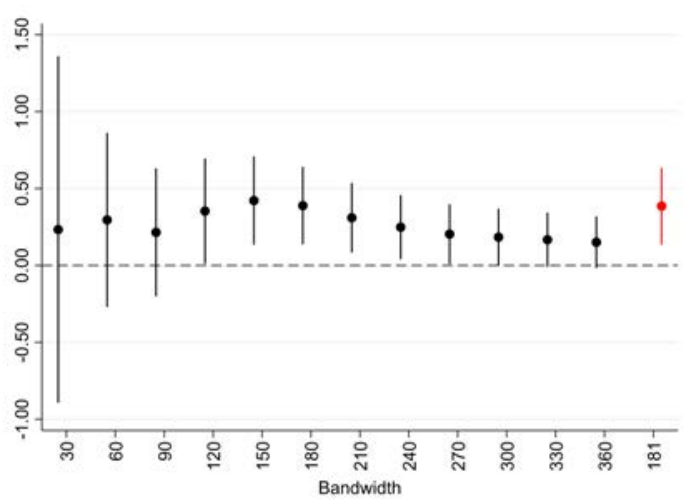

(b) Employment

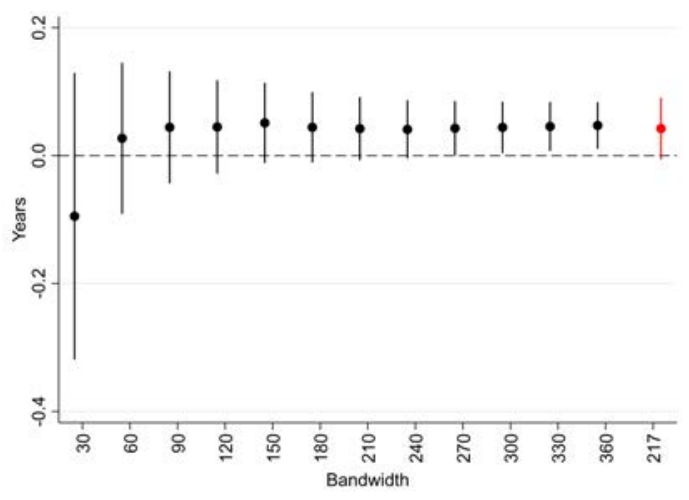

(d) Criminal Convictions

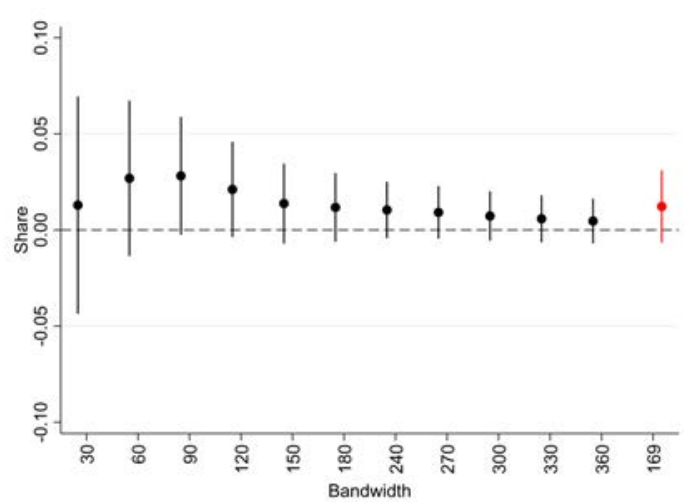

Figure 3: Sensitivity to Choice of Bandwidth

Notes: The red dots and bars are the RD estimates and 95-percent confidence interval of the RD estimates reported in Table 4 
(a) Earnings

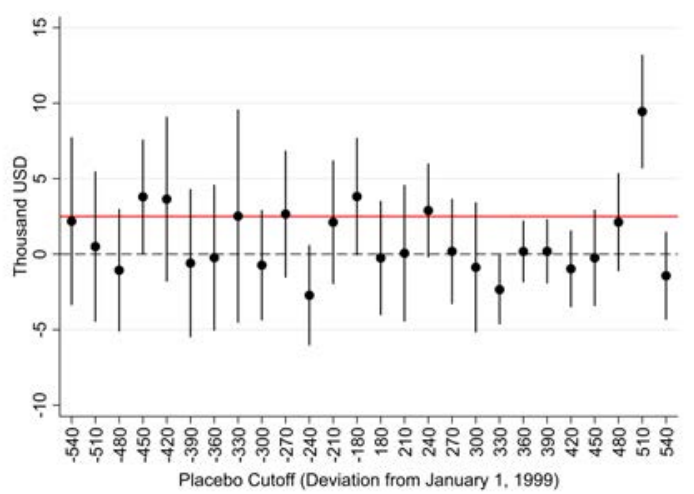

(c) Task Complexity

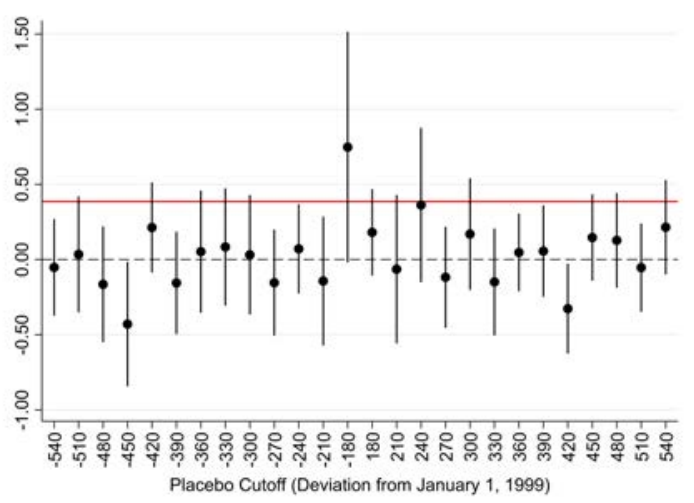

(b) Employment

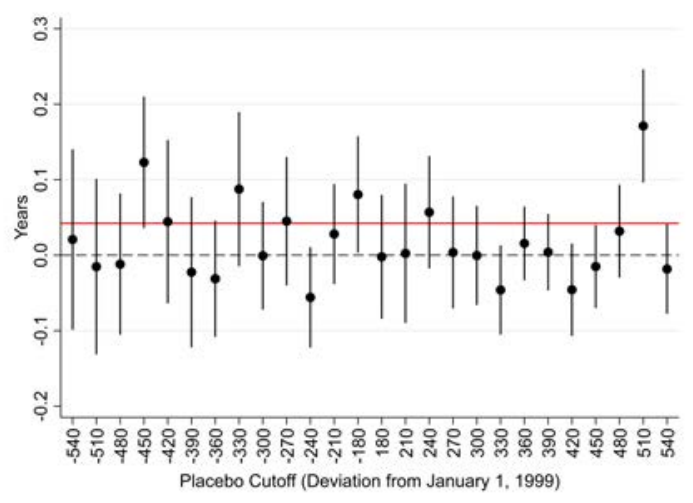

(d) Criminal Convictions

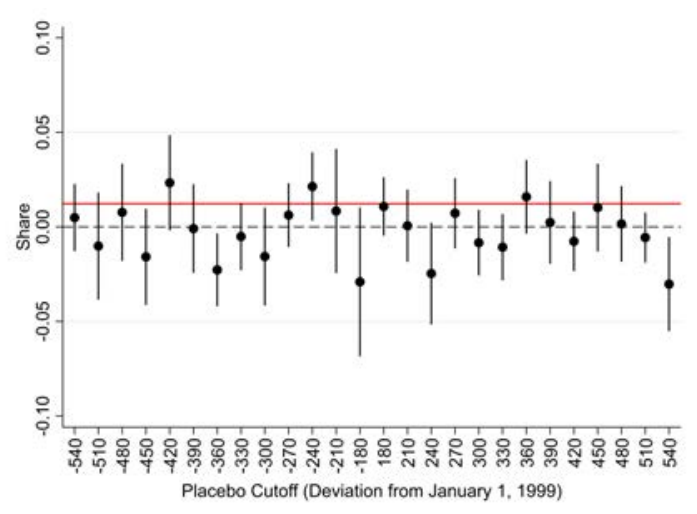

Figure 4: RD Estimates at Placebo Cutoffs

Notes: The red horizontal lines are the RD estimates reported in Table 4 
Table 5: Impact of the Reform on the Children

\begin{tabular}{|c|c|c|c|c|c|c|c|c|}
\hline & \multicolumn{4}{|c|}{ Boys } & \multicolumn{4}{|c|}{ Girls } \\
\hline & $(1)$ & $(2)$ & (3) & (4) & $(5)$ & (6) & (7) & (8) \\
\hline Took Any Exam in Lower Secondary School & $\begin{array}{l}0.169^{* *} \\
(0.069)\end{array}$ & $\begin{array}{l}0.146^{*} \\
(0.080)\end{array}$ & $\begin{array}{c}0.229^{* * *} \\
(0.056)\end{array}$ & $\begin{array}{c}0.152^{* * *} \\
(0.054)\end{array}$ & $\begin{array}{c}0.074 \\
(0.046)\end{array}$ & $\begin{array}{c}0.029 \\
(0.048)\end{array}$ & $\begin{array}{l}-0.022 \\
(0.054)\end{array}$ & $\begin{array}{l}-0.003 \\
(0.048)\end{array}$ \\
\hline Mean of Untreated at Cutoff & 0.64 & 0.67 & 0.63 & 0.68 & 0.81 & 0.86 & 0.84 & 0.81 \\
\hline Graduated Lower Secondary School & $\begin{array}{l}0.115^{* *} \\
(0.054)\end{array}$ & $\begin{array}{l}0.093^{* *} \\
(0.047)\end{array}$ & $\begin{array}{l}0.095^{*} \\
(0.056)\end{array}$ & $\begin{array}{c}0.163^{* * *} \\
(0.063)\end{array}$ & $\begin{array}{c}0.007 \\
(0.074)\end{array}$ & $\begin{array}{l}-0.036 \\
(0.071)\end{array}$ & $\begin{array}{c}0.004 \\
(0.059)\end{array}$ & $\begin{array}{l}-0.017 \\
(0.061)\end{array}$ \\
\hline Mean of Untreated at Cutoff & 0.69 & 0.73 & 0.71 & 0.67 & 0.75 & 0.80 & 0.80 & 0.83 \\
\hline Enrolled in Upper Secondary Education & $\begin{array}{c}0.066 \\
(0.052)\end{array}$ & $\begin{array}{c}0.014 \\
(0.054)\end{array}$ & $\begin{array}{c}0.062 \\
(0.049)\end{array}$ & $\begin{array}{l}0.084^{*} \\
(0.051)\end{array}$ & $\begin{array}{l}-0.029 \\
(0.071)\end{array}$ & $\begin{array}{l}-0.016 \\
(0.070)\end{array}$ & $\begin{array}{l}-0.064 \\
(0.058)\end{array}$ & $\begin{array}{l}-0.084 \\
(0.062)\end{array}$ \\
\hline Mean of Untreated at Cutoff & 0.78 & 0.81 & 0.78 & 0.75 & 0.77 & 0.79 & 0.83 & 0.85 \\
\hline Charged with a Crime & $\begin{array}{l}-0.154 \\
(0.094)\end{array}$ & $\begin{array}{c}-0.218^{* *} \\
(0.099)\end{array}$ & $\begin{array}{l}-0.057 \\
(0.076)\end{array}$ & $\begin{array}{l}-0.021 \\
(0.071)\end{array}$ & $\begin{array}{c}0.003 \\
(0.051)\end{array}$ & $\begin{array}{l}-0.045 \\
(0.039)\end{array}$ & $\begin{array}{l}-0.013 \\
(0.038)\end{array}$ & $\begin{array}{c}0.014 \\
(0.042)\end{array}$ \\
\hline Mean of Untreated at Cutoff & 0.63 & 0.62 & 0.55 & 0.54 & 0.11 & 0.12 & 0.13 & 0.12 \\
\hline Convicted of a Crime & $\begin{array}{l}-0.109 \\
(0.090)\end{array}$ & $\begin{array}{l}-0.165^{*} \\
(0.099)\end{array}$ & $\begin{array}{l}-0.047 \\
(0.069)\end{array}$ & $\begin{array}{l}-0.003 \\
(0.064)\end{array}$ & $\begin{array}{l}-0.026 \\
(0.043)\end{array}$ & $\begin{array}{l}-0.054 \\
(0.037)\end{array}$ & $\begin{array}{l}-0.027 \\
(0.034)\end{array}$ & $\begin{array}{l}-0.017 \\
(0.035)\end{array}$ \\
\hline Mean of Untreated at Cutoff & 0.47 & 0.45 & 0.42 & 0.42 & 0.12 & 0.11 & 0.11 & 0.11 \\
\hline $\mathrm{N}$ & 5,542 & 4,834 & 5,542 & 5,140 & 4,188 & 3,698 & 4,188 & 3,865 \\
\hline
\end{tabular}

Notes: $* \mathrm{p}<0.10, * * \mathrm{p}<0.05, * * * \mathrm{p}<0.01$. Table entries are the RD estimates $(\widehat{\tau})$, robust standard errors in parentheses, and the mean of the outcome for the untreated group measured at the cutoff $(\widehat{\alpha})$ from local linear estimation of model (1) using the triangular kernel and the optimal bandwidth selector from Calonico et al. (2019). Children of refugees born before 2003. Columns 1 and 5 use the admission date of the first parent. Columns 2 and 6 use the admission date of the father. Columns 3 and 7 use the admission date of the last parent. Columns 4 and 8 use the admission date of the mother. The outcomes measuring taking any exam in lower secondary school or graduating are dummies for taking the exam or graduating before age 17. Enrollment in upper secondary school is an indicator for enrolling prior to 2018. The crime outcomes are dummies for ever being charged with or convicted of a crime before 2018. 
Table 6: Municipality Characteristics

\begin{tabular}{lrrrr}
\hline & Mean & S.D. & RD Estimate & Confidence Interval \\
& $(1)$ & $(2)$ & $(3)$ & $(4)$ \\
\hline Urban Municipality & 0.33 & 0.47 & 0.11 & {$[-0.01 ; 0.24]$} \\
Five Largest Cities & 0.17 & 0.37 & 0.01 & {$[-0.08 ; 0.10]$} \\
Employment Rate 1996 & 0.74 & 0.04 & -0.00 & {$[-0.01 ; 0.01]$} \\
Unemployment Rate 1996 & 0.09 & 0.02 & 0.00 & {$[-0.00 ; 0.01]$} \\
Earnings 1996 & 28.52 & 3.69 & 0.43 & {$[-0.37 ; 1.23]$} \\
Number of Co-Nationals & 222.09 & 679.63 & -23.55 & {$[-180.01 ; 132.91]$} \\
Share of Co-Nationals & 0.00 & 0.00 & 0.00 & {$[-0.00 ; 0.00]$} \\
\hline
\end{tabular}

Notes: Mean (column 1), standard deviation (column 2), the RD estimate of the reform (column 3) and its 95-pct. confidence interval based on robust standard errors (column 4) for refugees granted refugee status in Denmark between January 1997 and December 2000. The RD estimates are from local linear estimation of model (1) using the triangular kernel and the optimal bandwidth selector from Calonico et al. (2019). Municipality characteristics refer to the municipality the refugee is placed in after admission. Urban municipalities are municipalities in the capital area or municipalities with a town of more than 45,000 inhabitants. The five largest cities are Copenhagen (including Frederiksberg Municipality), Aarhus, Odense, Aalborg and Esbjerg. Average income in the municipality is measured in 1,000 USD (2000 level). The number of observations is 8,558 . 
(a) Left Initial Municipality

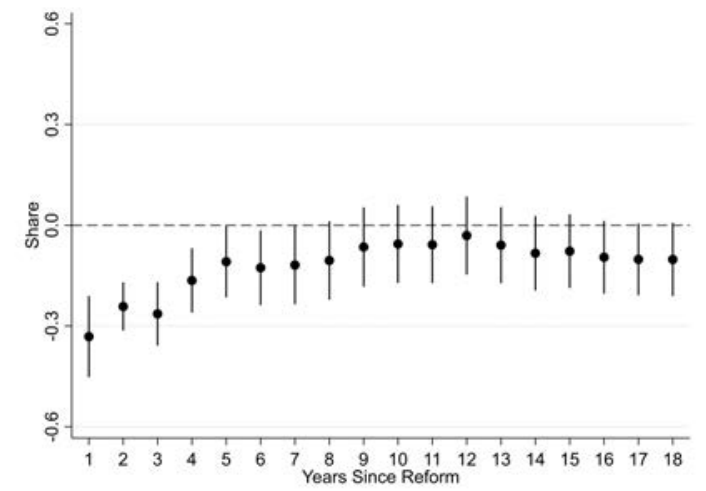

(b) Left Initial Municipality by Initial Placement

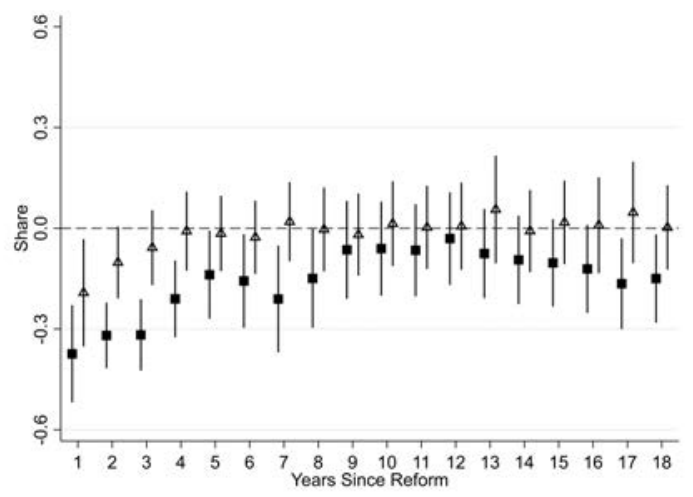

- all, $\boldsymbol{\square}$ initially placed in rural municipalities, and $\triangle$ initially placed in urban municipalities.

Figure 5: Mobility from Initial Municipality

Notes: RD estimates and 95-percent confidence intervals based on robust standard errors from local linear regressions using the triangular kernel and the optimal bandwidth selector from Calonico et al. (2019). 
(a) All

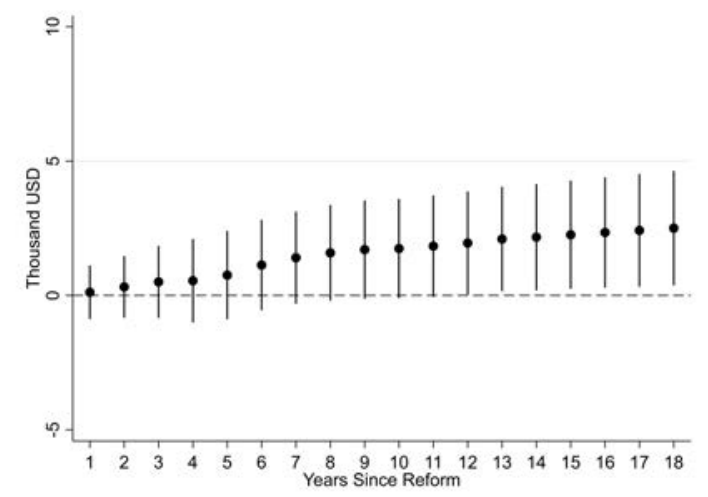

(b) By Exposure to Welfare Cut

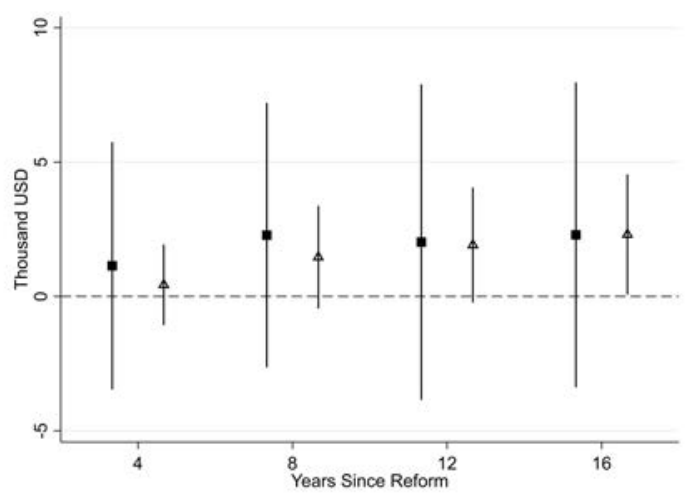

- all, $\square$ aged 18 to 24 with no children, and $\triangle$ everyone else.

Figure 6: Annual Earnings Effects

Notes: RD estimates and 95-percent confidence intervals based on robust standard errors from local linear regressions using the triangular kernel and the optimal bandwidth selector from Calonico et al. (2019). The outcome variable is the average cumulative earnings. Panel b splits refugees into those aged 18 to 24 with no children whose welfare benefits were unaffected, and everyone else.

(a) All

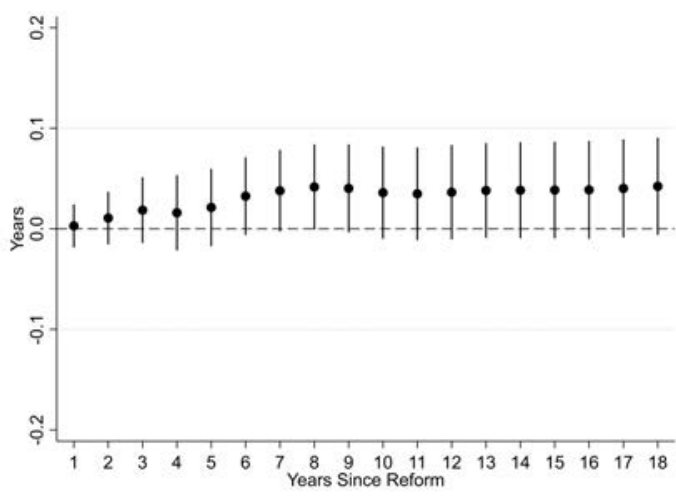

(b) By Exposure to Welfare Cut

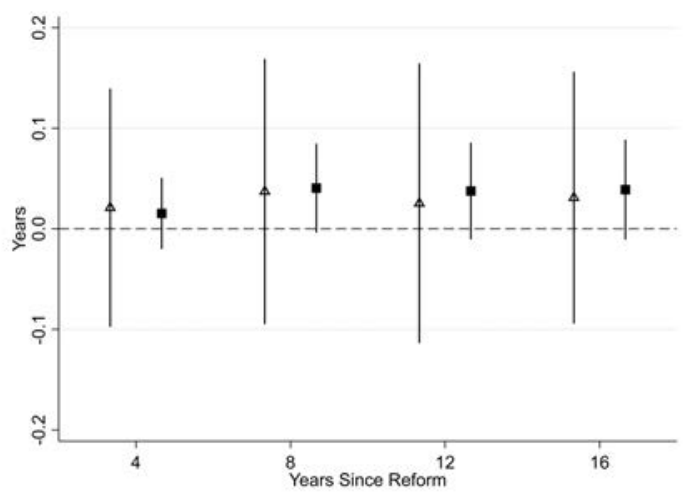

- all, $\square$ aged 18 to 24 with no children, and $\triangle$ everyone else.

Figure 7: Annual Employment Effects

Notes: RD estimates and 95-percent confidence intervals based on robust standard errors from local linear regressions using the triangular kernel and the optimal bandwidth selector from Calonico et al. (2019). The outcome variable is the average cumulative employment. Panel b splits refugees into those aged 18 to 24 who have no children whose welfare benefits were unaffected, and everyone else. 
Table 7: The Impact of the Reform on Disposable Income and Crime

\begin{tabular}{|c|c|c|c|c|c|}
\hline & \multirow[b]{2}{*}{$\begin{array}{c}\text { Disposable Income } \\
\text { (1) }\end{array}$} & \multicolumn{2}{|c|}{ All Crime } & \multicolumn{2}{|c|}{ Shoplifting Crime } \\
\hline & & $\begin{array}{c}\text { Charges } \\
\text { (2) }\end{array}$ & $\begin{array}{c}\text { Convictions } \\
\text { (3) }\end{array}$ & $\begin{array}{c}\text { Charges } \\
\text { (4) }\end{array}$ & $\begin{array}{c}\text { Convictions } \\
\text { (5) }\end{array}$ \\
\hline & \multicolumn{5}{|c|}{ Panel a. All } \\
\hline Year 1 & $\begin{array}{c}-2.698^{* * *} \\
(0.501)\end{array}$ & $\begin{array}{l}0.086^{* *} \\
(0.040)\end{array}$ & $\begin{array}{c}0.109^{* * *} \\
(0.042)\end{array}$ & $\begin{array}{l}0.076^{* *} \\
(0.032)\end{array}$ & $\begin{array}{l}0.070^{* *} \\
(0.027)\end{array}$ \\
\hline Year 2 & $\begin{array}{l}-0.146 \\
(0.525)\end{array}$ & $\begin{array}{l}0.015 \\
(0.024)\end{array}$ & $\begin{array}{c}0.030 \\
(0.026)\end{array}$ & $\begin{array}{c}0.005 \\
(0.016)\end{array}$ & $\begin{array}{l}0.008 \\
(0.014)\end{array}$ \\
\hline & \multicolumn{5}{|c|}{ Panel b. Age $<25$ and No Dependents } \\
\hline Year 1 & $\begin{array}{l}-1.739 \\
(1.237)\end{array}$ & $\begin{array}{l}-0.197 \\
(0.175)\end{array}$ & $\begin{array}{l}-0.025 \\
(0.119)\end{array}$ & $\begin{array}{l}-0.053 \\
(0.059)\end{array}$ & $\begin{array}{l}-0.042 \\
(0.043)\end{array}$ \\
\hline Year 2 & $\begin{array}{l}-0.952 \\
(1.212)\end{array}$ & $\begin{array}{l}-0.133 \\
(0.122)\end{array}$ & $\begin{array}{l}-0.162 \\
(0.105)\end{array}$ & $\begin{array}{l}-0.045 \\
(0.051)\end{array}$ & $\begin{array}{l}-0.052 \\
(0.051)\end{array}$ \\
\hline & \multicolumn{5}{|c|}{ Panel c. Others } \\
\hline Year 1 & $\begin{array}{c}-2.723^{* * *} \\
(0.513)\end{array}$ & $\begin{array}{c}0.135^{* * *} \\
(0.051)\end{array}$ & $\begin{array}{c}0.123^{* * *} \\
(0.044)\end{array}$ & $\begin{array}{l}0.091^{* *} \\
(0.036)\end{array}$ & $\begin{array}{l}0.076^{* *} \\
(0.030)\end{array}$ \\
\hline Year 2 & $\begin{array}{c}0.029 \\
(0.511)\end{array}$ & $\begin{array}{c}0.028 \\
(0.023)\end{array}$ & $\begin{array}{l}0.065^{* *} \\
(0.030)\end{array}$ & $\begin{array}{c}0.008 \\
(0.016)\end{array}$ & $\begin{array}{c}0.014 \\
(0.013)\end{array}$ \\
\hline
\end{tabular}

Notes: $* p=0.10, * * p=0.05, * * * p=0.01$. Table entries are the RD estimates and the robust standard errors in parentheses from a local linear estimation of model 11 using the triangular kernel and the optimal bandwidth selector from Calonico et al. (2019). 
(a) Communicative Tasks

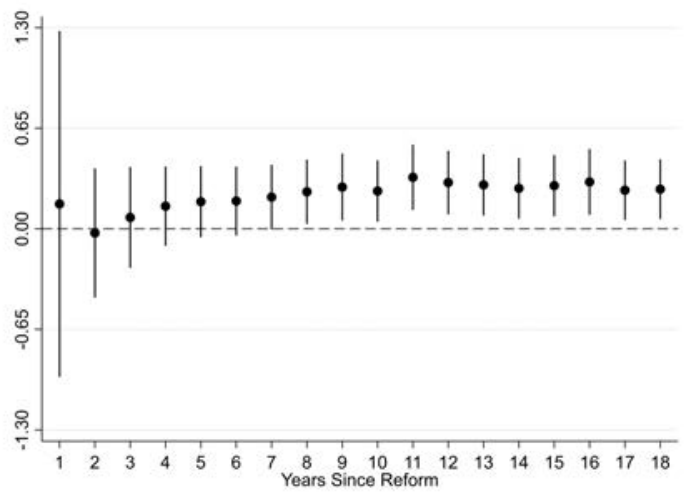

(c) Task Complexity

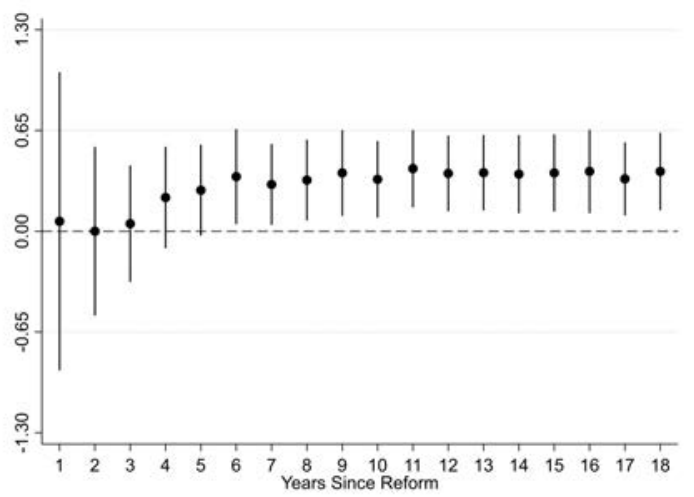

(b) Manual Tasks

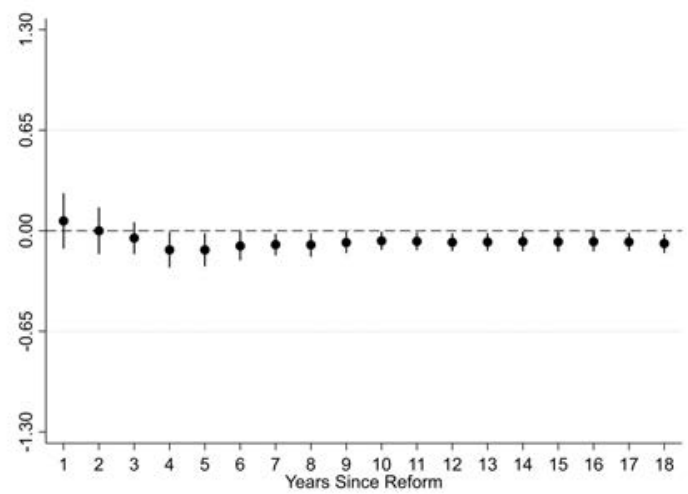

(d) Personal and Protective Services

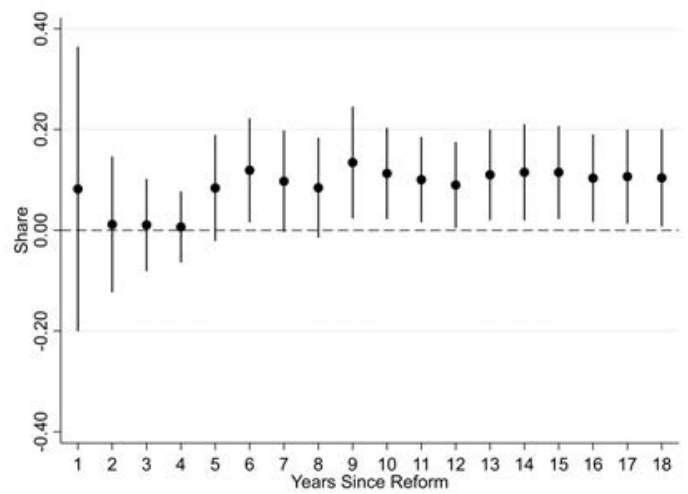

Figure 8: Specialization in the Labor Market

Notes: RD estimates and 95-percent confidence intervals based on robust standard errors from local linear regressions using the triangular kernel and the MSE-optimal bandwidth selector from Calonico et al. (2019). The outcome variables are the average cumulative task intensities and occupations conditional on employment. Panels a and b show the impact on $\log$ (communicative tasks) and $\log$ (manual tasks), respectively. Panels c and d show, respectively, the impact on the $\log (\operatorname{communicative}$ tasks)$\log ($ manual tasks) and working in personal and protective services. 
(a) Enrolled in Education in Denmark

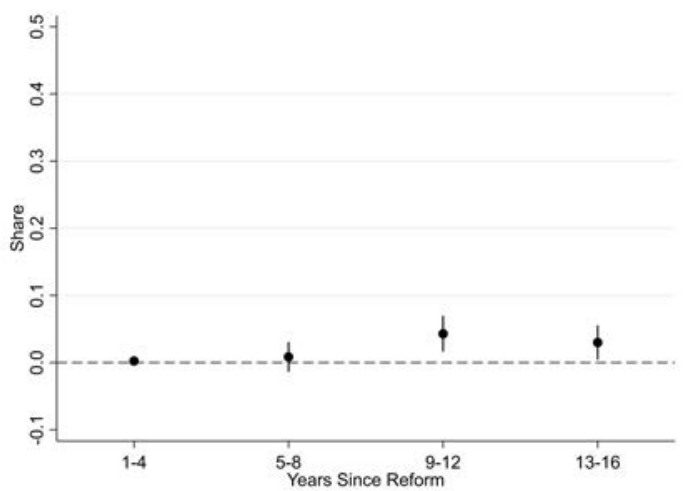

(c) Enrolled in Education in Denmark by Age

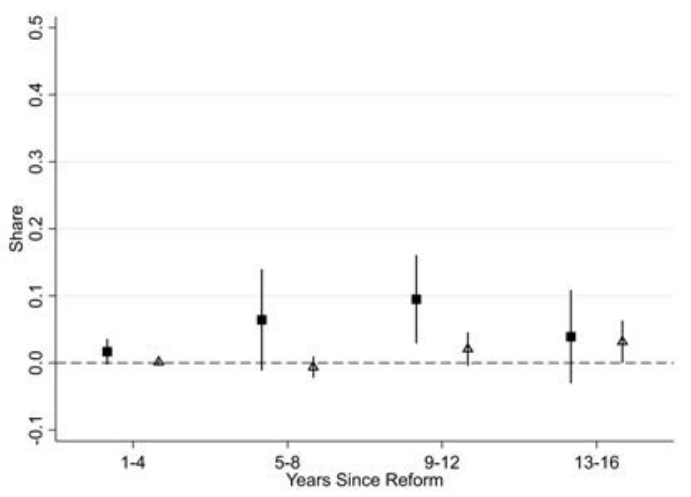

(b) Obtained Education in Denmark

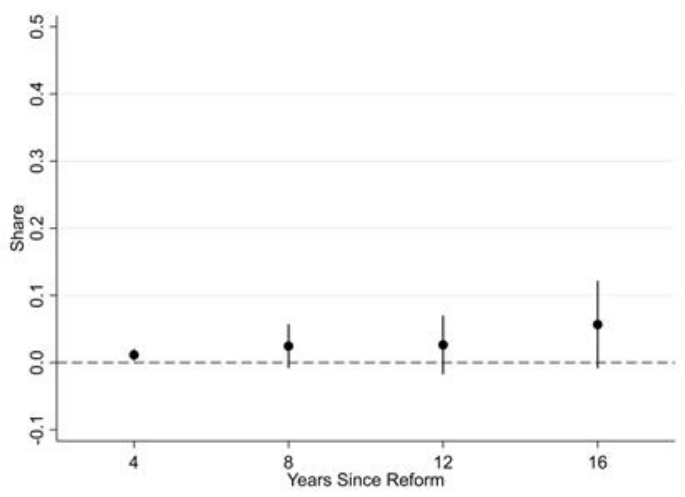

(d) Obtained Education in Denmark by Age

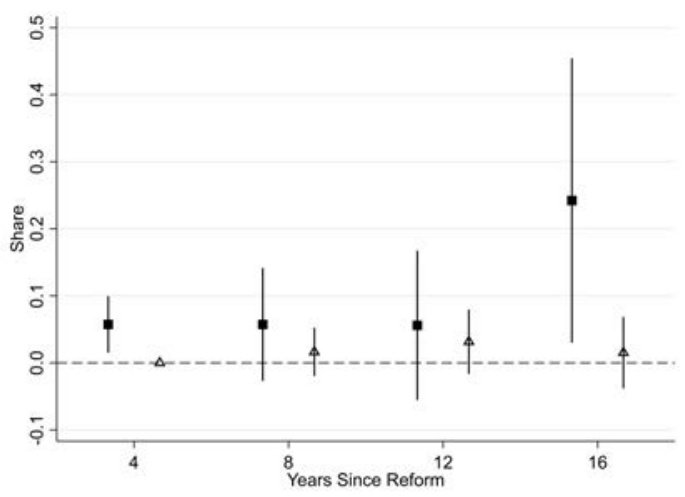

- all, $\square$ age 18 to 24 , and $\triangle$ everyone else.

Figure 9: Educational Attainment in Denmark

Notes: RD estimates and 95-percent confidence intervals based on robust standard errors from local linear regressions using the triangular kernel and the MSE-optimal bandwidth selector from Calonico et al. (2019). Panels a and b show, respectively, the impact on enrollment in and obtaining education in Denmark. Enrollment is calculated as 4-year averages, and obtaining education is an indicator for ever obtaining education in Denmark. Panels c and d split refugees into those aged 18 to 24 and everyone else. 
Table 8: Heterogeneous Effects, Sub-Sample Analysis

\begin{tabular}{|c|c|c|c|}
\hline & $\begin{array}{l}\text { Earnings } \\
\text { (1) }\end{array}$ & $\begin{array}{c}\text { Employment } \\
\text { (2) }\end{array}$ & $\begin{array}{c}\text { Task Complexity } \\
\text { (3) }\end{array}$ \\
\hline & \multicolumn{3}{|c|}{ Panel a. Alphabet of Mother Tongue } \\
\hline Latin Alphabet & $\begin{array}{c}-0.542 \\
(1.574)\end{array}$ & $\begin{array}{c}-0.012 \\
(0.042)\end{array}$ & $\begin{array}{c}0.433^{* *} \\
(0.179)\end{array}$ \\
\hline $\begin{array}{l}\text { Other Alphabet } \\
\text { Than Latin }\end{array}$ & $\begin{array}{c}4.112^{* * *} \\
(1.500)\end{array}$ & $\begin{array}{l}0.074^{* *} \\
(0.031)\end{array}$ & $\begin{array}{l}0.356^{*} \\
(0.187)\end{array}$ \\
\hline Urban Area & $\begin{array}{c}{ }^{I} \\
4.758^{* * *} \\
(1.656)\end{array}$ & $\begin{array}{c}\text { anel } b \text {. Initial } 1 \\
0.112^{* * *} \\
(0.040)\end{array}$ & $\begin{array}{l}\text { lacement } \\
0.452^{* *} \\
(0.204)\end{array}$ \\
\hline Rural Area & $\begin{array}{l}1.205 \\
(1.431)\end{array}$ & $\begin{array}{c}0.005 \\
(0.031)\end{array}$ & $\begin{array}{l}0.288^{*} \\
(0.157)\end{array}$ \\
\hline
\end{tabular}

Notes: $* p=0.10, * * p=0.05, * * * p=0.01$. Robust standard errors in parenthesis. Each column refers to a different outcome variable. All outcomes are measured in year 18 and show the average cumulative effects. Each row shows RD estimates from a regression on a sub-sample using the optimal bandwidth from the full sample. 
Table 9: Societal Cost-Benefit Analysis

\begin{tabular}{lrrrrrr}
\hline & & & & & & Years Before \\
& $(1)$ & $(2)$ & $(3)$ & $(4)$ & $(B+D W L) / C$ & $N P V>0$ \\
& 35.2 & -2.8 & 7.7 & 40.1 & 15.4 & 5 \\
\hline Base Scenario & 35.2 & -3.9 & 7.2 & 38.4 & 10.8 & 6 \\
Alternative Price & 23.0 & -2.8 & 5.0 & 25.3 & 10.1 & 5 \\
Discount Rate 7\% & 35.2 & -2.8 & 0.0 & 32.4 & 12.6 & 5 \\
Tax Distortion Rate & 35.2 & -16.0 & 3.1 & 22.3 & 2.4 & 6 \\
With Cost of Education & & & (5) & (6) \\
\hline
\end{tabular}

Notes: Columns 1 to 5 are measured in 1,000 USD and column 6 is denoted in years. $B$ is benefits, $C$ is costs, $D W L$ if the deadweight loss (or gain in our setting) from (lower) taxation, and $N P V$ is the net present value of the investment over 18 years. 
A Appendix: Additional Tables and Figures 
(a) Age

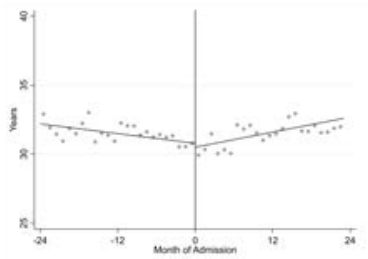

(e) Children 3-17y

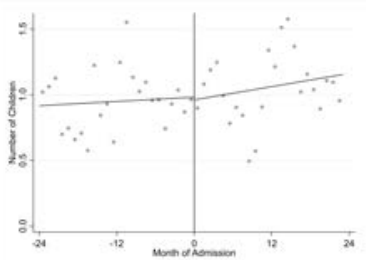

(i) Speaks Arabic

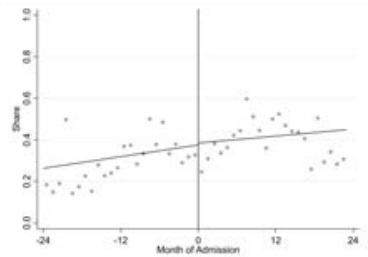

(m) Danish 3

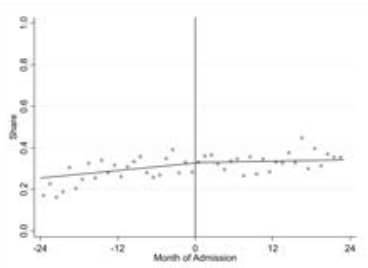

(q) Other Refugees

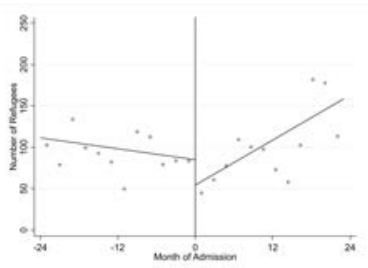

(u) Employment Rate

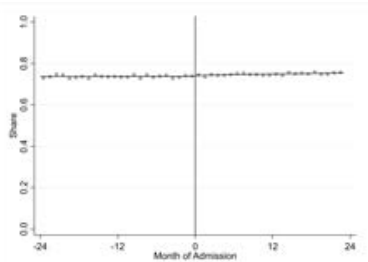

(y) Girl

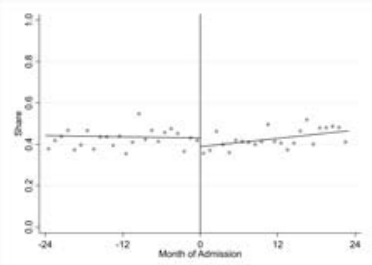

(b) Married

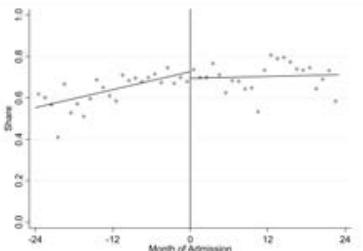

(f) Iraq

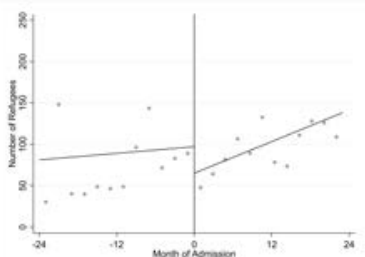

(j) Speaks Dari

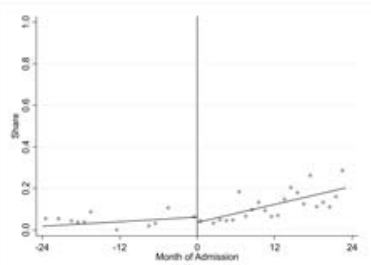

(n) Quota Refugees

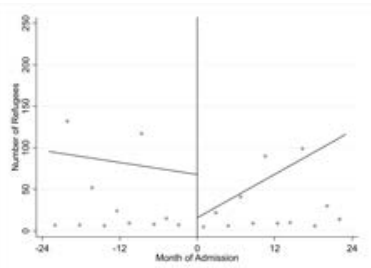

(r) Wait Time Asylum

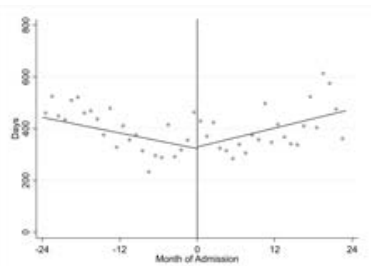

(v) Earnings

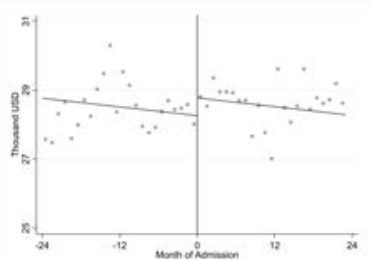

(z) Age Child

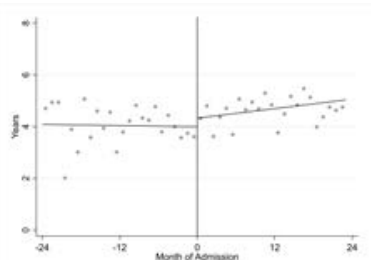

(c) Female

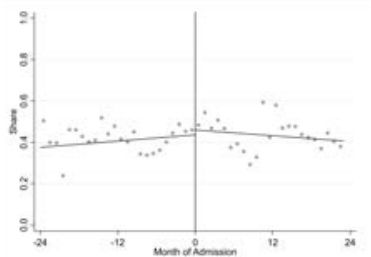

(g) Afghanistan

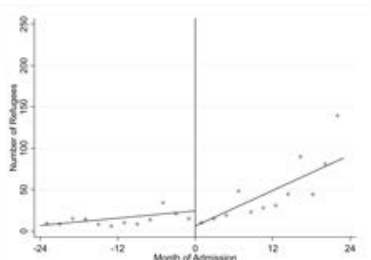

(k) Danish 1

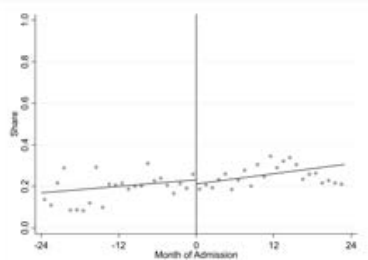

(o) Convention Refugees

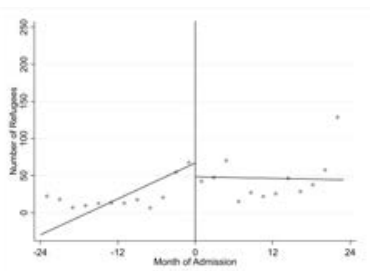

(s) Urban Municipality

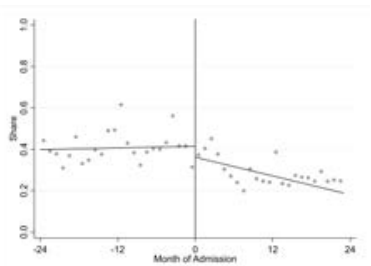

(w) Number Co-Nationals

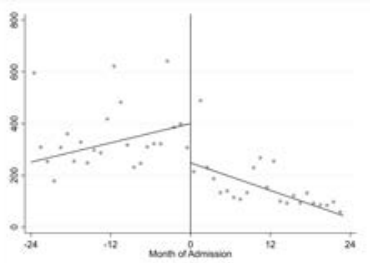

() Iraq Child

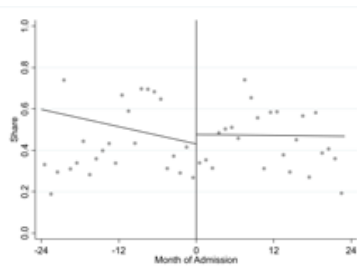

(d) Children $<3 y$

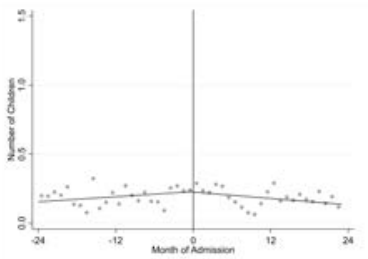

(h) Other Country

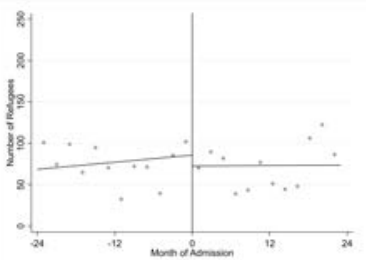

(1) Danish 2

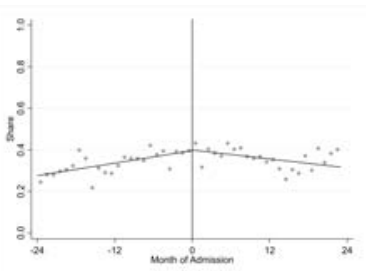

(p) Family-Reunified

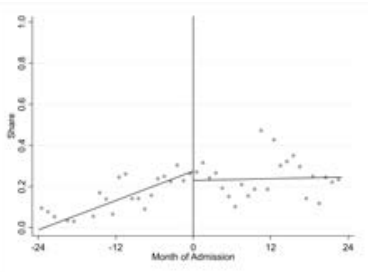

(t) Five Largest Cities

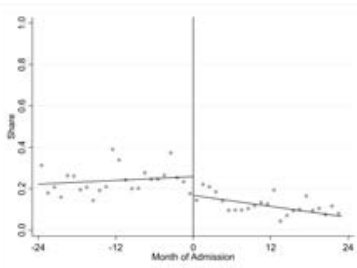

(x) Share Co-Nationals

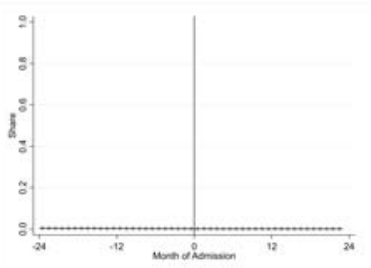

() Afghanistan Child

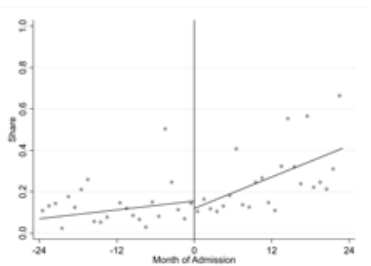

Figure A.1: Predetermined Covariates by Month of Admission

Notes: Each panel shows a predetermined covariate from Table 3 (we exclude the unemployment rate and other country child to fit the figure on one page). The dots correspond to sample means by one-month bins. Bins with less than 5 observations are excluded. 
Table A.1: The Impact of the Reform on Marriage and Fertility

\begin{tabular}{lcccc}
\hline & $\begin{array}{c}\text { Spouse Danish } \\
(1)\end{array}$ & $\begin{array}{c}\text { Spouse Same Ethnic Origin } \\
\text { Nomber of Children }\end{array}$ & $\begin{array}{c}\text { Years to First Child } \\
(4)\end{array}$ \\
\hline RD Estimate & 0.014 & -0.032 & 0.094 & -0.092 \\
Mean of Untreated at Cutoff & $(0.010)$ & $(0.041)$ & $(0.138)$ & $(0.455)$ \\
$\mathrm{N}$ & 0.014 & 0.527 & 1.244 & 4.141 \\
\hline
\end{tabular}

Notes: $* p=0.10, * * p=0.05, * * * p=0.01$. Table entries are the RD estimates $(\widehat{\tau})$, robust standard errors in parentheses, and the mean of the outcome for the untreated measured at the cutoff $(\widehat{\alpha})$ from a local linear estimation of model (1) using the triangular kernel and the optimal bandwidth selector from Calonico et al. (2019). Column 1 shows the share married to a Danish spouse, column 2 shows the share married to a spouse of the same ethnic origin as themselves, column 3 provides the impact on the number of children born after admission until year 18, and column 4 shows the year of the first-born child post admission (measured in years after admission). The outcomes are average cumulative in columns 1 and 2 . 
Table A.2: Municipality Characteristics, 1997 vs. 2000

\begin{tabular}{lrrrr}
\hline & Mean & S.D. & RD Estimate & Confidence Interval \\
& $(1)$ & $(2)$ & $(3)$ & $(4)$ \\
\hline Urban Municipality & 0.31 & 0.46 & -0.08 & {$[-0.12 ;-0.04]$} \\
Five Largest Cities & 0.15 & 0.35 & -0.10 & {$[-0.13 ;-0.07]$} \\
Employment Rate 1996 & 0.75 & 0.04 & 0.00 & {$[0.00 ; 0.01]$} \\
Unemployment Rate 1996 & 0.08 & 0.02 & 0.00 & {$[-0.00 ; 0.00]$} \\
Earnings 1996 & 28.65 & 4.08 & 0.11 & {$[-0.17 ; 0.39]$} \\
Number of Co-Nationals & 176.94 & 552.21 & -128.69 & {$[-197.59 ;-59.78]$} \\
Share of Co-Nationals & 0.00 & 0.00 & -0.00 & {$[-0.00 ; 0.00]$} \\
\hline
\end{tabular}

Notes: Mean (column 1), standard deviation (column 2), the RD estimate of the reform (column 3) and its 95-pct. confidence interval based on robust standard errors (column 4) for refugees obtaining refugee status in Denmark in 1997 or 2000. The RD estimates are from linear regressions based on all admissions in 1997 and 2000 using a uniform kernel. Municipality characteristics refer to the municipality the refugee is placed in after admission. Urban municipalities are municipalities in the capital area or municipalities with a town of more than 45,000 inhabitants. The five largest cities are Copenhagen (including Frederiksberg Municipality), Aarhus, Odense, Aalborg and Esbjerg. Average income in the municipality is measured in 1,000 USD (2000 level). The number of observations is 4,592. 


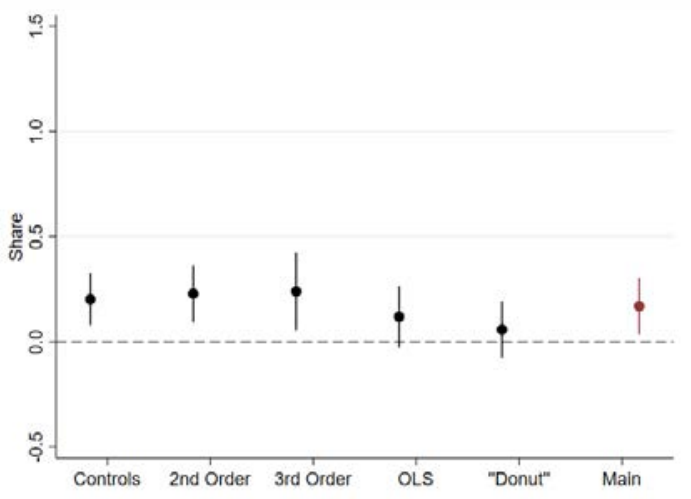

(c) Bandwidth, Took Any Exam in Lower Secondary School

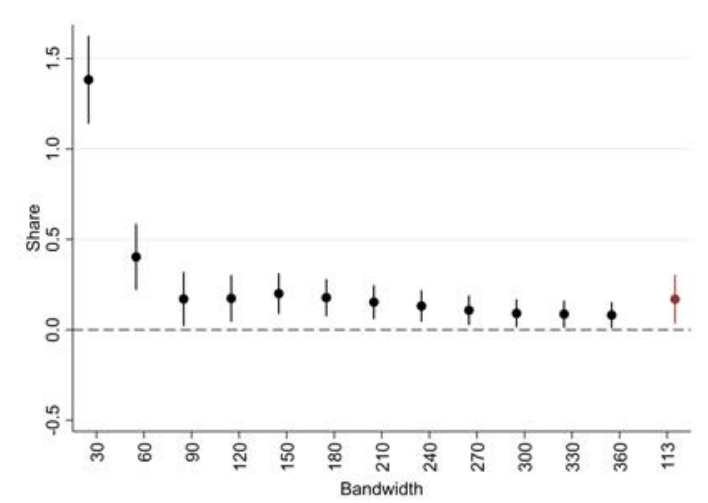

(e) Placebo Cutoffs, Took Any Exam in Lower Secondary School

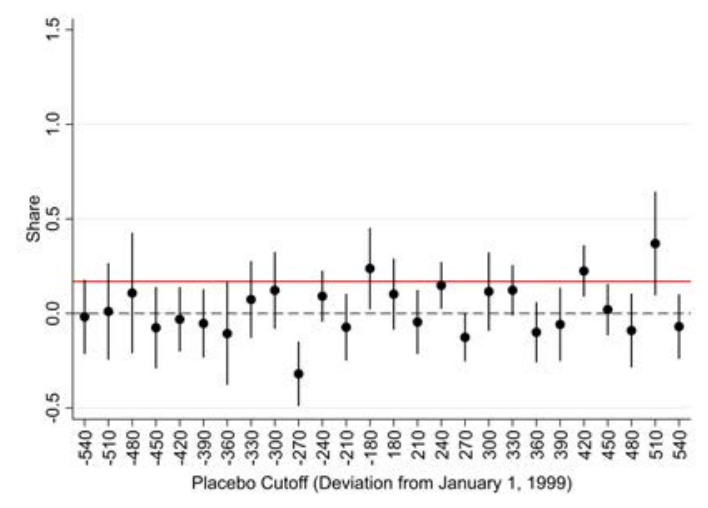

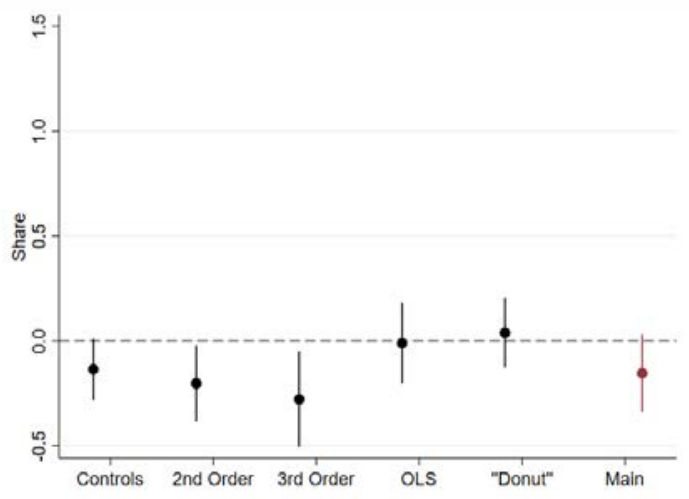

(d) Bandwidth, Charged with a Crime

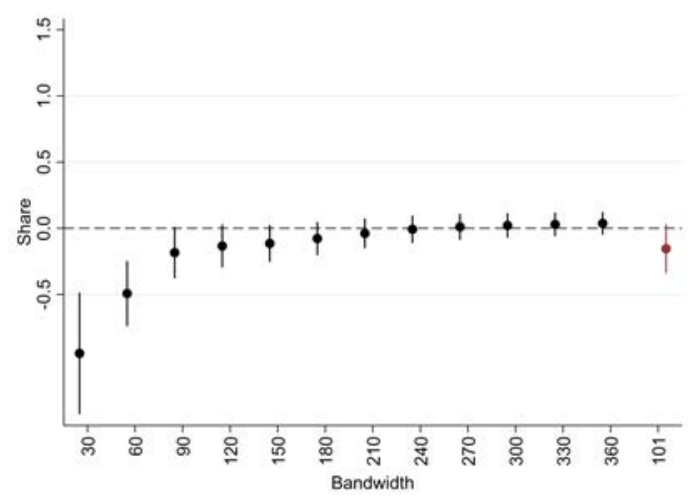

(f) Placebo Cutoffs, Charged with a Crime

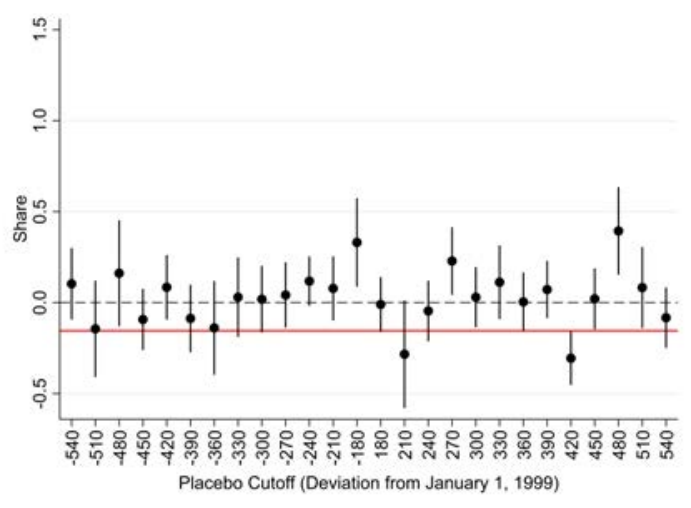

Figure A.2: Robustness Checks, Boys

Notes: The red dots and bars show the RD estimate and 95-percent confidence interval using the optimal bandwidth from Calonico et al. (2019). The sample is boys born before 2003 using the first parental admission date as assignment to treatment. Panels a and $\mathrm{b}$ show the sensitivity to the choice of bandwidth. In Panel $\mathrm{c}$ and $\mathrm{d}$ examine estimates at made-up cutoff points. The red solid line shows the estimates at the true cutoff. Panels e and $\mathrm{f}$ compare the main specification (red) to estimates including parental control variables, using 2 nd or 3rd order polynomials or OLS, and excluding refugees admitted in the four weeks immediately around the cutoff (“donut”). Control variables are age, age squared, unmarried, female, number of children between 0-2 years old and 3-17 years old, Iraq, Afghanistan, speaks Arabic, Danish 1, 2 or 3 (unknown level is the reference), quota refugee, family-reunified or other refugee (convention refugee is the reference). 


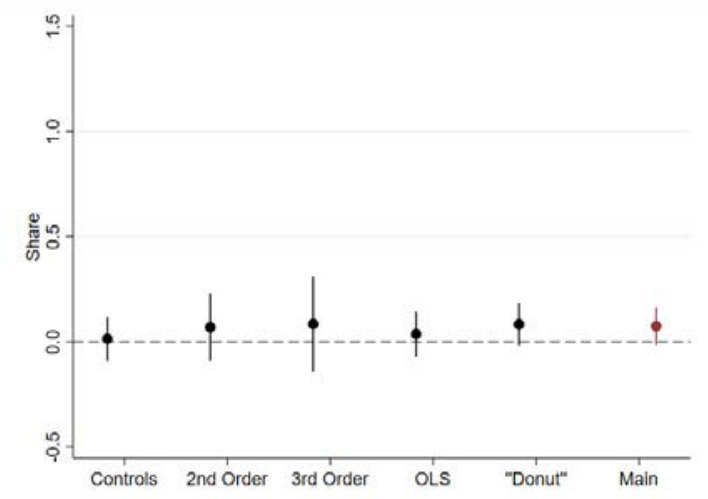

(c) Bandwidth, Took Any Exam in Lower Secondary School

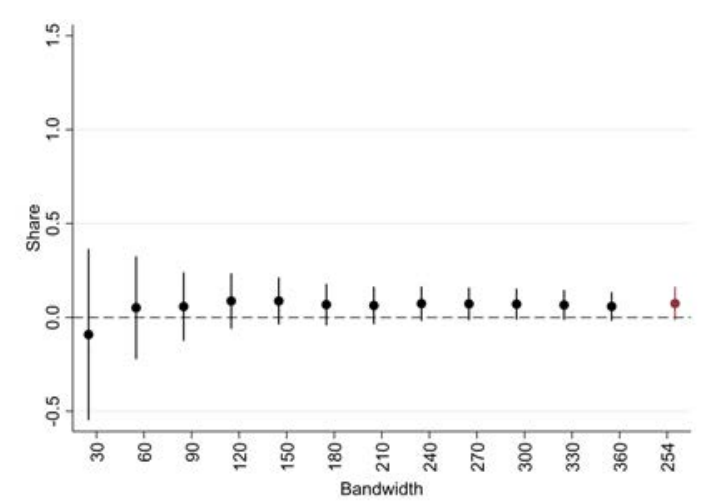

(e) Placebo Cutoffs, Took Any Exam in Lower Secondary School

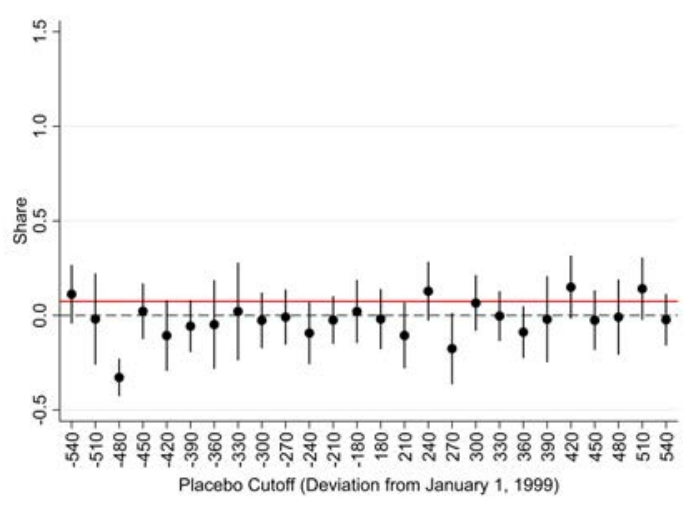

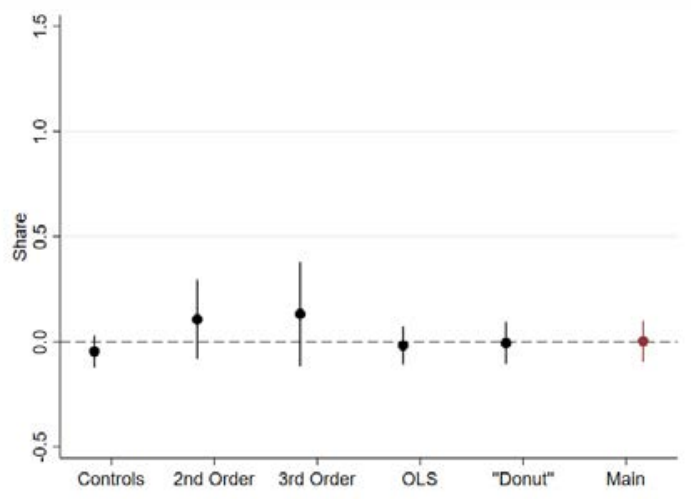

(d) Bandwidth, Charged with a Crime

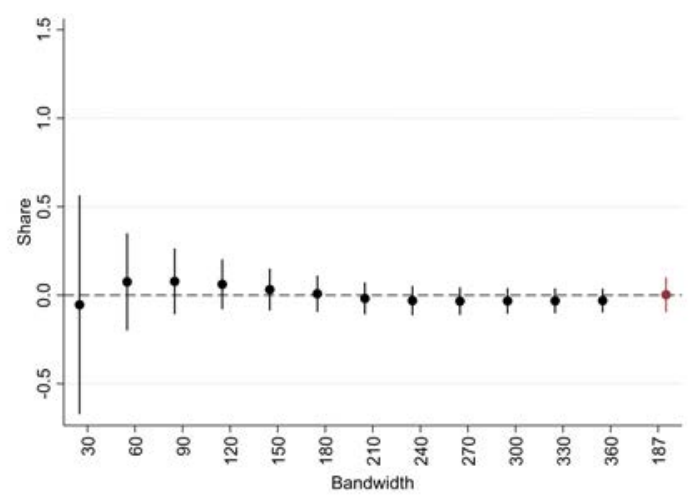

(f) Placebo Cutoffs, Charged with a Crime

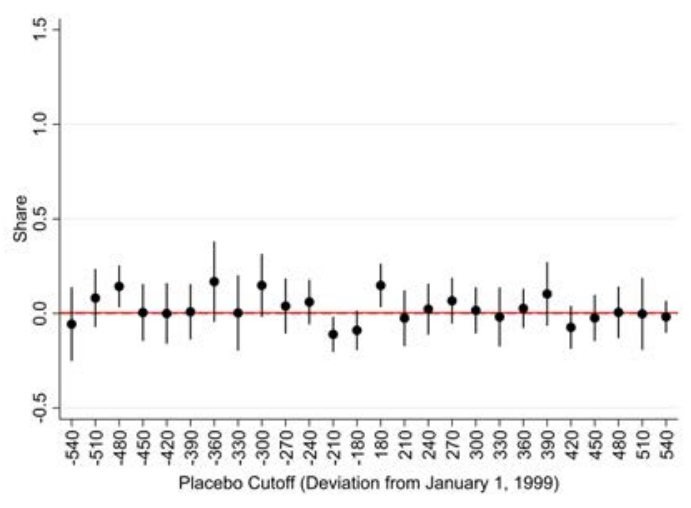

Figure A.3: Robustness Checks, Girls

Notes: The red dots and bars show the RD estimates and 95-percent confidence interval using the optimal bandwidth from Calonico et al. (2019). The sample is girls born before 2003 using the first parental admission date as assignment to treatment. Panels $\mathrm{a}$ and $\mathrm{b}$ show the sensitivity to the choice of bandwidth. Panels $\mathrm{c}$ and d examine estimates at made-up cutoff points. The red solid line shows the estimates at the true cutoff. Panels e and $\mathrm{f}$ compare the main specification (red) to estimates including parental control variables, using 2 nd or 3rd order polynomials or OLS, and excluding refugees admitted in the four weeks immediately around the cutoff ("donut"). Control variables are age, age squared, unmarried, female, number of children between 0-2 years old and 3-17 years old, Iraq, Afghanistan, speaks Arabic, Danish 1, 2 or 3 (unknown level is the reference), quota refugee, family-reunified or other refugee (convention refugee is the reference). 
(a) Enrolled in Lower Secondary School

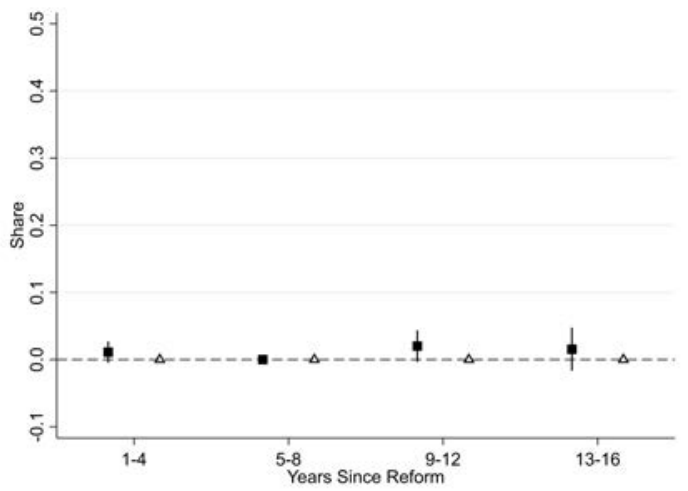

(c) Enrolled in Vocational Education

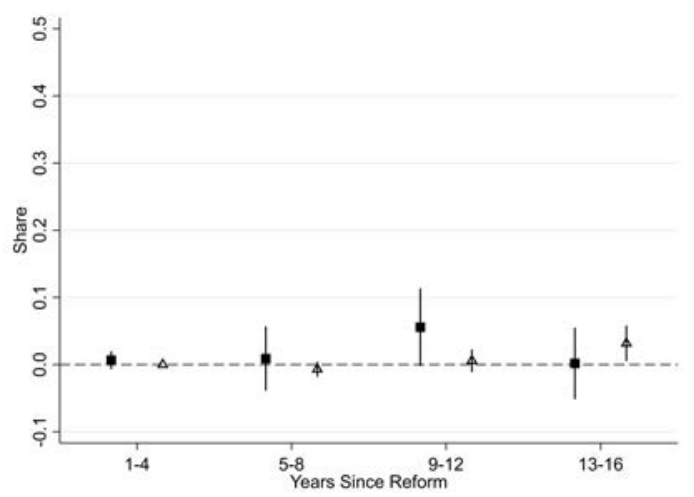

(e) Enrolled in Academic Education

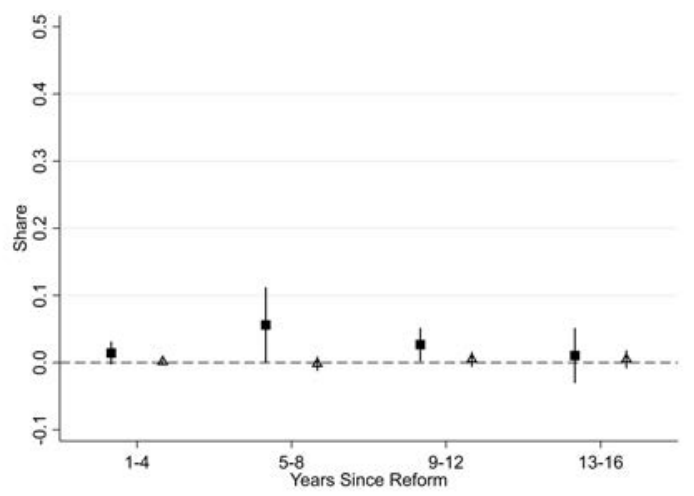

(b) Completed Lower Secondary School

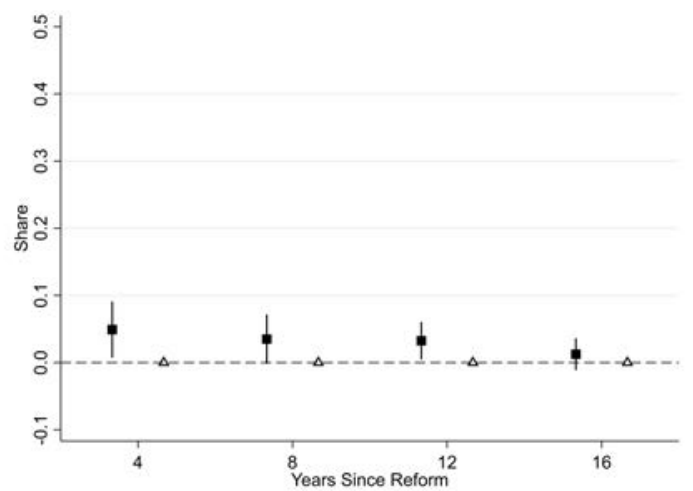

(d) Completed Vocational Education

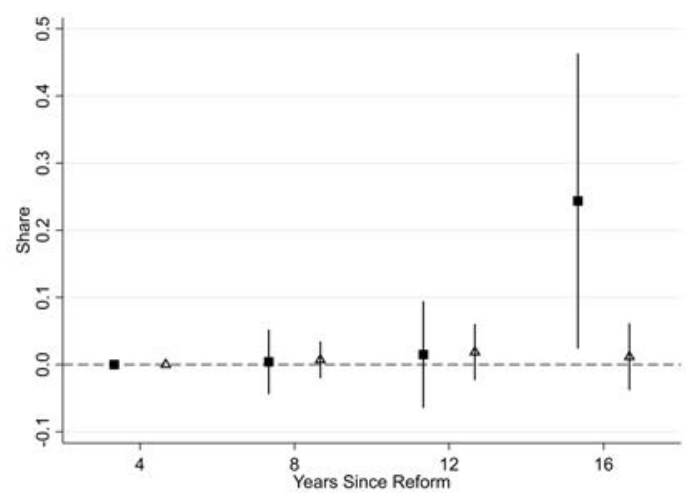

(f) Completed Academic Education

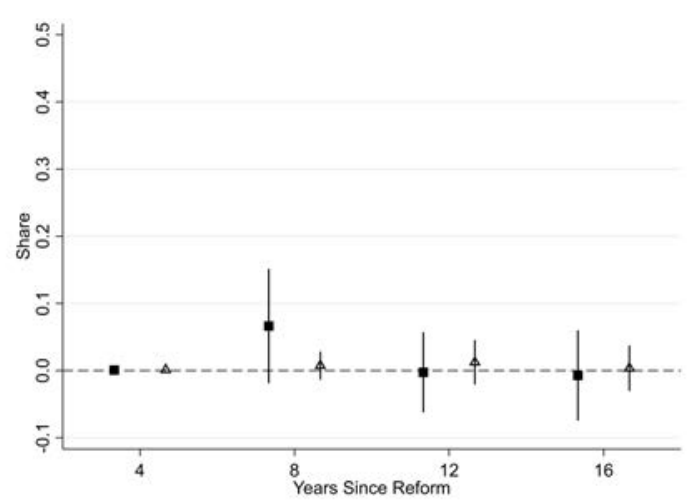

age 18 to 24 , and $\triangle$ everyone else.

Figure A.4: Level of Educational Attainment in Denmark by Age Groups

Notes: RD estimates and 95-percent confidence intervals based on robust standard errors from local linear regressions using the triangular kernel and the MSE-optimal bandwidth selector from Calonico et al. (2019). The Panels split refugees into those aged 18 to 24 and everyone else. 
Table A.3: Heterogeneous Effects, Interactions

\begin{tabular}{|c|c|c|c|}
\hline & $\begin{array}{l}\text { Earnings } \\
\text { (1) }\end{array}$ & $\begin{array}{l}\text { Employment } \\
\text { (2) }\end{array}$ & $\begin{array}{l}\text { Task Complexity } \\
\text { (3) }\end{array}$ \\
\hline & \multicolumn{3}{|c|}{ Panel a. Alphabet of Mother Tongue } \\
\hline \multirow[t]{2}{*}{ RD } & $4.112^{* * *}$ & $0.074^{* *}$ & $0.356^{* *}$ \\
\hline & $(1.545)$ & $(0.031)$ & $(0.179)$ \\
\hline \multirow[t]{2}{*}{ Latin Alphabet } & $2.949^{* *}$ & $0.085^{* *}$ & -0.263 \\
\hline & $(1.271)$ & $(0.035)$ & $(0.180)$ \\
\hline \multirow[t]{2}{*}{ Interaction Term } & $-4.654^{* *}$ & -0.087 & 0.077 \\
\hline & $(2.198)$ & $(0.053)$ & $(0.249)$ \\
\hline \multirow[t]{3}{*}{ Constant } & $6.381^{* * *}$ & $0.149^{* * *}$ & $-1.234^{* * *}$ \\
\hline & $(0.838)$ & $(0.019)$ & $(0.118)$ \\
\hline & \multicolumn{3}{|c|}{ Panel b. Initial Placement } \\
\hline \multirow[t]{2}{*}{ RD } & 1.205 & 0.005 & $0.288^{*}$ \\
\hline & $(1.450)$ & $(0.031)$ & $(0.155)$ \\
\hline \multirow[t]{2}{*}{ Urban Area } & $-2.495^{*}$ & -0.052 & -0.013 \\
\hline & $(1.286)$ & $(0.033)$ & $(0.180)$ \\
\hline \multirow[t]{2}{*}{ Interaction Term } & 3.553 & $0.106^{* *}$ & 0.164 \\
\hline & $(2.255)$ & $(0.053)$ & $(0.256)$ \\
\hline \multirow[t]{2}{*}{ Constant } & $8.386^{* * *}$ & $0.202^{* * *}$ & $-1.318^{* * *}$ \\
\hline & $(0.852)$ & $(0.020)$ & $(0.110)$ \\
\hline
\end{tabular}

Notes: RD estimates from local linear regressions using the triangular kernel and the optimal bandwidths from the full sample without interaction terms. Robust standard errors in parenthesis $(* p=0.10, * * p=0.05, * * * p=0.01)$. Each column refers to a different outcome variable. All outcomes are measured in year 18 and show the average cumulative effects. 


\section{B Appendix: Cost-Benefit Analysis of the Language Training Expansion}

We calculate the net present value $(N P V)$ of the expansion of language training as:

$$
N P V=B-D W L-C=\sum_{i=1}^{18} \frac{b_{i}-d w l_{i}-c_{i}}{(1+r)^{i}}
$$

Where $B$ are the benefits, $C$ are the costs, and $r$ is the societal discount rate. $D W L$ is the deadweight loss (or gain) from changes in the distortion of taxation as a result of the impact on the fiscal budget. We also calculate the benefit-cost ratio, and the time needed before the $N P V$ is positive.

We include gross earnings as the only benefit. They are estimated directly in Section V.A It implies that any positive impacts on the offspring are neglected. The costs of the additional hours provided in the language course are measured by the operating costs described in Section II.B and taken directly from the law we analyze (Act on Integration No. 474, section 45(5-7) and section 59(3-4)). In addition to these costs and benefits, we include the deadweight loss to society resulting from the impact on the fiscal budget. In the main analysis we assume a tax distortion rate of 50 percent (see e.g. Heckman et al. 2010, for a similar approach).

We calculate the net present value of the change in the fiscal budget as the sum of the changes in tax revenue, savings on welfare benefits and the added costs of the program. Here we assume an average income tax rate of 32 percent for workers and of 26 percent for the unemployed ${ }_{11}^{6}$ The savings on welfare benefits are not counted as a benefit in the cost-benefit analysis for society as it is a transfer (redistribution). All Danish prices are converted to Danish price levels in 2000 using the consumer price index and converted to USD using an exchange rate of 6.6 DKK/USD ${ }^{62}$

Hence, in the base scenario (in the first row of Table 9 in the main text) we make the following assumptions:

1. The reform extends the previous language learning provision by 30 percent ( 430 hours) and increases the maximum duration of the program from 18 months to 3 years (see Section II.B in the main text). We assume the additional language instruction is equal to 6 months $(0.3 \times 18$ months $=6$ months), and assume that the operating costs per month equal the activity-based payment of DKK 3,300 to the municipality. We split the costs equally between the second and third year of

\footnotetext{
${ }^{61}$ This is based on mean average tax payments for the employed and unemployed in a report by Rambøll and the Danish Center for Social Science Research (2013), the best estimates of the relevant average tax rates we are aware of.

${ }^{02}$ These conversions are applied to all nominal variables throughout the paper.
} 
the program.

2. The discount rate is 3 percent.

3. The tax distortion rate is 50 percent.

We conduct simple sensitivity analyses for each of the items above and add an additional cost through the impact on education (in rows two to four of Table 9 in the main text):

1. Use the earliest operating costs with direct information on prices per module available (wWw. integrationsbarometer. dk). This is from 2008 and the price is deflated to 2000 prices. The average pay per module in 2008 was DKK 33,735, 20,064 and 17,394 for a participant in Danish course 1, 2 and 3, respectively. We use a weighted average with the share of participants at each course level in $1999(0.32,0.35,0.33$; Table 1$)$. We assume one module is one sixth of the total hours $(1,830 / 6=340$ hours $)$, so the extra hours amount to 1.4 modules ${ }^{63}$

2. Discount rate is 7 percent.

3. The tax distortion rate is 0 percent (this is the worst case since it enters as savings in the net costs).

4. Include the costs of additional education for the population aged below 25 (Appendix Figure A.4 64 They constitute 13.7 percent of the sample. The price is approximated by the public expenditure per pupil for basic, vocational and academic education. We use the simple average across types of education; hence, it is not weighted by uptake of immigrants. It is assumed that basic schooling completion takes two years, vocational education takes four years and academic education takes five years. The earliest year for which we have information on prices is 2014 for basic and vocational education and from 2007 for academic education. They are deflated to 2000 prices using the consumer price index. The added cost of education is not included in the base scenario because educational attainment takes time, and we are, therefore, not seeing all the benefits that come from it.

We neglect the cost of crime because it is assessed to be very small. This is based on the following: The welfare reduction raised criminal convictions in the first year by 10 percent, arising mainly from an increase in shoplifting. The sentence for shoplifting is a small fine in Denmark, so the costs consist of

\footnotetext{
${ }^{63}$ The total hours is 1,830 after the reform and there are six modules after the reform. This structure did not exist before. This approach gives as a higher estimate of the operating costs of the program compared to our baseline.

${ }^{64}$ For basic schooling and vocational training: https://www.uvm.dk/institutioner-og-drift/ oekonomi-og-drift/regulerede-institutioner/takstkatalog-og-finanslov/takstkatalog and for academic education: https://ufm.dk/uddannelse/videregaende-uddannelse/universiteter/ okonomi/uddannelsestilskud(accessed December 12, 2019).
} 
resources spent by the police, the court, the defence and the prosecution. Using previous estimates of these costs, an estimate of the cost of such a crime is USD 200.

Results of the societal cost-benefit analysis are shown in Table 9 and discussed in Section VIII. The impact on the fiscal budget is shown in Appendix Table B.1 below. Income tax and savings on social welfare payments are positive for the public coffers and the operating costs are the costs for the public coffers 65

Although we do not provide estimates of the uncertainty of the numbers in Appendix Table B.1, they are all sufficiently large to support the conclusion that the additional investment in language training was beneficial to the society and the government. The net monetary benefit for the refugee is simply the sum of the impact on the difference in post-tax earnings and benefits because the program is free of charge for the participants. This difference is also large and positive, effectively ruling out that the net benefit for the recipient, which could include mental costs of attending the course, is negative.

Table B.1: Fiscal Cost-Benefit Analysis

\begin{tabular}{lrrrrr}
\hline & Income Tax and & Operating & \multicolumn{3}{r}{ Years Before } \\
Government & Welfare Savings & Costs & $N P V$ & $B / C$ & $N P V>0$ \\
& $(1)$ & $(2)$ & $(3)$ & $(4)$ & $(5)$ \\
\hline Base Scenario & 18.0 & -2.6 & 15.4 & 7.0 & 6 \\
Alternative Price & 18.0 & -3.6 & 14.4 & 5.0 & 6 \\
Discount Rate 7\% & 12.4 & -2.4 & 10.0 & 5.3 & 6 \\
With Education & 18.0 & -12.0 & 6.3 & 1.5 & 6 \\
\hline
\end{tabular}

Notes: The rows are the different scenarios described in the text. Columns 1 to 4 are measured in 1,000 USD and column 5 is denoted in years. $N P V$ is the net present value of the investment, $B$ is benefits, and $C$ is costs.

\footnotetext{
${ }^{65}$ Note, a change in the deadweight loss from distortionary taxation is only a cost (or benefit in our case) from the perspective of society and is, therefore, not part of the fiscal cost-benefit analysis.
} 